\title{
Control Room Habitability System Review Models
}

Manuscript Completed: November 1990

Date Published: December 1990)

Prepared by

H. Gilpin

Science Applications International Corporation 1710 Goodridge Drive

Mcl ean, VA 22102

Prepared for

Division of Safety Issue Resolution

Office of Nuclear Regulatory Research

U.S. Nuclear Regulatory Commission

Washington, DC 20555

NRC FIN D2096 


\section{$\underline{\text { ABSTRACT }}$}

This report provides a method of calculating control room operator doses from postulated reactor accidents and chemical spills as part of the resolution of TMI Action Plan III.D.3.4. The computer codes contained in this report use source concentrations calculated by either TACT5, FPFP, or EXTRAN, and transport them via user-defined flow rates to the control room envelope. The codes compute doses to six organs from up to 150 radionuclides (or 1 toxic chemical) for time steps as short as one second. Supporting codes written in Clipper assist in data entry and manipulation, and graphically display the results of the FORTRAN calculations. 
Section Page

ABSTRACT .. . . . . . . . . . . . . . . . . . . .

LIST OF FIGURES. . . . . . . . . . . . . . . . . vii

PREFACE. . . . . . . . . . . . . . . . . . . . ix

1. INTRODUCTION . . . . . . . . . . . . . . 1

2. METHODOLOGY.................... 2

2.1 Source Term Quantification. . . . . . . . . 2

2.2 Transport to Control Envelope Room Boundary... . 2

2.3 Control Room Habitability System Effectiveness. . 3

3. DISCUSSION OF CODES............... 8

$3.1 \mathrm{CRH}$.................... 11

3.2 CONHAB. . . . . . . . . . . . . . . . 14

3.3 CHEM. . . . . . . . . . . . . . . . . . . . 16

3.4 CRHPLOTR and CRHPLOTC . . . . . . . . . . . . . 16

3.5 Data Files. . . . . . . . . . . . . . 16

4. USERS GUIDE TO THE COMPUTER CODES. . . . . . . . . 19

4.1 Radiological Evaluation............ 19

4.1.1 Executing the CRH Code . . . . . . . . . 20

4.1.2 Executing the CONHAB Code. ........ 40

4.1.3 Executing the CRHPLOTR Code. . . . . . 42

4.2 Toxic Gas Evaluation.............. 42

5. CODE INSTALLATION. . . . . . . . . . . . . 44

6. EXAMPLE PROBLEM. . . . . . . . . . . . . . . 45

7. REFERENCES ................... 47 
TABLE OF CONTENTS (Continued)

Appendix

$\begin{array}{llc}\text { A } & \text { CRH CODE LISTING } & \text { A-1 } \\ \text { B } & \text { CONHAB CODE LISTING } & \text { B-1 } \\ \text { C } & \text { CHEM CODE LISTING } & \mathrm{C}-1 \\ \text { D } & \text { CRHPLOTR CODE LISTING } & \mathrm{D}-1 \\ \text { E } & \text { CRHPLOTC CODE LISTING } & \mathrm{E}-1 \\ \text { F } & \text { NUCLIDE LIBRARY ICRP.02 } & \mathrm{F}-1 \\ \text { G } & \text { NUCLIDE LIBRARY ICRP.30 } & \mathrm{G}-1 \\ \text { H } & \text { DATABASE FILE STRUCTURES } & \mathrm{H}-1 \\ \text { I } & \text { SAMPLE OUTPUT FROM CONHAB } & \mathrm{I}-1 \\ \mathrm{~J} & \text { SAMPLE OUTPUT FROM CHEM } & \mathrm{J}-1\end{array}$




\section{LIST OF FIGURES}

Page

Figure 1 - Control Room Habitability System Model . . . 4

Figure 2. Radiological Analysis Flowchart. . . . . . 9

Figure 3 - Toxic Chemical Analysis Flowchart. . . . . . 10

Figure 4 - CRH Block Diagram. . . . . . . . . . . 12

Figure 5 - CONHAB Program Flow. . . . . . . . . . 15

Figures 6 through 22 - Screen Printouts from CRH Code 


\section{PREFACE}

Under NRC contract number NRC-03-87-029, Science Applications International Corporation (SAIC) has been tasked to 'develop bases for proposed review procedures and acceptance criterid, with supporting documentation, sufficient to permit revision of the Standard Review Plan in such a manner as to correct a11 known objections to the current CRHS review.' This report provides a method of calculating control room operator doses from postulated reactor accidents and chemical spills as part of the resolution of TMI Action Plan III.D.3.4. The computer codes contained in this report use source concentrations calculated by either TACT5, FPFP, or EXTRAN, and transport them via user defined flow rates to the control room envelope. The codes compute doses to six organs from up to 150 radionuclides (or 1 toxic chemical) for time steps as short as one second. Supporting codes written in clipper assist in data entry and manipulation, and graphically display the results of the FORTRAN calculations. 


\section{INTRODUCTION}

General Design Criterion (GDC) 19 requires that every plant have a control room that is protected from "accident conditions, including loss-of-coolant accidents." To determine whether or not an applicant's plant complies with GDC 19, the NRC staff performs an assessment of the plant's control room habitability system (CRHS) using Section 6.4 of the Standard Review Plan (SRP) "Control Room Habitability System." Control room protection is the subject of TMI Action Plan III.D.3.4, "Control Room."

Concerns have been raised by the NRC staff. The concerns may be divided into four components using a systems approach: (a) the challenges to control room habitability, (b) the effectiveness of design features of control room habitability systems and the guidance for their review, (c) the means of assuring adequate testing and maintenance of the CRHS, and (d) the estimation of accident consequences to the control room occupants to be used in implementing GDC 19. This report will address components (b) and (d) by providing a computer based model of the CRHS, and, using source insults calculated by the Fission Product Flow Path code, TACT5, and EXTFAN, by computing doses or exposures to control room occupants from radionuclides or toxic gases.

The new model represents an attempt to provide a more realistic evaluation of control room protection than the steady-state Murphy-Campe model (reference 1) used by the NRC in past control room habitability evaluations. The steadystate model is believed to be more conservative in most cases than a time dependent model. The new model also incorporates an improved, more realistic meteorological dispersion calculation based on recent work by Ramsdell (references 5,6, and 7). The new, time based dispersion calculation correlates well with existing experimental data, and is generally less consarvative than the traditional Gaussian plume calculation (reference 7 ). 


\section{METHODOLOGY}

The proposed model can be broken into three subsections; source term quantification, transport to the control room envelope, and CRHS effectiveness.

\subsection{SOURCE TERM QUANTIFICATION}

The source term for control room habitability analysis can be broken into two classes, radiological and chemical. Obviously, radiological sources would be used in calculating doses to the control room occupants from postulated reactor accidents, and chemical sources would be used to evaluate toxic gas exposure due to onsite or offsite chemical spills or releases.

The radiological source proposed for use is the standard "TID 14844" source term, which is based upon direct ratios of reactor power levels to determine core radionuclide concentrations. Standard Regulatory Guide 1.3 and 1.4 assumptions are used to determine chemical form, plate out factors, and release fractions. As new source term information from ongoing research becomes available, the model can be easily updated.

\subsection{TRANSPORT TO CONTROL ROON ENYELOPE BOUNDARY}

The transport of the source term to the control room boundary can occur either through the plant; for example, ducts, rooms, and penetrations; or through the atmosphere from the point of release to the point of entry into the control room boundary, for example, containment leakage or stack releases. For radiological calculations, the Fission Product Flow Path (FPFP) code (reference 3 ) is used to calculate through-plant transport of radionuclides, and TACT5 (reference 4) is used to calculate transport of radionuclides up to the point of release to the atmosphere. The CONHAB code discussed later incorporates the dispersion calculation required to calculate the concentrations at the air intakes. For toxic chemical calculations, the 
EXTRAN code will transport vapors from the point of release to the control room air intake.

The use of these codes is discussed in the respective references, and will not be discussed here, other than how they interface with the new model.

\subsection{CONTROL ROON HABITABILITY SYSTEM EFFECTIVENESS}

It is beileved that most existing control room habitability systems can be modeled by a combination of one or more of the following systems:

1) Control room pressurization by filtered outside air can be used to reduce the ingress of contaminated air.

2) The control room air can be recirculated through filters to remove contamination already in the control room volume.

3) Multiple widely separated air intakes can be monitored, and air from the least contaminated used to ventilate the control room.

4) Compressed air can be used to either pressurize the control room, or through breathing masks, supply uncontaminated air to the occupants.

5) The control room can be sealed to minimize the entrance of contaminants.

Any combination of these at any given time can be modeled by the diagram presented in Figure 1. Note that Figure 1 provides for four separate pathways into the control room volume, two through control room air intakes which presumably take air from the atmosphere, and two 'user defined' pathways which can model other modes of ingress such as adjoining rooms, penetrations, swinging doors, etc. For radiological calculations, the proposed model will use a TACT5 calculated source to one or both air intakes, and an FPFP source to one or both of the 'user defined' sources. For toxic chemical 
Figure 1

Control Room Habitability System Model

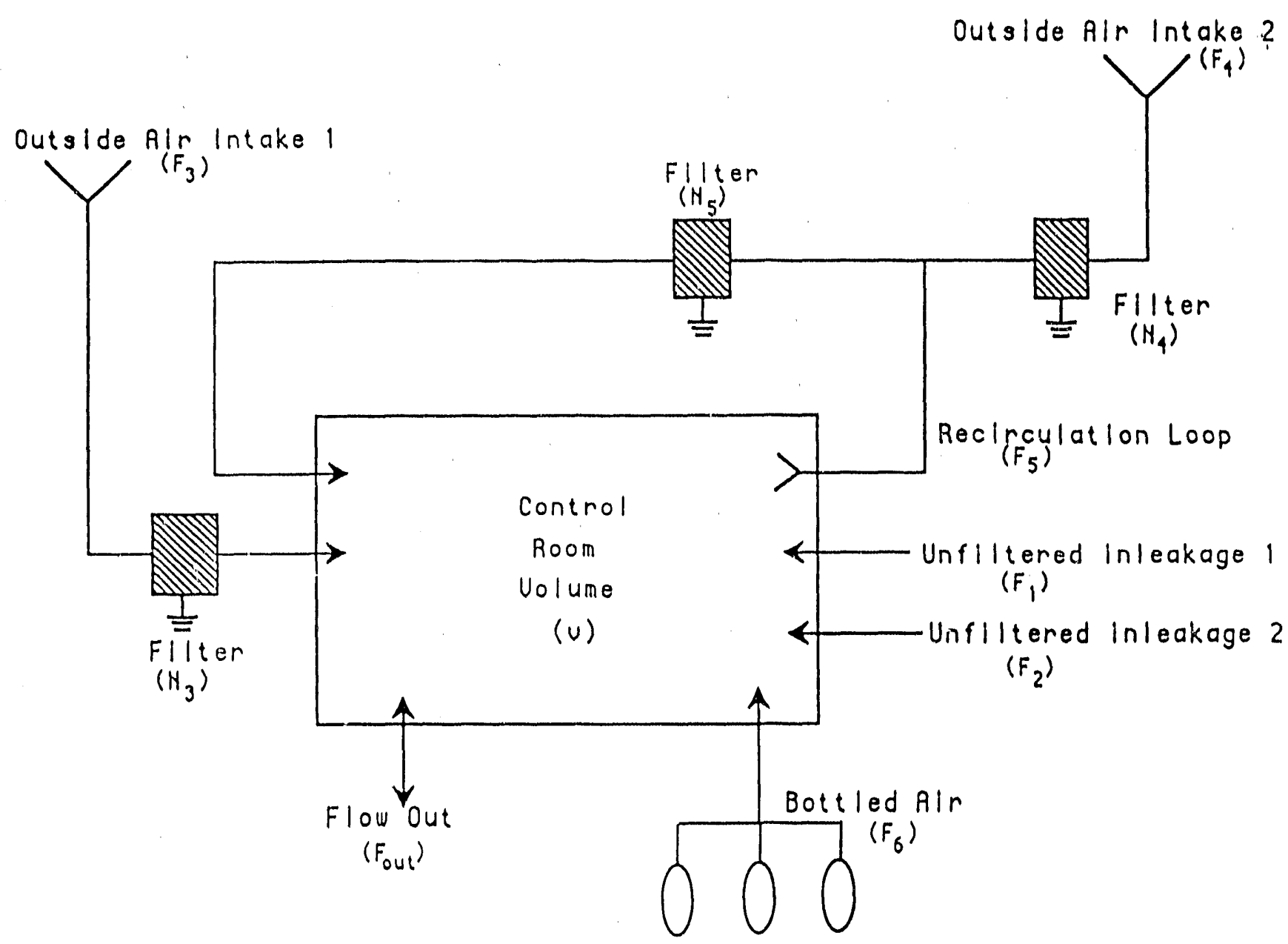


calculations, the model will use a source calculated by EXTRAN to any or all of the four pathways.

Most, if not a11, plants realign their system from a 'normal' ventilation mode to an 'accident' mode either automatically or manually through procedure in the event of an accident. Realignments can also occur throughout the course of the accident. Therefore, the parameters appearing in Figure 1 could change at any time during the thirty day period of interest. Additionally, it is anticipated that the source term at the control room boundary will change over the course of the accident. The dose calculation is therefore broken into time steps, the beginning and ending times being determined by the time at which any of the modeled parameters change.

\subsection{MATHEMATICAL IREATMENT}

For each time interval, the control room air concentration for each contaminant is determined as follows:

Let $A(t)$ represent the activity of a particular nuclide (in curies) at time $t$ in the control room.

Then the rate at which the activity of this nuclide changes is given as

$\underline{d A}(t)=$ (rate of nuclide entering)-(rate of nuclide leaving) $d t$

Referring to Figure 1 , let $C_{n}$ represent the concentration $\left(\mathrm{Ci} / \mathrm{m}^{\wedge} 3\right)$ at source $n, F_{n}$ the flow rate $\left(m^{\wedge} 3 / s\right)$ from source $n$ to the control room, and $N_{n}$ the filter efficiency of filter $n$ for the nuclide in question, then the rate entering the control room from the plant and environment becomes:

$$
R_{\text {in }}=C_{1} F_{1}+C_{2} F_{2}+C_{3} F_{3}\left(1-N_{3}\right)+C_{4} F_{4}\left(1-N_{4}\right)\left(1-N_{5}\right)
$$


From Figure 1, it is obvious that the flow out of the control room is given as (by conservation of mass):

$$
F_{\text {out }}=F_{1}+F_{2}+F_{3}+F_{4}+F_{6}
$$

Then the rate of activity leaving the control room is given as:

$$
R_{\text {out }}=F_{\text {out }}(A(t) / V)+F_{5} N_{5} A(t) / V
$$

where $V$ is the volume of the control room $\left(m^{\wedge} 3\right)$. The second half of this equation represents removal by a recirculation loop filter.

Thus the original equation becomes:

$$
\frac{d A(t)}{d t}=R_{\text {in }}-A(t)\left(F_{\text {out }}+F_{3} N_{5}\right) / V
$$

Using the integrating factor $e^{t(\text { Fout }+F 5 \text { N5)/V }}$ and solving yields

$$
A(t)=V /\left(F_{\text {out }}+F_{5} N_{5}\right) R_{\text {in }}+c e^{-t(\text { Fout }+F 5 N 5) / V}
$$

Subjecting to the initial condition $A(0)=0$ gives

$$
A(t)=V /\left(F_{\text {out }}+F_{5} N_{5}\right) R_{\text {in }}-V /\left(F_{\text {out }}+F_{5} N_{5}\right) R_{\text {in }} e^{-t(\text { fout }+F 5 N 5) / V}
$$

which represents the activity in curies in the control room at $t i m e$ ' $t$ ' for any nuclide of interest. The dose to a person in the control room from this nuclide is coniputed by multiplying the concentration in the control room by a dose conversion factor and a delta $t$ in seconds, and a breathing rate if other than whole body or skin dose. Each of these doses is then reduced by an occupancy factor, to account for the fact that one individual will not remain in the control room for the entire 30 days, and a geometry factor, if appropriate. The geometry factor is taken from Murphy-Campe as $1173 . /\left(V^{\wedge} .338\right)$, and represents an attempt to correct for a finite rather than 
semi-infinite cloud of gamma emitters, upon which the dose conversion factors are based. Note that radioactive decay and daughter product build-up were not included up to this point in the calculation.

At the enc of each time step, the concentrations at each of the four sources and in the control room are decayed, and daughter products added back in. Only the daughter with the largest production factor is used in the calculation. For example, if a nuclide can decay ic two or more daughters, only the most probable daughter is used. The total dose to an individual is obtained by summing the dose contributions from each ruclide and each time step.

For a toxic gas analysis, the same formulation above holds, except that there is no decay or geometry factor correction. 


\section{DISCUSSION OF CODES}

Figure 2 represents the flow of information from start to finish for the evaluation of radiological exposure. Figure 3 represents the information flow for toxic chemical exposure evaluation. The description and use of FPFP, TACT5, and EXTRAN is left to the respective users manuals (references 3-5). All three have been modified to produce an output file which can be read by e ither CONHAB or CHEM.

A detailed tour through each step is described in section 4, the users guide. Basically, to perform a radiological dose calculation, the following steps are performed:

1) Review FSAR, SER, and licensee submittals to identify all pathways of radionuclides from the source to the control room boundary.

2) For those pathways which involve transport through the building or buildings (not through the atmosphere), run FPFP. Two pathways at a time can be modeled by CONHAB. If there are more than two, perform multiple runs and sum the results of CONHAB.

3) For pathways which involve transport through the atmosphere to a control room air intake, run TACT5. Note that it is not necessary to input meteorological information into TACT5 as CONHAB incorporates its own model.

4) Examine licensee submittals and FSAR to determine configurations and flow rates for the control room habitability system being evaluated. Run CRH and build the CRHS model.

5) From the CRH main menu, select 'Set up for calculation' option and designate the datafiles created in steps 2 through 4 . Exit from CRH. 


\section{FIGURE 2}

\section{RADIOLOGICAL ANALYSIS FLOWCHART}

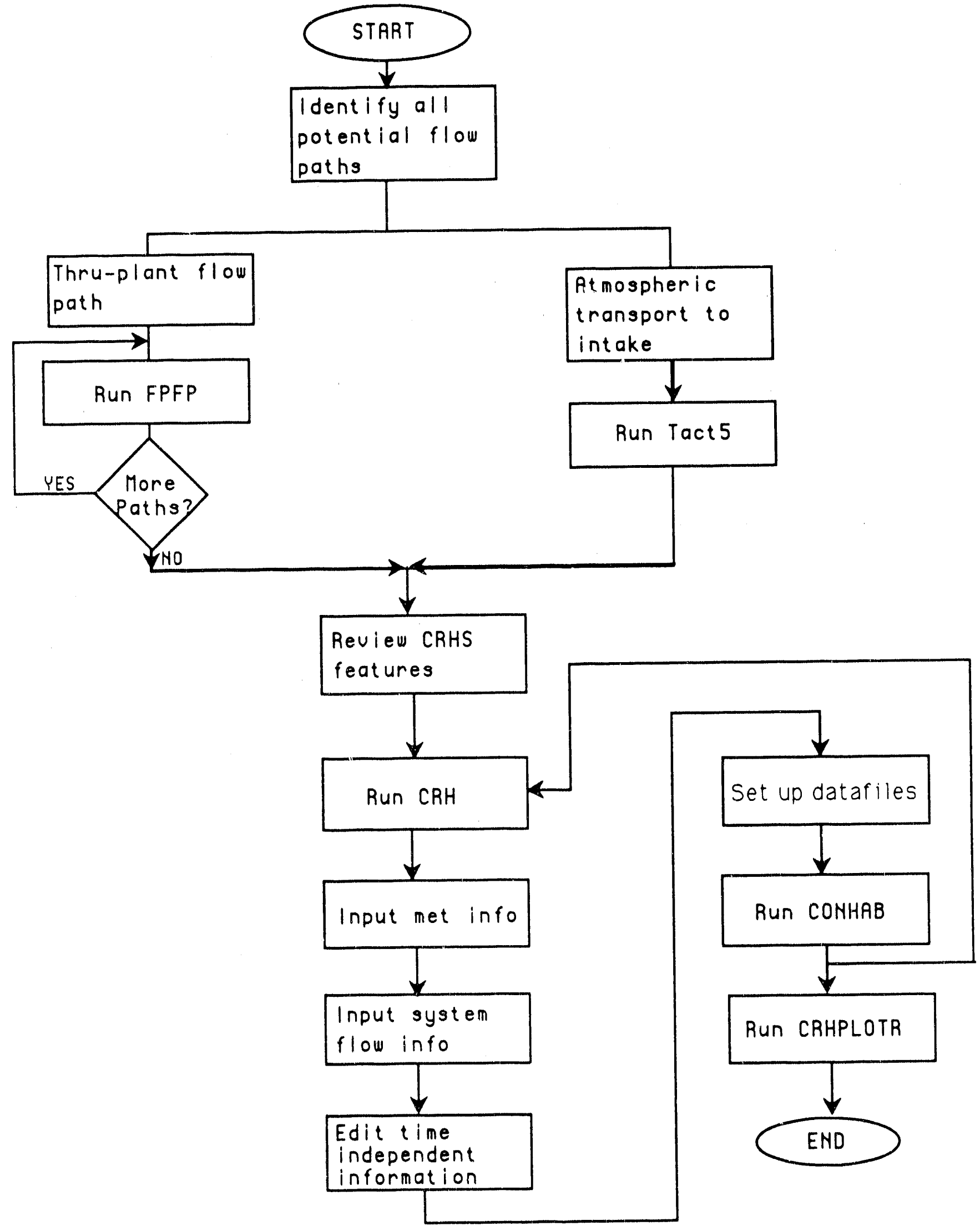




\section{FIGURE 3}

\section{TOHIC CHEMICAL ANALYSIS FLOWCHART}

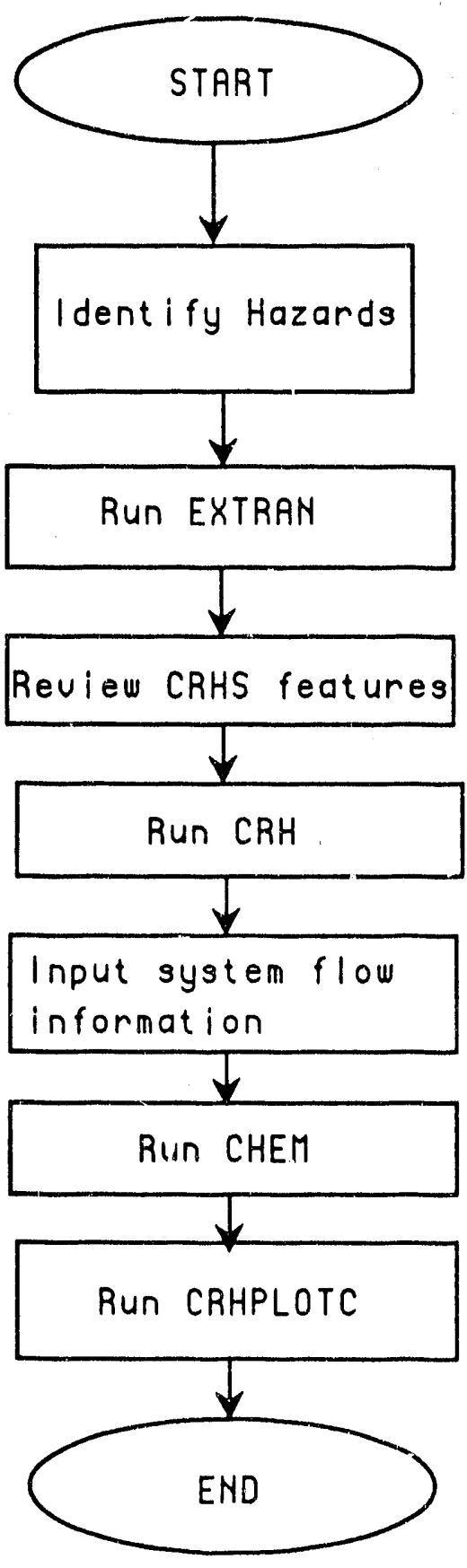


6) Run CONHAB to perform dose calculations.

7) If desired, run CRHPLOTR to plot results.

To perform a toxic gas analysis, run EXTRAN instead of FPFP and TACT5, CHEM instead of CONHAB, and CRHPLOTC instead of CRHPLOTR to plot the results.

Figure 3 provides a flow chart for performing a toxic gas analysis.

The description of CRH, CONHAB, CHEM, CRHPLOTR and CRHPLOTC follows.

\subsection{CRH}

The CRH code is a pop-up menu driven program designed to aid in inputting meteorological and system flow data. It also contains a full screen editor for making modifications to data files, assists in managing the datafiles required by CONHAB and CHEM to perform an evaluation, and has context sensitive unit conversion for all parameters (CONHAB and CHEM Use predominantly MKS units, the Rem and Curie being the two exceptions). The program itself is written in CLIPPER, a pseudo dBase III compiler, to take advantage of its database functions and editing features. Figure 4 is a block diagram of the $\mathrm{CRH}$ code. A program listing is provided in Appendix $A$.

The primary function of CRH is to allow input of CRHS parameters and meteorological parameters for subsequent use by the CONHAB or CHEM codes. There are five basic 'screens' utilized for data input. All five are discussed in detail in Section 4. Each screen will carry forward information from time step to time step, so that only information that changes will need to be entered. The first screen is the meteorological data input screen. As with all of the input screens, full screen editing is permitted. That is, it is possible to move the cursor around the screen to enter, change, or correct values before they are written to disk. Specifics on cursor movement and data entry are discussed in Section 4. 


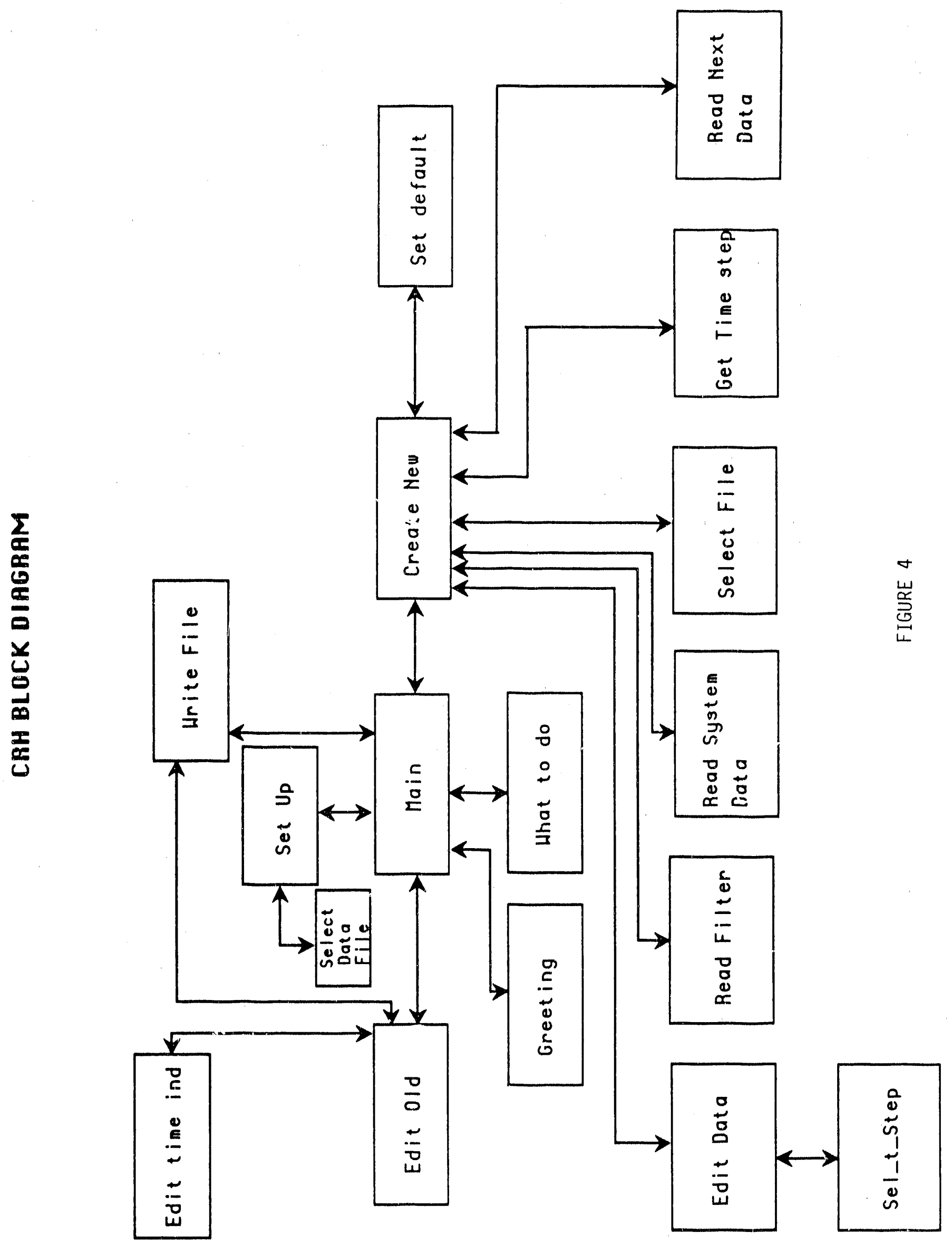


The next two screens present a graphical representation of the CRHS similar to that shown in Figure 1. The first of these two accepts flow rate and control room volume information. The second accepts filter efficiency data.

The fourth data screen is the edit screen. It lists all data from the previous three screens for each time step and allows full screen editing. This screen may al so be used for data input by selecting 'Tabular' rather than 'Graphical' input screens when prompted.

The fifth input screen allows editing or time independent variables such as power level and chemical form fraction. It is accessed from the edit option.

A secondary function of $\mathrm{Cl} Y$ is the assemblage of all data files in preparation for running CONHAB. CONHAB requires six data files as input. CRH will prompt for the selection of filenames for each of these according to a predetermined file naming convention (template). The user is not required to adhere to the naming convention set up in CRH, but for simplicity, it is recommended. Unless specifically changed by the user, the data files will all conform to the following conventions:

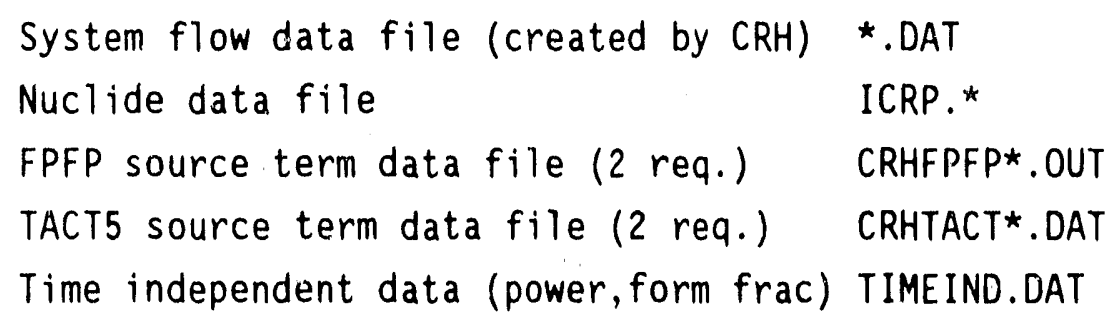

CRH creates a separate file named CRHSYS.DAT which contains the names of the selected data files. CONHAB reads this file to determine which data files to use in the calculation. 


\subsection{CONHAB}

The CONHAB code is the calculational program for computing estimated doses due to radiological releases. It reads the file CRHSYS.DAT which is created by $C R H$, and subsequently opens the files listed for input. It computes control room concentration and associated doses to six organs from up to 122 nuclides, each capable of being modeled as three chemical forms (elemental, organic and particulate), from up to four sources, and 2.6 million time steps (the number of seconds in a month). The code reports dose at each time step and on the hour for the first day, and then at each time step and every 24 hours for 30 days. Each report produces an output file used to plot dose vs. time via the CRHPLOTR prograin. Figure 5 is a simplified flow chart of the CONHAB program. A FORTRAN listing of the code can be found in Appendix $B$.

The model incorporated in CONHAB is discussed in the Methodology section above. Radionuclides are introduced as a concentration $\left(\mathrm{C} / \mathrm{m}^{\wedge} 3\right)$ at up to four intake points, and based on the CRHS alignment as set up by the program CRH, transported to the control room volume. The concentrations at each of the four source locations are updated according to the schedule in the associated datafile. The source concentrations are assumed constant over any time intervals between those set in the source data file. That is, the source concentrations are not reduced as radionuclides are removed to the CRHS. This assumption bacomes more conservative as the source volume decreases or the flow rate from the source volume increases. Radioactive decay and daughter product build-up are accounted for at all source locations and the control room. Filtration and dilution are the only other removal mechanisms considered. Deposition and resuspension are not modeled.

For ease of computation, radionuclides are decayed at the end of each time step, rather than integrated over the time step. This assumption is conservative as the maximum concentration of radionuclides present over a particular time step is used in the dose calculation (ie no reduction in quantity by decay before the end of the time step). Note also that radioactive decay is generally small in comparison to other removal processes 


\section{CONHAB PROGRAM FLOW}

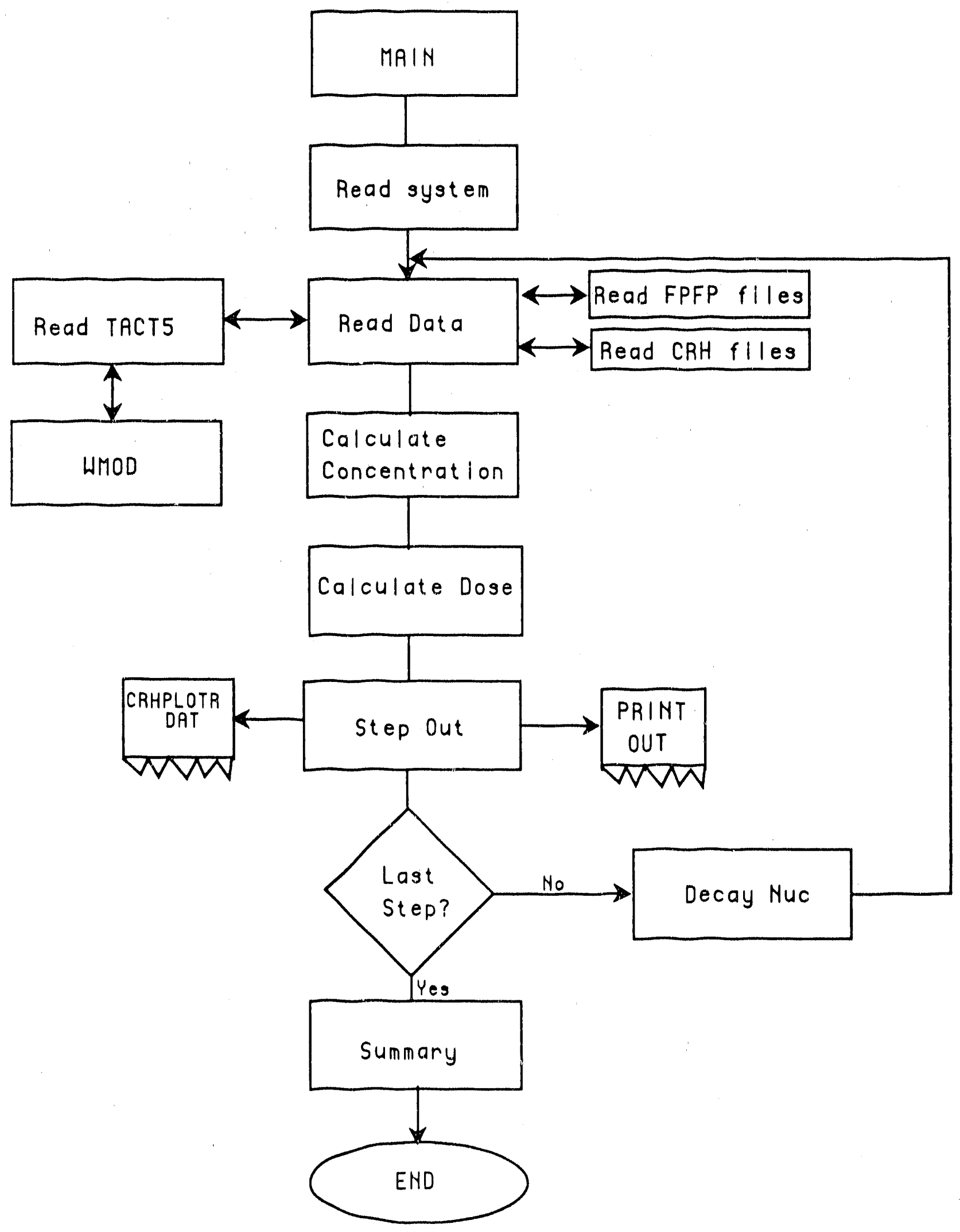

FIGURE 5 
in the control room especially if using the TID source term, whicn contains only relatively long lived radionuclides. Daughter product build-up is a small contributor which somewhat lessens this conservatism.

\subsection{CHEM}

The CHEM code is the equivalent of CONHAB, only it is used for evaluation of toxic gas concentrations rather than radionuclides. The mathematical model incorporated into the code is identical to that in CONHAB. The o.lly removal process modeled, however, is dilution. The code reads an output file generated by the EXTRAN code (reference 5), and applies this source to each of the four potential entry points to the control room. Since the recirculation loop and all the filters are ineffective in reducing the toxic gas concentration, each of the four entry points are treated identically. Fresh air intake is modeled by using bottled air. The code transports gas into the control room as set up by the CRH code, and reports concentrations, mean concentrations, and exposure at each time step. A data file is generated which can be used by the CRHPLOTC program to graphically display the data. Appendix $C$ contains a FORTRAN listing of the CHEM code.

\subsection{CRHPLOTR AND CRHPLOTC}

The CRHPLOTR and CRHPLOTC codes plot the results of a radiological or toxic gas analysis, respectively. Both are written in CLIPPER using FLIPPER graphics libraries. They are designed to run correctly on most $P C$ display systems (VGA, EGA, CGA, and Hercules). Both aiso give the option to print the graphs on a printer. Listings for these codes appear respectively as Appendices $D$ and $E$.

\subsection{DATA FILES}

There are two permanent data file libraries, ICRP.02 and ICRP.30. Both of these contain the same types of information, but the ICRP.30 library has been updated to contain dose conversion factors from the International Commission 
on Radiation Protection (ICRP) publication 30. It is anticipated that the NRC will approve use of the ICRP 30 data some time in the fuirure. Appendix $F$ contains a listing of ICRP.02, and AppendiX G is a listing of ICRP.30.

The files are organized as follows:

line 1: Nuclide name ( 8 characters)

Iine 2: Decay rate $(1 / \mathrm{hr})$, source (C1/MWt) (both 1 PE13.6)

line 3: Dose conversion factors for whole body, skin, thyrotd, lung, bone, and liver (1P6E13.6)

line 4: Internal identification number (I6), group number (I6), identification number of daughter (18), daughter production factor (E10.3), secondary daughter ID (I8), and secondary daughte:" production factor (E10.3)

This is repeated for each of the 122 nuclides in the 1 ibrary. Note that the information for secondary daughter product formation is present, al though it not used by the code because it is an insignificant contributor.

There are eight types of data files which contain problem specific information for performing radiological calculations. Seven of these are input to the CONHAB code, and one is an output file from CONHAB.

CRHSYS.DAT - Contains the file names of all data files required for executing a particular problem with the CONHAB code.

TIMEIND.DBF - Contains time independent information: reactor power TIMEIND.DAT level, and chemical form fractions for each of the nuclide groups. The .DBF file is a dBase file, and the .DAT is the associated ASCII file. The ASCII file is read by CONHAB. 


$$
\begin{aligned}
& \text { user-named.DBF - Contains the information input to the CRH code for } \\
& \text { ".DAT meteorology and system flow. Structure of the files } \\
& \text { is presented in Appendix H. The. DBF file is a dBase } \\
& \text { file, and the .DAT file is the associated ASCII file } \\
& \text { which is read by CONHAB. }
\end{aligned}
$$

CRHTACT*.DAT - Output from the TACT5 code which is used to provide a source to either of the two outside air intakes.

CRHFPFP*.OUT - Output from the FPFP code which is used to provide a source to the two user defined unfiltered inleakage pathways.

CRHPLOTR.DAT - Output file from CONHAB which is used by CRHPLOTR to plot dose vs. time on the computer screen for the current case.

The CHEM program uses only three datafiles, an output file from EXTRAN, a data file created by CRH with system flow information, and an output file produced by CHEM (CRHPLOTC.DAT) for plotting the results on the computer screen. 


\section{USERS GUIDE TO THE COMPUTER CODES}

This section contains a detalled discussioil of the use of the computer codes CRH, CONHAB, CHEM, CRHPLOTR and CRHPLOTC. Before attempting to execute any of these codes, they must be installed on the hard disk of a Personal Computer (PC). Instructions for doing this appear in Section 5, codes Installation. All five of the codes listed above have been complled and linked, and are in an executable form (suffix EXE). This section assumes the codes have been installed and are resident in one subdirectory on the hard disk. For convenience, it is recommended that all datafiles also reside in the same directory, with backup files maintained on floppy disk. The codes are discussed in order of execution for performing a standard radiological and toxic chemical evaluation.

\subsection{RADIOLOGICAL EVALUATION}

The first step in performing a radiological control room evaluation is a review of plant specific information from the FSAR, SER, and any licensee submittals to determine what hazards are present and what potential flow paths exist to transport contaminants to the control room boundary. The flow paths can be divided into those which are through-plant; for example, those which are transported from room to room by ducts, doorways, and passages; or those which are transported by the outside atmosphere to the control room air intakes, for example, containment leakage or stack releases.

For each through-plant pathway, the code FPFP (reference 3) must be executed. After each run, a file named CRHFPFP.OUT will be created. Rename this file CRHFPFP*.OUT, where * is any legal filename character, a letter or number, before performing the next run; CRHFPFP.OUT is overwritten every time FPFP is executed. Create as many CRHFPFP*.OUT files as there are pathways through the plant to the control room, being careful not to give any two the same name. Note, however, that CONHAB can only use two of these at a time. If there are more than two, execute CONHAB multiple times and sum the results. It is much 
more conventent and usually suffictent to define only two pathways to begin with.

Choose one of the FPFP output files to be user-defined unfiltered source one, and the other to be user-defined unfiltered source two. It is irrelevant which source is chosen as one or two, but this convention must be carried through the remainder of the problem in order to tell CONHAB which source goes with which flow rate.

For through atmosphere pathways, TACT5 (reference 4) must be run. TACT5 need only be run once regardless of the number of control room air intakes, as the CRH and CONHAB codes contain the required meteorological information to correctly transport the contaminants. The meteorological information does not need to be entered into the TACT5 input deck, because the only information required by CONHAB is the number of curies of each radionuclide released to the environment for each time step in TACT5. This information is automatically written to a file by the new (6/90) version of TACT5. Rename the file CRHTACT.DAT (created by TACT5) CRHTACT*.DAT as beiore. Make a copy of this file using a different character for '*.' The DOS commands for these two steps are: c: \RENAME CRHTACT.DAT CRHTACT*.DAT <ret> and $c: \backslash C O P Y$ CRHTACT*.DAT CRHTACT\#.DAT <ret> where '*' and '\#' are different characters. CONHAB requires two separate input files, even though they are identical. This allows future flexibility to apply differing sources to each intake.

At this point there will be four source files; two CRHFPF.P*. OUT and two

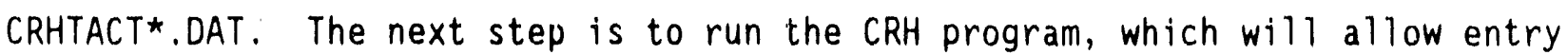
of meteorological, system design, and time independent plant specific data.

\subsubsection{Executing the CRH Code}

Begin execution of the CRH code by typing CRH at the DOS prompt and striking return. Figure 6 will be displayed. Strike any key to continue, and the screen will appear as in Figure 7 . This will be referred to as the 'main menu' in CRH. From this menu, the user may either create a new data file, 


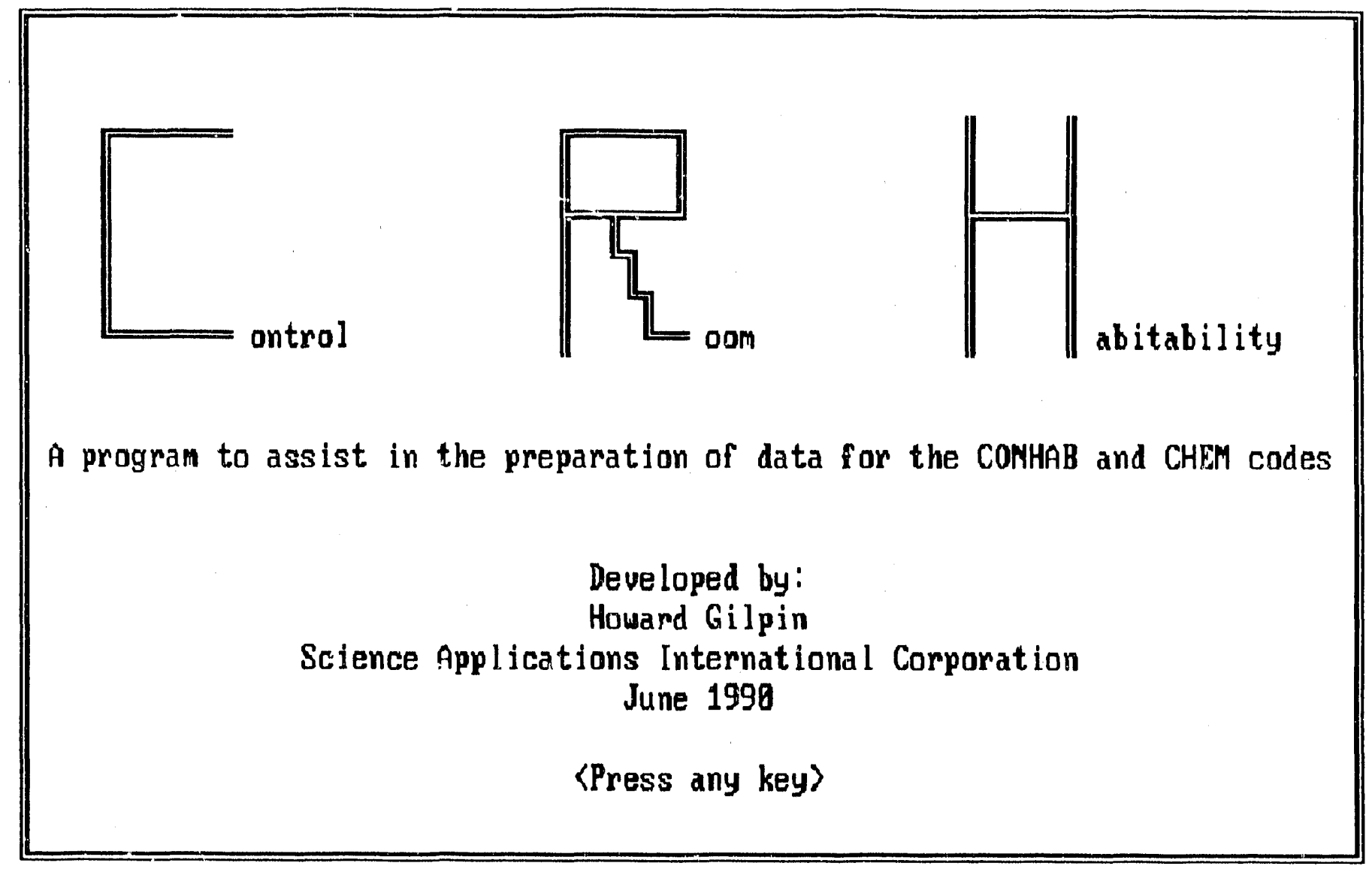

FIGURE 6 


\section{Select desired action:}

Create a new data fils (or overurite an old one)

Buit ah existing data file

Assign data files in ipreparation for ruming calculation

Exit to DOS

FIGURE 7 
edit an old data file, edit the time independent information, designate which data files to use in the CONHAB calculation, or exit to DOS.

To create a new input file, highlight 'Create a new data file' as shown in Figure 7 and strike return. The computer will respond with Figure 8 . To create a new file, strike return with the highlight on '<creates.' The computer will then prompt for a new file name. Do not include a suffix. The code will automatically add a .DAT suffix to the data file. Enter any eight character designator as a file name. To overwrite an old file which is no longer needed, cursor down with the arrow keys, highlight the file to overwrite, and strike return.

At this point, the prograin will ask whether to use the graphical input screens or the tabular input screen. The tabular input screen is identical to the edit screen, however the graphical screens are easier to understand. Select the graphical screens by either hitting return or striking 'G.' No carriage return is necessary.

The next prompt asks how many time steps will be entered. It is allowed to enter a number larger than the anticipated number of time steps, and then enter dummy information for time steps after 720 hours (30 days). There should be a time step any time a piece of information such as flow rates, meteorological information, etc. changes. Enter an appropriate number and strike return.

The program will prompt for the first start time as shown in Figure 9. Enter the first start time in either seconds, minutes, or hours; strike return. The 'Select urits:' menu will appear. Highlight the units for the time just entered, and strike return. Repeat this step for the end time of the time step, which will also be the start time of the next time step.

The next screen to appear is the 'Meteorological Input' screen as shown in Figure 10. This screen is used to enter parameters which will be used by CONHAB to compute a dispersion factor to be applied to the TACT5 sources. The 


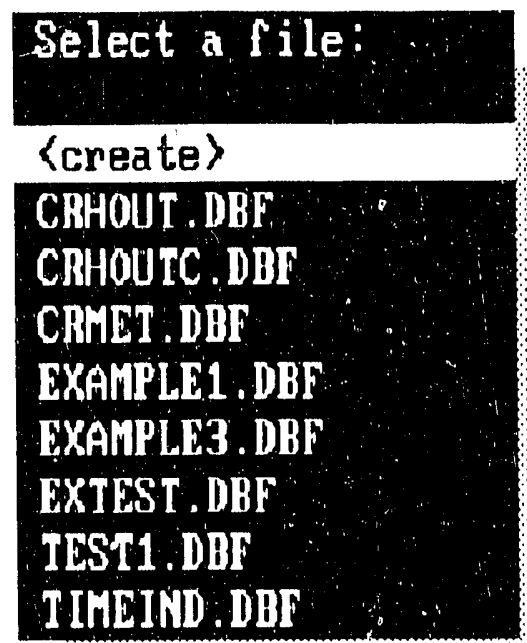

FIGURE 8 
Start time:

End time:

0.00

2 .

\section{Select units:}

hours

minutes

seconds

FIGURE 9 


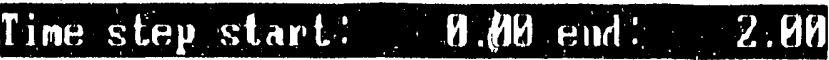

\section{JETEOROLOGICAL INPUT}

\section{Effluent}

vertical velocity

$(\mathrm{m} / \mathrm{s})$

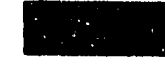

Effluent flow

rate $\left(m^{\wedge} 3 / s\right)$

0.00

Relesse Height $(m)$ 0.80

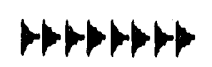

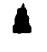

$\uparrow$

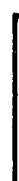

Horlzontal distance to receptor (n)

Receptor

Height $(m) \uparrow$ 0. 80

Horizontal stability class $\theta$

Uertical stability class 0

FIGURE 10 
current time step start and end times appear in the upper left corner for reference. For each of the parameters, enter the appropriate value and strike return. Do not use scientific notation. The program will respond to the carriage return with the 'Select desired units:' menu as shown in Figure 11. As before, highlight the units for the datum entered and hit return. Note that if the data being entered is already in the default units (mks), the unit menu can be avoided by striking the down arrow key rather than return after entering a number. The last two prompts on the screen, horizontal and vertical stability class, require a number, 1-7, which represents the appropriate Pasquill stability class $(A=1, B=2$, etc.). There are no unit menus for these two parameters.

After entering the vertical stability class value, the program will display the 'Control Room Habitability System Flows' input screen as shown in Figure 12. This screen accepts system flow parameters and an occupancy factor. Enter the parameters as before. There are unit conversion menus for all values except the occupancy factor (see Figure 13). Note that on color monitors, the prompts and the flow paths are color coordinated to assist in identifying which prompt goes with which flow path.

After entering an occupancy factor, the screen will appear as in Figure 14. This screen allows the input of filter efficiancies each of the three filters. A unit conversion menu will prompt for each entry for either fraction or percent units. Upon entering the last filter efficiency, the program will request the next time step start and end time. The entire process is then repeated until all time steps have been entered. Note that for each time step, information has been carried forward from the previous time step. Thus, if a parameter has not changed, the user can simply cursor past it with the arrow keys. Using the return key will have the same effect, however this will cause the unit conversion menus to appear. Note also that any data which was not entered in mks units has been converted to mks at this point. Be careful not to incorrectly change the units to other than the default mks (always the first choice in the unit menus) when using the return key to move through the screen. 


\subsection{9 end: 2.00}

IETEOROLOGICAL INPUT

Effluent

vertical velocity

$(\mathrm{m} / \mathrm{s}) \quad 3.00$

Erfluent flow

rate $\left(\mathrm{m}^{\wedge} 3 / \mathrm{s}\right)$

0.98

Release
Height (in)
0.80

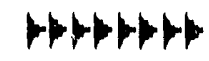

$\Delta$

$\Delta$

$\uparrow$ Horizontal distance

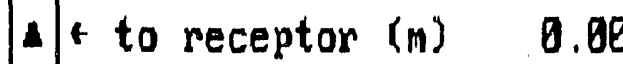

\section{Select desired units: ... eed}

meters/sec

ft/min

90

ft/getc

miles/hour

Recep

Height $(m)$

0.80

$\uparrow$

Building

Height (m)

Building area $\left(\mathrm{n}^{\wedge} 2\right) \quad 0.8$

0.00 $\downarrow-1$

Horizontal stability class $\theta$

Vertical stability class $\theta$

FIGURE 11 I 


\section{Time step start: 9.90 end: 2.09}

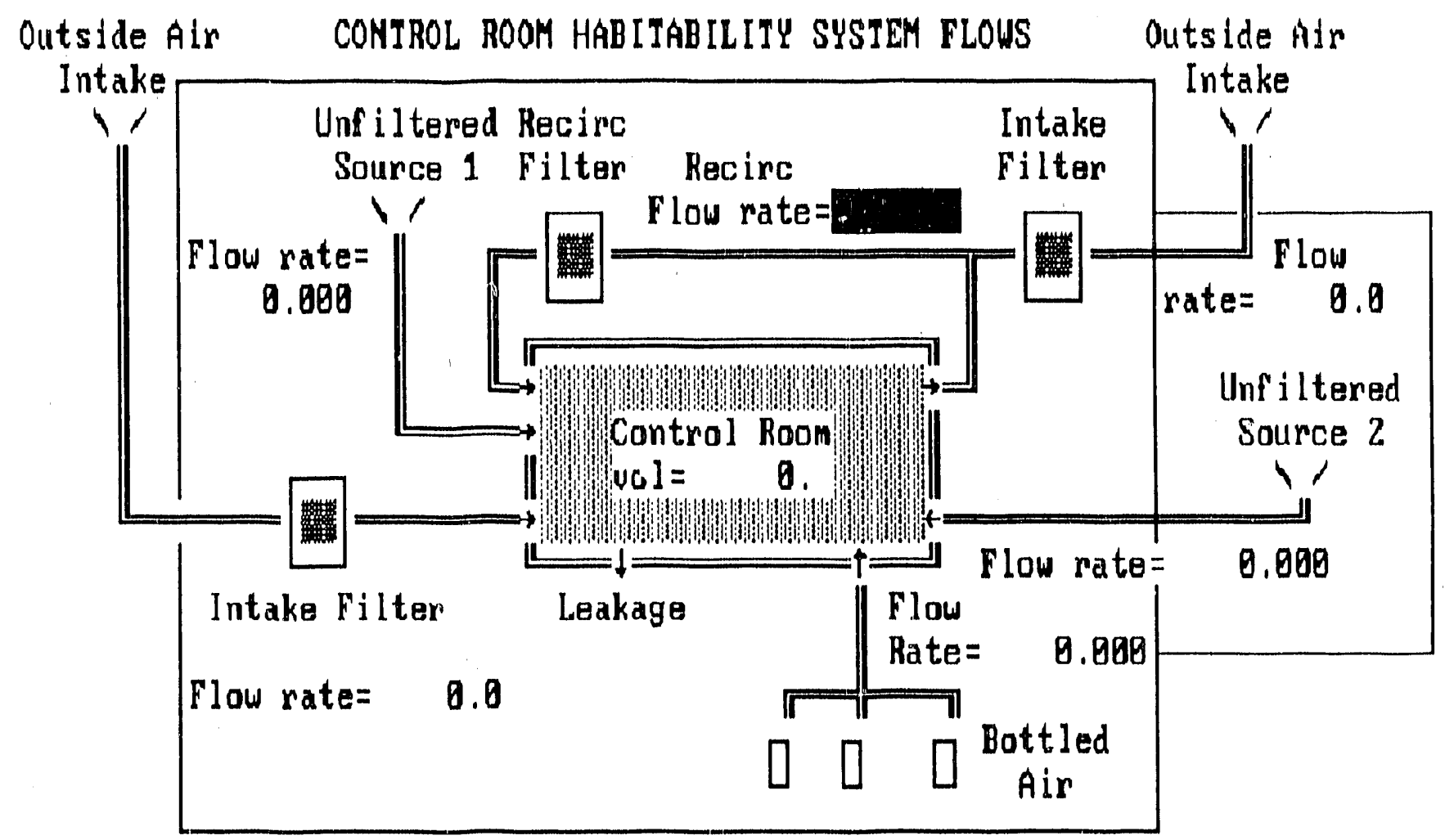

Dccupancy Factor 0.0000

FIGURE 12 


\section{Time step start: $\quad 0,80$ end: 2.08 .}

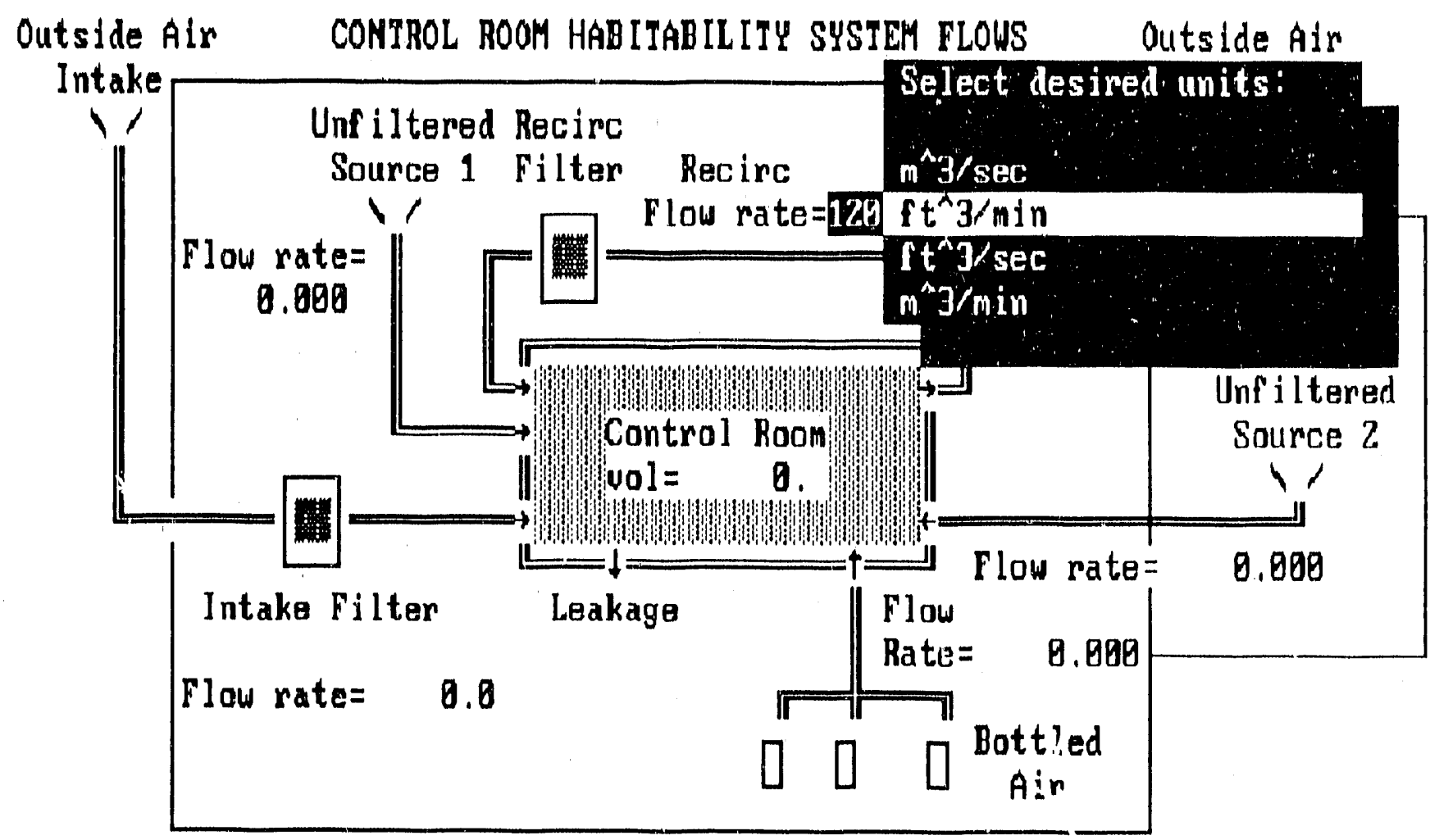

Dccupancy Factor 0.000

FIGURE 13 


\section{Time step start: 0.08 end $\quad 2.00$}

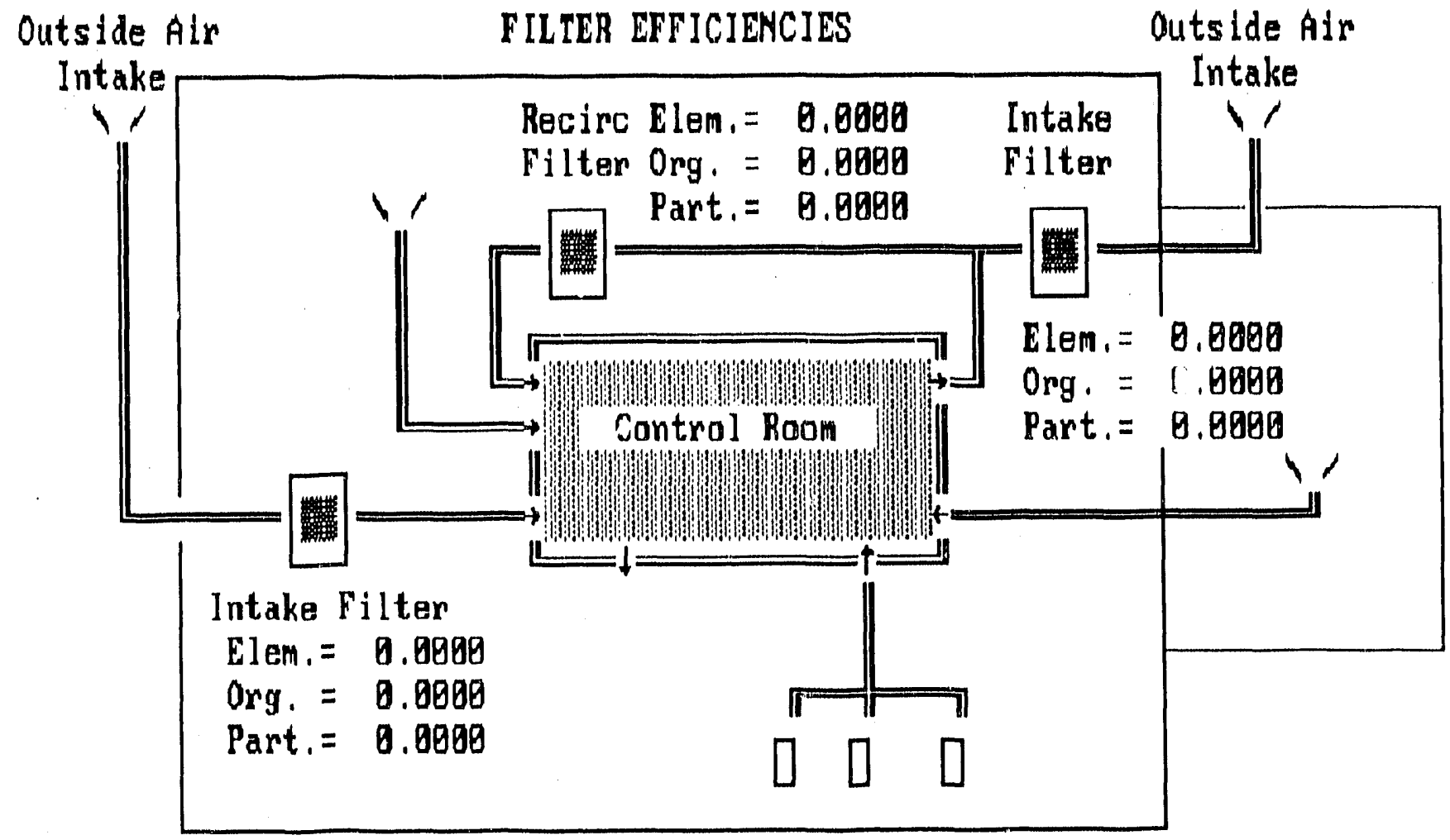

FIGURE 14 
After entering the information for the last time step, control is passed back to the main menu. At this point, the data can be edited if necessary by highlighting 'Edit an existing data file' as shown in Figure 15. The program will respond with the edit menu as shown in Figure 16 . To edit the time independent data (necessary to change the power level), highlight the first option and strike return. This produces Figure 17, the 'Time Independent Data' edit screen. Using the cursor keys, highlight and change information as necessary. When finished, strike return on the last prompt. This will return control to the edit menu.

To edit the meteorology or system flow information entered above, highlight the 'Edit meteorology and/or system flow data' option as shown in Figure 18 and strike return. The program will then prompt for which file to edit. Highlight the filename entered in the 'Create file' option above; strike return. Note that the menu will scroll to reveal more filenames as the cursor is moved to the bottom of the menu box.

The screen will then appear as in Figure 19, although the time steps 1isted may be different. Move the highlight to the time step to edit and strike return. When finished editing, strike return over the 'Finished editing' option to return to the edit menu.

Selecting one of the time steps to eait will produce the edit screen as shown in Figure 20. This screen contains all the time dependent information entered with CRH. Use the arrow keys or the return key to highlight and change any of these values. There are no unit conversion menus on this edit screen. Enter all values in the units listed to the right of the screen. Strike return on the control room volume prompt to finish editing this time step. This returns control to Figure 19 to either edit another time step or return to the edit menu.

After selecting 'Finished editing,' the program will return to the main menu. At this point, all data for performing a calculation should be on the hard disk. Highlight the 'Assign data files...' option as shown in Figure 21 and 


\section{Select desired action: \\ (Preate a new data file (or averwrite all old oune)}

Edit an existing data flle

Assign data files in preparation for ruming calculation

Exit to DOS

FIGURE 15 


\section{Select desired action:}

Edit time independent data (farm frac, power level)

Edit meteorology andror. system flow data.

Edit source tern data (disabled)

Return to main menu

FIGURE 16 


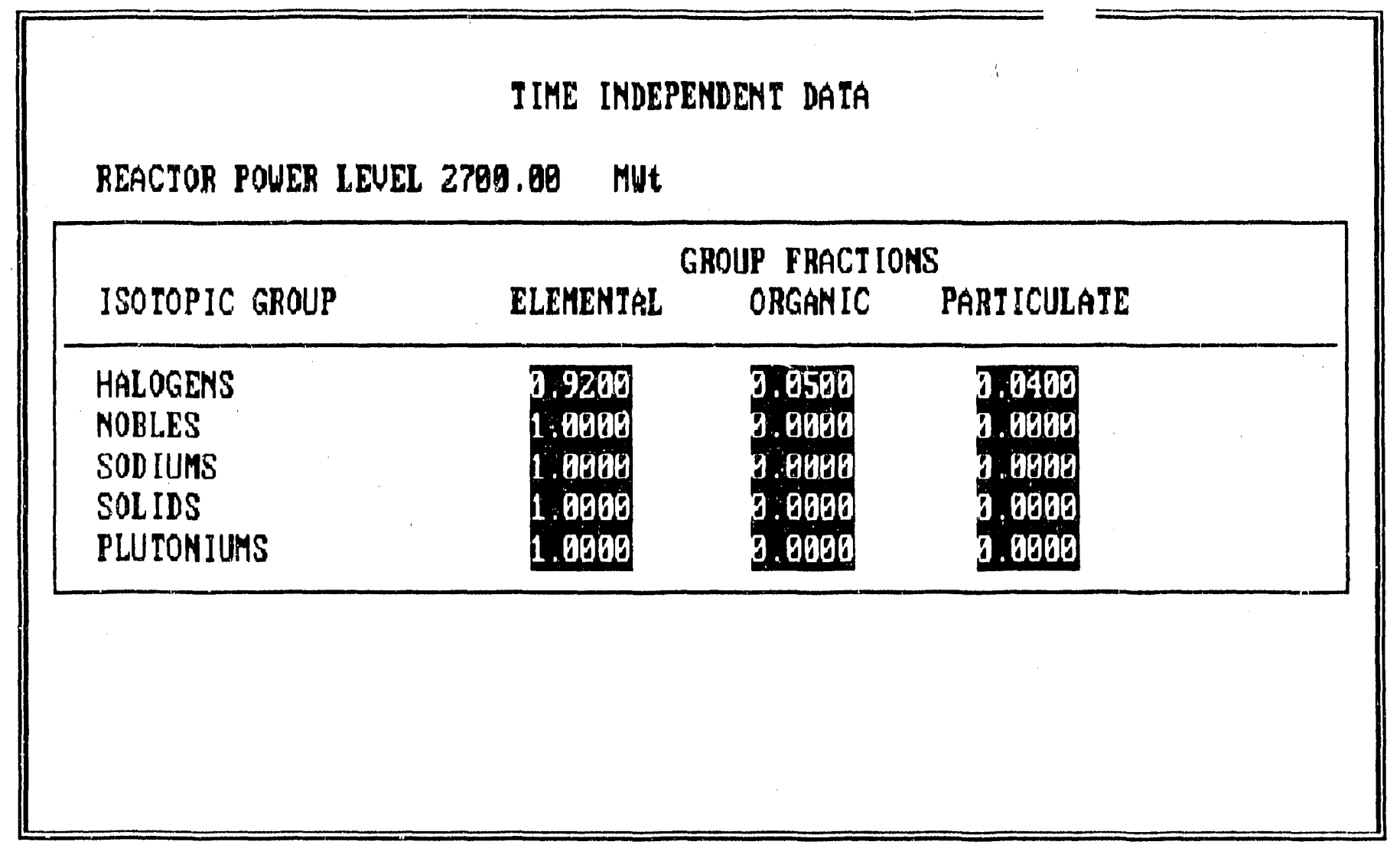

FIGURE 17 


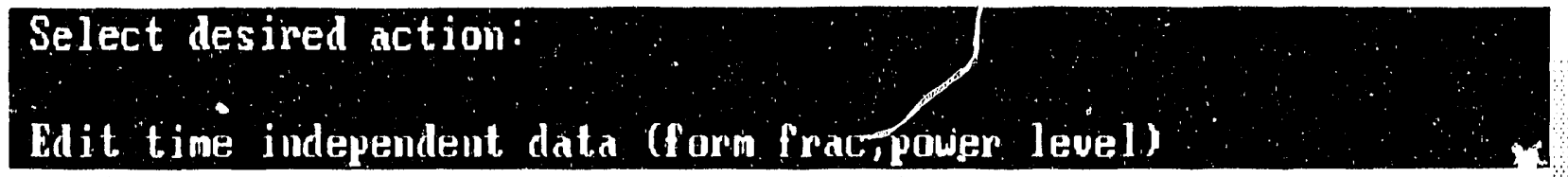

Edit meteorology and/or system flow data

Dedit source term data 〈disabled入

Return to main memu

FIGURE 18 


\section{Tighlight the time step to edit and hit return.}

Finished editing

3.89 to 8.80

3.90 to 96.80

96.00 to 300.00

390.09 to 720.09

FIGURE 19 


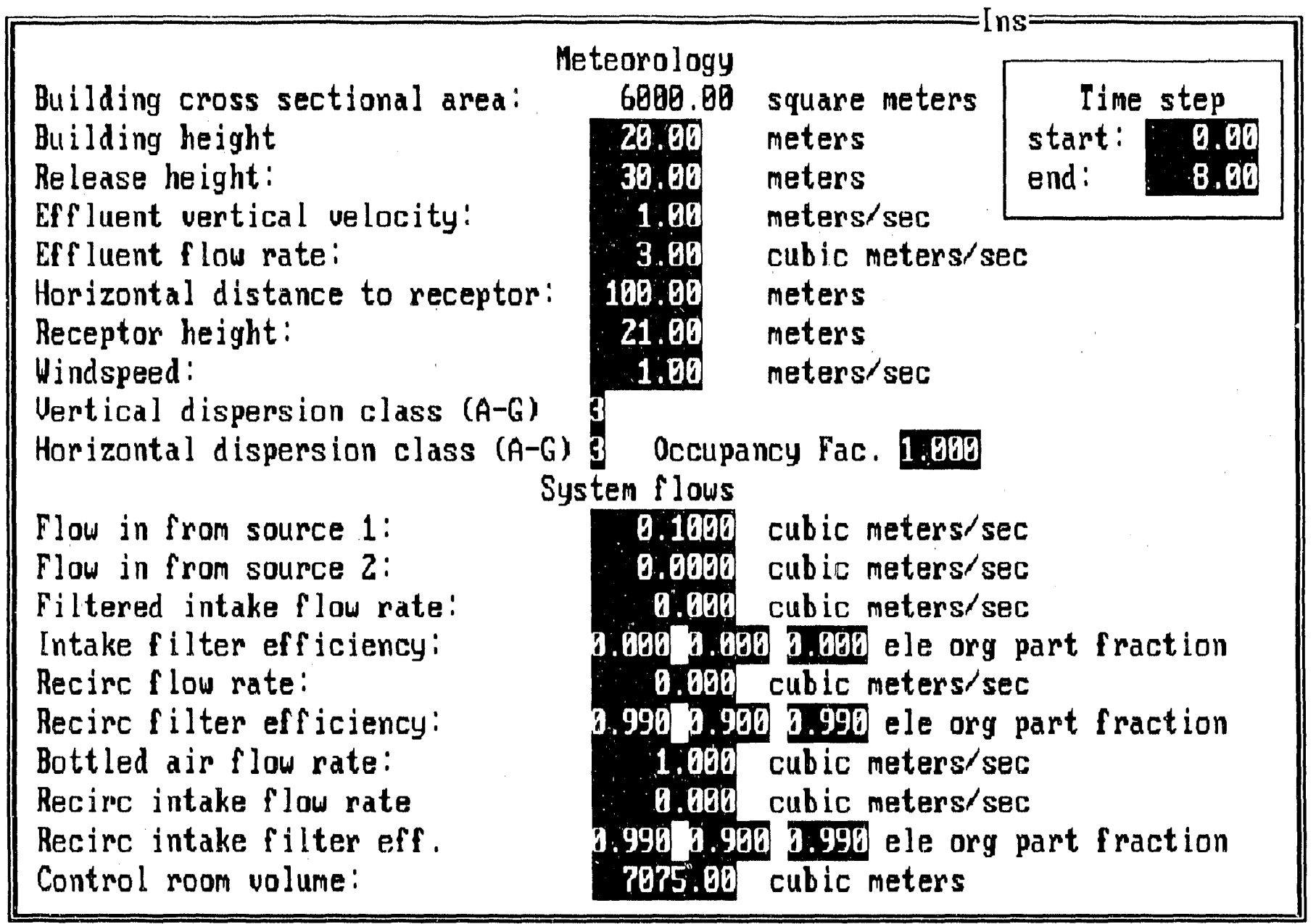

FIGURE 20 


\section{Select desired action:}

Create a new data file (or overurite an old one)

Wit an existing data file

Assign data flles in preparation for running calculation

Exit to DoS

FIGURE 21 
strike return. This option allows the user to identify which data files to use in the subsequent calculation. The screen will prompt for which meteorology and system flow file to use. Highlight the file created above and strike return. Note that the data file listed here will have a .DAT extension, while the file as listed for editing will have a .DBF extension. The program will then ask which nuclide file to use. Select either ICRP.02 or ICRP. 30 and hit return. Next, the program needs to know the user defined unfiltered source 1 file name as created by FPFP. Highlight the filename and strike return. Repeat for unfiltered source 2.

The program will then prompt for each of the two TACT5 source files created by TACT5 as described abnve. Highlight one of the files and strike return, then repeat for the second file.

The program will then display each of the files selected, as shown in Figure 22. If they are correct, press ' $y$ ' or strike return. If not, type ' $n$ ' and repeat these steps with the correct file names.

When the file names are correct, type ' $y$ ' or strike return to return to the main menu. The files are set up for performing the calculation at this point. Exit to DOS from the main menu.

Changes to the meteorology and system flow data file can be made by executing CRH again and following the instructions for editing above. If no file names have changed, the 'Assign data files...' step may be omitted before rerunning CONHAB.

\subsubsection{Executing the CONHAB Code}

From the DOS prompt, type 'CONHAB' and strike return. This will begin execution of the calculational code. The program will prompt for an output destination. Type 'CON' to send the output to the screen, 'PRN' to send it to the printer, or a valid filename to produce an ASCII output file which can be printed, viewed, or edited later. The program will then begin echoing input 
The following files have been selected:

Meteorology and control room system f low data: EXAMPLE3.DAT Nuclear data file: ICRP.92

User defined unfiltered source 1: CRHFPFP1.0UT User def ined unfiltered source 2 : CRHFPFP2. OUT Source to filtered intake: Source to recirc loop filtered intake: CRHTACI4.DAT CRHTAC T5.DAT

Are these selections correct $(Y / N)$ ? $Y$ 
and printing results for each time step to the selected device. A summary table will be printed on the screen regardless of output destination. CONHAB also generates a datafile which is used to plot the data on the computer screen.

\subsubsection{Executing the CRHPLOTR Code}

Type 'CRHPLOTR' and strike return to begin the plotting routine. Respond appropriately to the questions asked, and the program will plot dose versus time for whole body, thyroid, and skin doses. Hit any key to display individual plots of dose vs. time for the same organs.

\subsection{TOXIC GAS EVALUATION}

Performing a toxic gas analysis is similar to the procedure previously outlined. Instead of using FPFP and TACT5, the code EXTRAN is executed to compute a toxic gas concentration at the control room air intake. Refer to the EXTRAN manual for performing an EXTRAN calculation. EXTRAN will produce an output file which can be read by the CHEM code. Make note of the file name produced by EXTRAN.

Run the $\mathrm{CRH}$ code as described in section 4.1.1 above. When creating a datafile, note that the meteorology input screen can be omitted (enter all zeros and any number between 1 and 7 for the stability classes) because EXTRAN incorporates all atmospheric diffusion calculations. The filter efficiency screen can also be ignored, as the filters have no effect on the toxic gas concentration in the control room. The only screen which contains data required by the CHEM code is the system flow input screen. Enter appropriate information for each time step as described above. The EXTRAN source will be applied to any and all of the four potential pathways into the control room volume for which the user designates a non-zero flow rate.

After entering the system flow parameters, skip the 'Assign data files...' step, as CHEM does not require this. Exit to DOS. Type CHEM at the DOS 
prompt and the calculational program will begin execution. It will prompt for both the EXTRAN output file and the system flow file created with CRH. The program will then print instantaneous and mean concentrations, and exposure in the control room for each time step. When the program is finished, type CRHPLOTC at the DOS prompt to plot the results on the computer screen. 


\section{b. COOE IMSTALLATION}

The CRH codes require an IBM-PC or PS-2 compatible microcomputer with a hard disk to operate. A version of the codes which utflize a numeric co-processor is avallable.

To install the CRH codes on the hard drive of a PC, follow these steps:

1) Create a subdirectory.

$C: \backslash>m$ m $c r h$

2) Change to the new subdirectory.

$C: \mid>c d$ crh

3) Insert the CRH disk into drive A of the computer. Copy a 11 of the files into the crh subdirectory.

C: $\backslash$ CRH $\backslash>$ Copy $a: * *$ 


\section{EXAMPLE PROBL.EM}

A sample problem has been included with the distribution disks to allow verification that the codes have been installed and are executing properly. The sample problem uses the following data files:

- Through atmosphere source as calculated by TACT5 is identical to Example 1 in NUREG/CR-5106 'Users Guide for the TACT5 computer code.' The filenames for these two files are CRHTACT1.DAT and CRHTACT2.DAT.

- Through plant sources are the sample output from the FPFP code, labeled CRHFPFP1.DAT and CRHFPFP2.DAT on the distribution disk.

$0 \quad$ Meteorology and system flow file EXAMPLE.DAT.

- ICRP.02 nuclide library.

To execute the sample problem, run CRH and use the 'Assign data files...' option to select each of the files listed above. Then exit to DOS and type CONHAB at the DOS prompt. Select CON to display the output on the screen, PRN to send it to the printer, or a file name to save output to a file for later printing. Note that the code will display a summary table, and that if necessary, the output data can be retrieved from the file CRHPLOTR.DAT, which is always created, regardless of where the output is directed. The CRHPLOTR.DAT file is used as input to the plotting routine CRHPLOTR.EXE. Only the first two and last pages of the output have been included in Appendix I. Sample plots from CRHPLOTR and CRHPLOTC are attached.

Sample input files for the CHEM code are also included. The sample system flow file is named EXAMCHEM.DAT, and the sample EXTRAN output file is EXOUT.OUT. Execute the sample problem by typing CHEM at the DOS prompt and striking return. Enter EXAMCHEM.DAT for the system flow file, and EXOUT.OUT for the EXTRAN output file. The output will be sent to the screen. Again, the output can be retrieved from disk by printing the file CRHPLOTC.DAT, or 
the output can be printed by typing $\langle$ Ctrl> $\langle$ Print Scrn> after typing the EXTRAN file name but before hitting return. Type $\langle$ Ctrl $>\langle P r i n t ~ S c r n\rangle$ again to turn the printer off after the code has executed. 


\section{REFERENCES}

1 Murphy, K. G., and K. M. Campe, "Nuclear Power Plant Control Room Ventilation System Design for meeting General Design Criterion 19,"

Proceedings of the 13th AEC Air Cleaning Conference, August 12-15, 1974, San Francisco, California, CONF-740807. U.S. Atomic Energy Commission, Washington, DC.

2 Driscol1, J. W., Control Room Habitability Survey of Licensed Commercial Nuclear Power Generating Stations, Argonne National Laboratory, NUREG/CR-4960, October 1988.

3 Owczarski, P. C. and D. D. Yasuda, "FPFP: A Code for Following Airborne Fission Products in Generic Nuclear Plant Flow Paths, "Pacific Northwest Laboratory, Draft Letter Report, November 1988.

4 West, D. B. and H. E. Gilpin, User's Guide for the TACT5 Computer Code, Science Applications International Corporation, NUREG/CR-5106, June 1988 .

5 Ramsde 11, J. V. and G. L. Andrews, EXTRAN: A Computer Code for Estimating Concentrations of Toxic Substances at Control Room Air Intakes, Pacific Northwest Laboratory, NUREG/CR-XXXX, December 1988.

6 Ramsde11, J. V., Atmospheric Diffusion for Control Room Habitability Assessments, Pacific Northwest Laboratory, NUREG/CR-5055, May 1988.

7 Ramsde11, J. V., "Diffusion in Building Wakes for Ground Level Releases," Atmospheric Research, in press. 
APPENDIX A

CRH CODE LISTIMG 


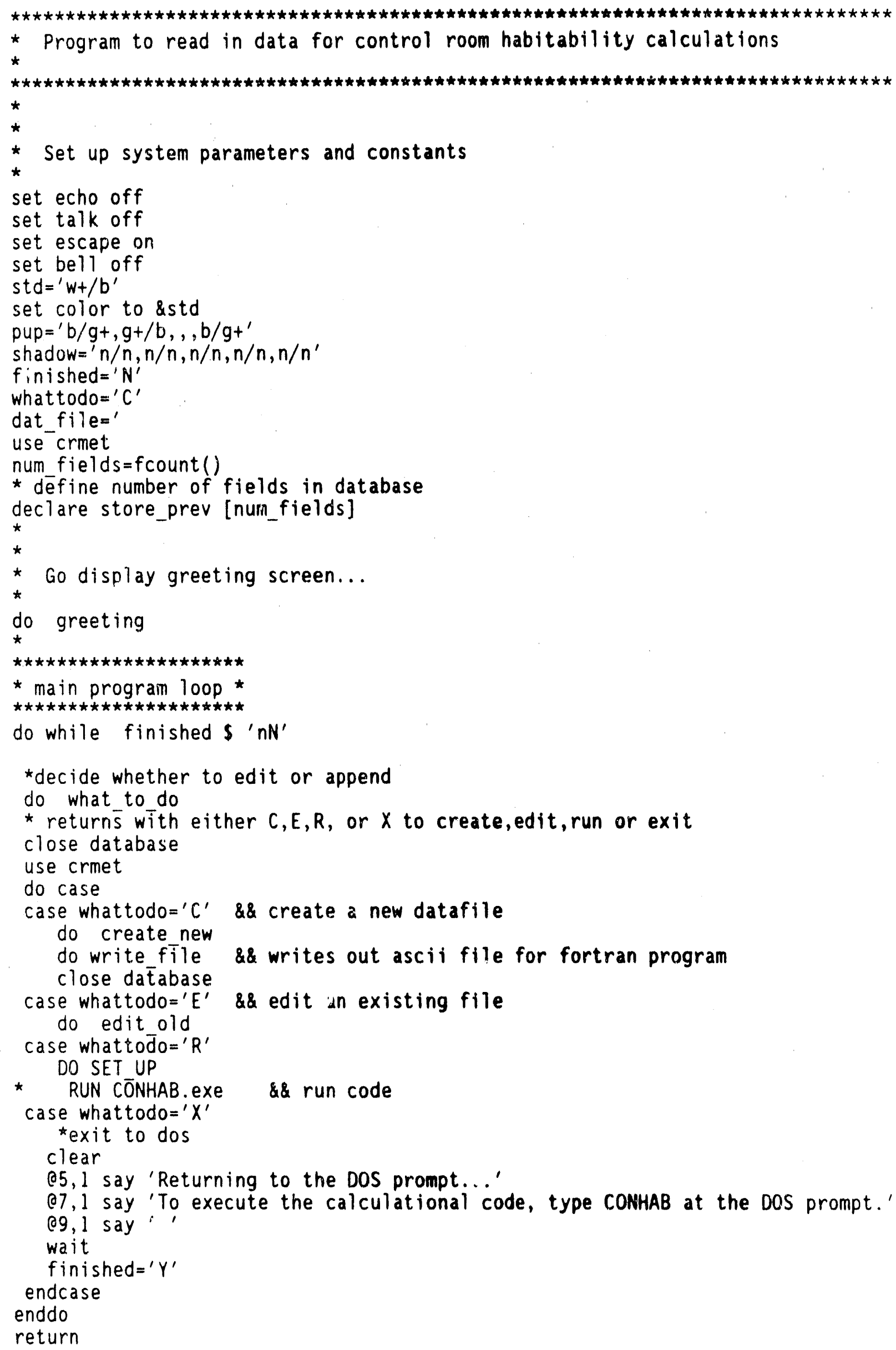




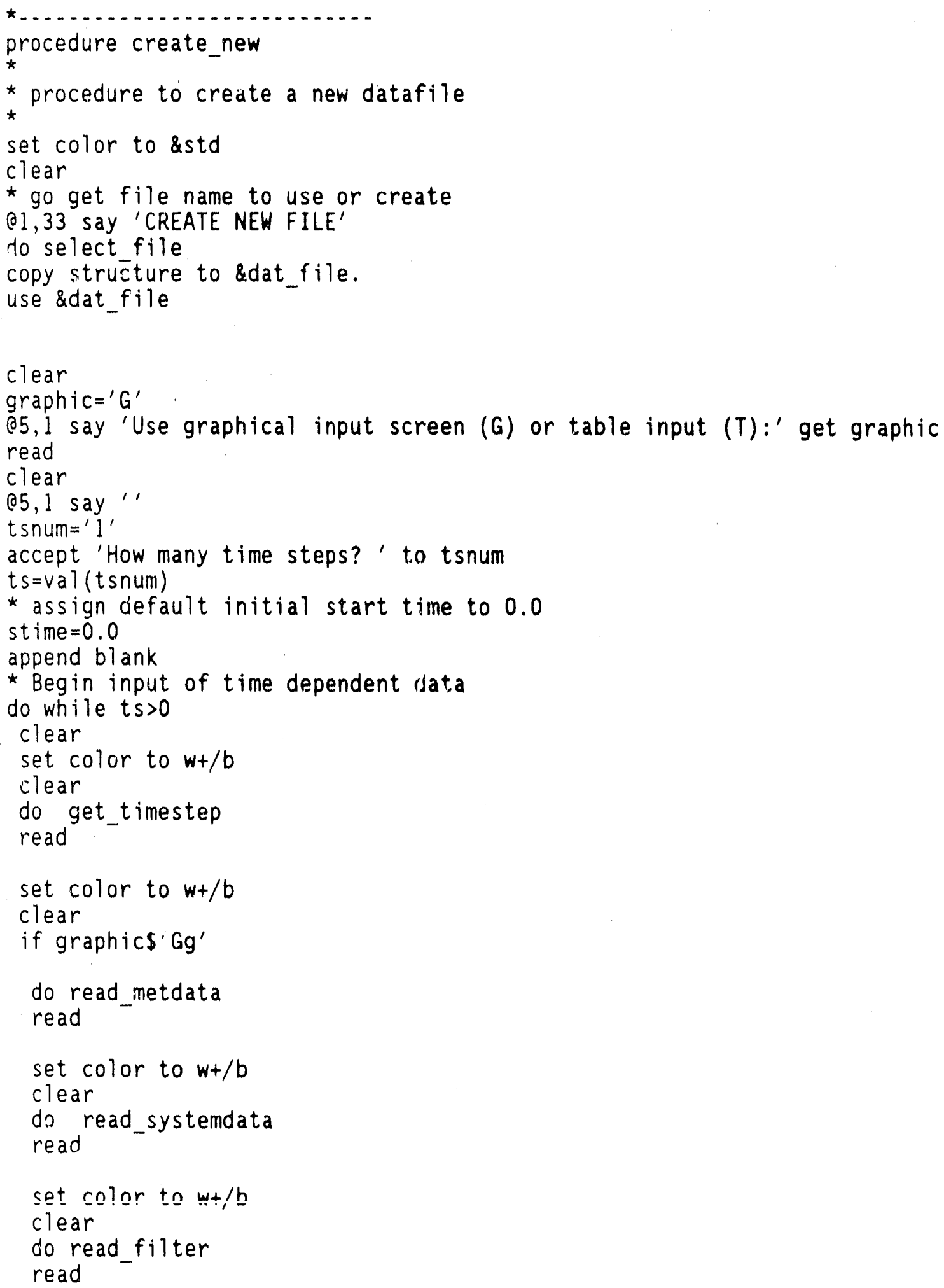




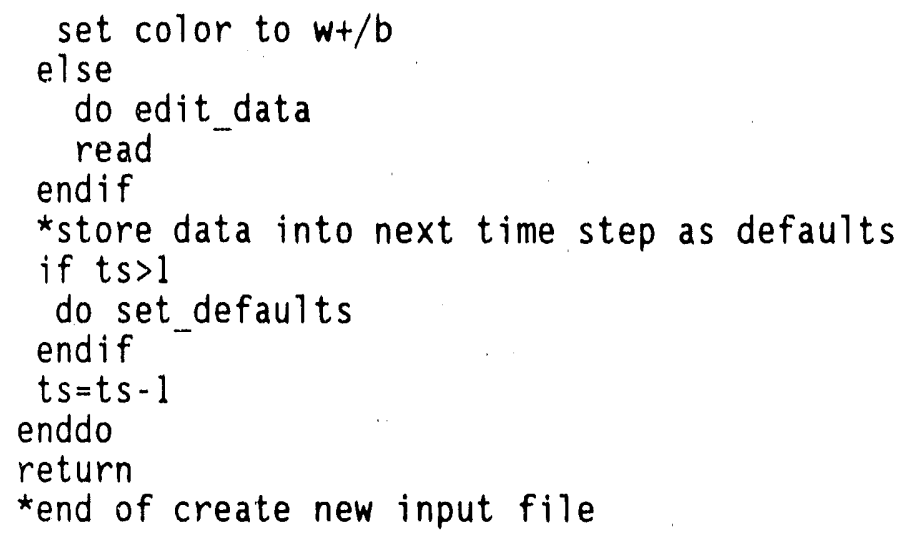




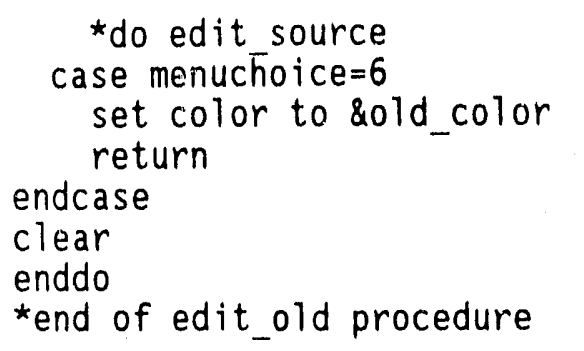

procedure edit timeind

use timeind

go top

a 2,29 SAY "TIME INDEPENDENT DATA"

c 4,5 SAY "REACTOR POWER LEVEL"

( ) 4, 25 GET TIMEIND->POWER PICTIJRE "9999.99"

( 4,35 SAY "MWt"

( ) 6,39 SAY "GROUP FRACTIONS"

d 7,5 SAY "ISOTOPIC GROUP

(2) 9,5 SAY "HALOGENS"

( ) 9,30 GET TIMEIND->HELE PICTURE "9.9999"

(0) 9, 43 GET TIMEIND->HORG PICTURE "9.9999"

( 9, 56 GET TIMEIND->HPART PICTURE "9.9999"

(c) 10,5 SAY "NOBLES"

( ) 10, 30 GET TIMEIND->NELE PICTURE "9.9999"

( ) 10, 43 GET TIMEIND->NORG PICTURE "9.9999"

( 10, 56 GET TIMEIND->NPART PICTURE "9.999"

(d) 11,5 SAY "SODIUMS"

( 11, 30 GET TIMEIND->NAELE PICTURE "9.9999"

Q 11,43 GET TIMEIND->NAORG PICTURE " $9.9999 "$

( 11,56 GET TIMEIND->NAPART PICTURE "9.9999"

(2) 12,5 SAY "SOLIDS"

( ) 12, 30 GET TIMEIND->SELE PICTURE "9.9999"

( 12,43 GET TIMEIND->SORG PICTURE "9.9999"

(c) 12,56 GET TIMEIND->SPART PICTURE "9.9999"

a 13,5 SAY "PLUTONIUMS"

( ) 13, 30 GET TIMEIND->PELE PICTIJRE "9.9999"

@ 13, 43 GET TIMEIND->PORG PICTURE "9.9999"

(a 13,56 GET TIMEIND->PPART PICTURE "9.9999"

a 0,0 TO 20,79 DOUBLE

(a) 5,2 TO 14,77

(d) 8,3 TO 8,76

read

copy to timeind.dat delimited

close databases

return

procedure set_up

*this procedures sets up data files for conhab program

set color to \&std

close database

do while. T.

clear

O1,1 say 'The FORTRAN program CONHAB noeds to know what data files to use...'

22, 1 say 'First, pick which meteorology and system flow file to use' 
wait

ftemp $=\prime \star$.dat

do sel_dat_file

datfile $=$ dat_file

clear

Q1,1 say 'Now pick which NUCLIDE DATA FILE to use...'

wait

ftemp $=^{\prime}$ ICRP. . ${ }^{\prime \prime}$

DO SEL DAT FILE

nucfile $=$ dat_file

clear

(l, l say 'Now select SOURCE file for unfiltered source 1 (created by FPFP)...'

wait

ftemp $=$ ' CRHFPFP*. OUT'

DO SEL DAT FILE

STFILE $\overline{\mathrm{I}}=$ DAT $\bar{T}$ FILE

CLEAR

01,1 SAY 'Same thing for unfiltered source $2 \ldots$ '

wait

ftemp $=$ 'CRHFPFP ${ }^{\circ}$. OUT'

do sel dat file

stfile $\overline{2}=d a \bar{t}$ file

clear

01, l say 'Select SOURCE file for filtered intake l (usually from TACT5)...'

wait

ftemp $=$ ' CRHTACT $^{\star}$. DAT'

do sel dat file

stfile $\overline{3}=$ da $_{\text {t }}$ file

clear

01,1 say 'And the SOURCE file for filtered intake 2 (feeds the recirc loop)...'

wait

ftemp $=$ ' CRHTACT ${ }^{\star}$. DAT'

do sel dat file

stfile $\overline{4}=d a \bar{t}$ file

clear

answ $={ }^{\prime} Y^{\prime}$

(1, 1 say 'The following files have been selected:'

03, 1 say 'Meteorology and control room system flow data: '+ datfile

04, 1 say 'Nuclear data file:

Q5, 1 say 'User defined unfiltered source 1:

[6, 1 say 'User defined unfiltered source 2:

07,1 say 'Source to filtered intake:

't nucfile

08,1 say 'Source to recirc loop filtered intake:

015,1 say 'Are these selections correct $(Y / N)$ ?' get answ

't stfilel

'+ stfile2

't stfile3

read

if answs'Yy'

exit

endif

enddo

set alte to crhsys.dat

set alte on

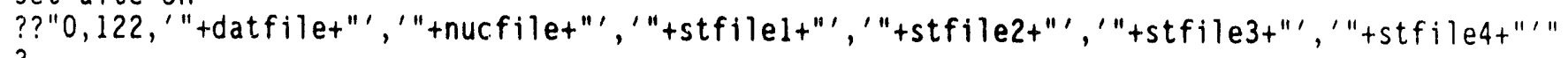

?

set alte off

close alte

clear

Q5, 1 say 'To execute the calculational code, select Exit to DOS at the next'

06,1 say 'menu, and then type CONHAB.'

Q9, 1 say',

wait 
return

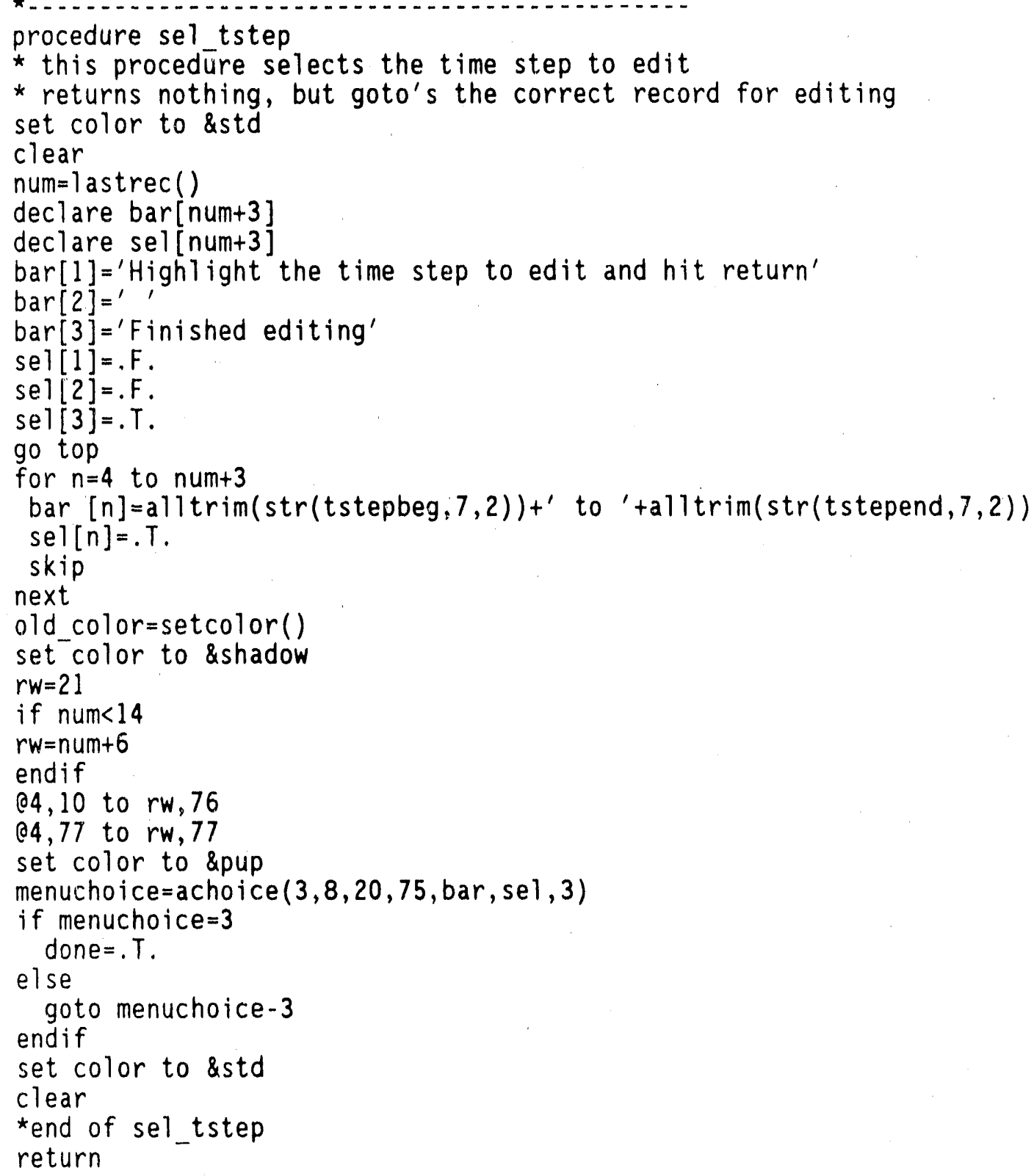




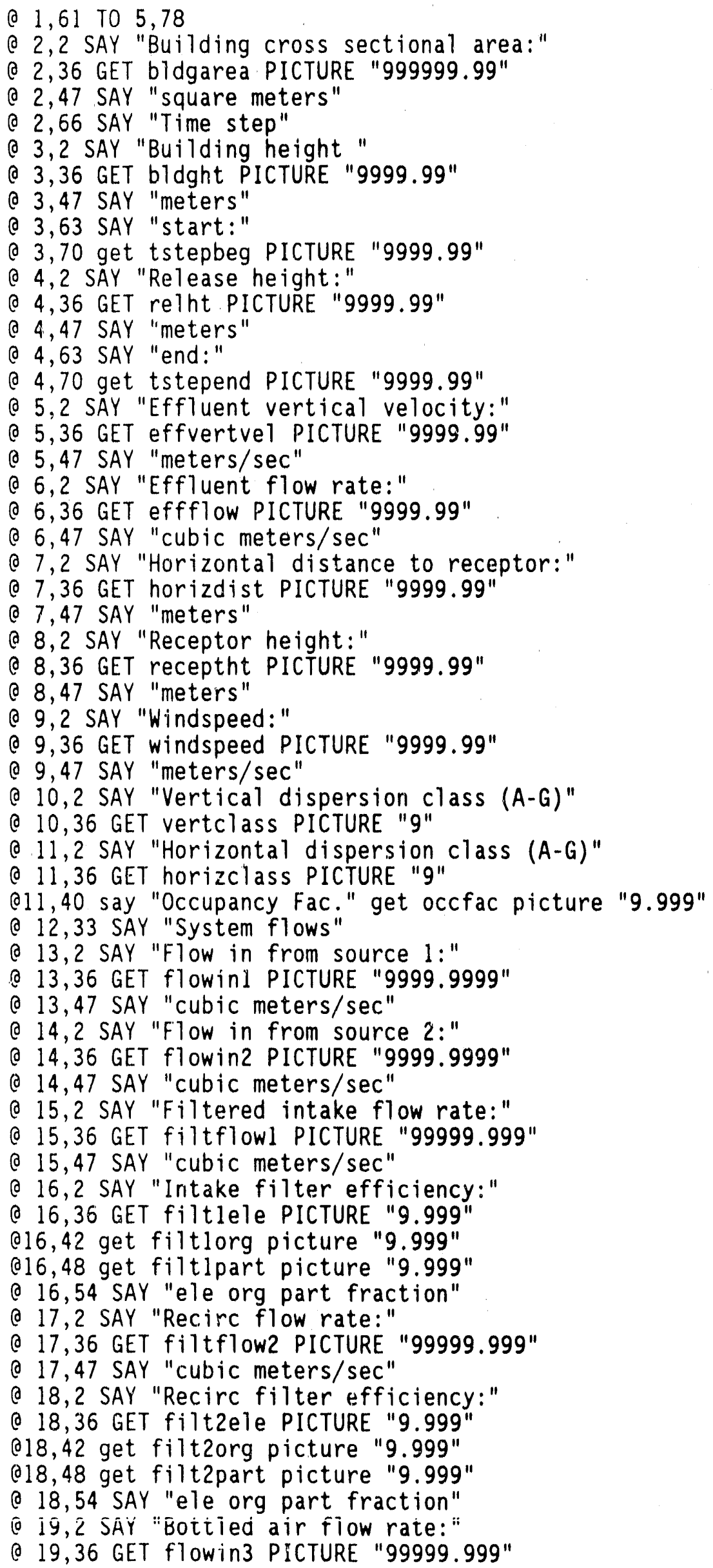


0 19,47 SAY "cubic meters/sec"

020,2 say "Recirc intake flow rate"

020,36 get filtflow3 picture "99999.999"

020,47 say "cubic meters/sec"

Q21,2 say "Recirc intake filter eff."

Q21,36 get filt3ele picture "9.999"

021,42 get filt3org picture "9.999"

021,48 get filt3part picture "9.999"

021,54 say "ele org part fraction"

Q22,2 SAY "Control room volume:"

Q22,36 GET crvolume PICTURE "999999.99"

022,47 SAY "cubic meters"

read

clear

set color to \&std+\&pup

do sel_tstep

enddo

return

procedure what to do

*put procedure here to select whether to edit an old data set or create a new *one

$\star$

* returns whattodo $=$ ' $e$ ' to edit or ' $c$ ' for new

what todo $=$ ' $C$ '

set color to \&std

clear

d 1,36 say 'MAIN MENU'

declare bar[6]

bar $[1]=$ ' Select desired action:'

bar [2] $=1$ '

bar $[3]='$ Create a new data file (or overwrite an old one)'

bar [4] = 'Edit an existing data file'

bar $[5]=$ 'Assign data files in preparation for running calculation'

$\operatorname{bar}[6]=$ ' Exit to DOS'

declare sel[6]

sel $[1]=. F$.

$\operatorname{sel}[2]=. F$.

$\operatorname{sel}[3]=. T$.

sel $[4]=. T$.

$\operatorname{sel}[5]=. T$.

$\operatorname{sel}[6]=. T$.

old_color =setcolor ()

set color to \&shadow

04,10 to 9,76

04,77 to 9,77

set color to \&pup

menuchoice $=$ achoice $(3,8,8,75$, bar, se 1,3$)$

do case

case menuchoice $=3$

what todo $=$ ' $C$ '

case menuchoice $=4$ what todo $=$ ' $E^{\prime}$

case menuchoice $=5$ what todo $={ }^{\prime} R^{\prime}$

case menuchoice $=6$

what todo $={ }^{\prime} X$ '

endcase 
set color to \&old_color clear

return

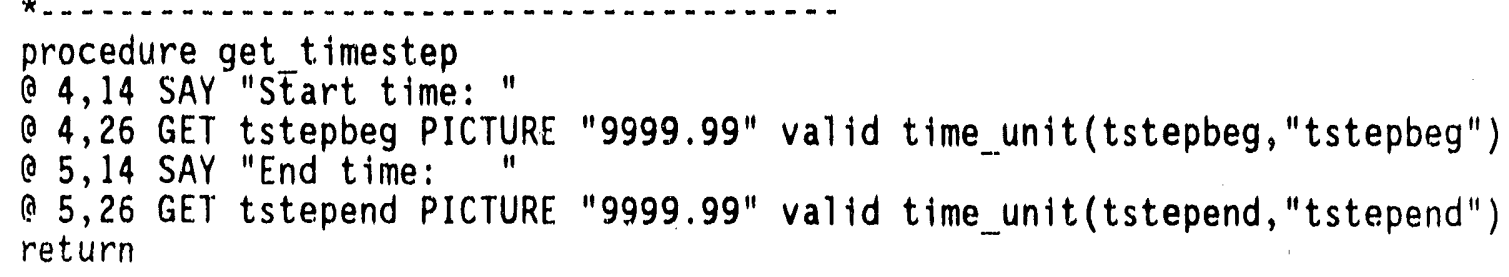




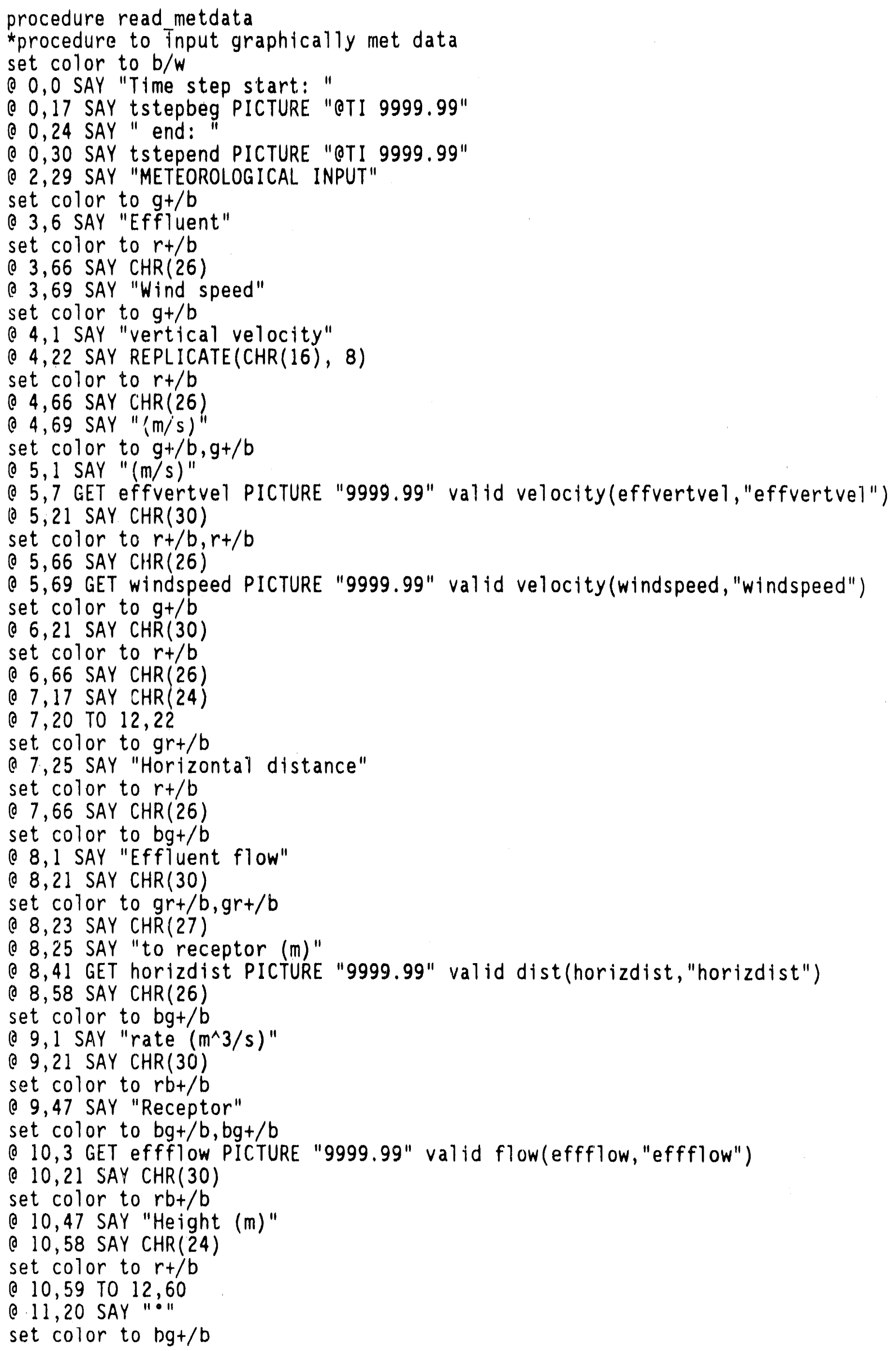


(2) 11,21 $\operatorname{SAY} \operatorname{CHR}(30)$

set color to $r b+/ b, r b+/ b$

(1) 11,48 GET receptht PICTURE "9999.99" valid dist(receptht, "receptht")

set color to $r+/ b$

c 11,59 SAY "O०"

0 12,10 SAY "Release"

(c) 12,20 TO 16,61

0 12,20 SAY "úáêááááááááááááááááááááááááááááááááááâêe"

set color to $g r+/ b$

(a) 12,66 SAY CHR(24)

set color to $r+/ b$

c 13,9 SAY "Height (m)"

(d) 13,20 SAY "०"

set color to $\mathrm{grt} / \mathrm{b}$

(e 13,63 SAY "Butlding"

set color to $r+/ b, r+/ b$

( 14,10 GET relht PICTURE "9999.99" valid dist(relht, "relht")

set color to $g+/ b, g+/ b$

( 14,27 SAY "Butlding area $\left(m^{\wedge} 2\right)$ "

( 14,47 GET bldgarea PICTURE "99999.9" valid area(bldgarea, "bldgarea")

set color to $g r+/ b, g r+/ b$

(a) 14,62 SAY "Height (m)"

(a 15,64 GET bldght PICTURE "9999.99" valid dist(bldght, "bldght")

set color to $r+/ b$

c 16,17 SAY CHR(25)

set color to $r b+/ b$

a 16,58 SAY CHR(25)

set color to $\mathrm{grt} / \mathrm{b}$

(d) 16,66 SAY CHR(25)

set color to $b g+/ b, b g+/ b$

Q 18,37 SAY "Horizontal stability class $(1-7)$ "

0 18,70 GET horizclass PICTURE "9" valid (1<=horizclass . and. horizclass $<=7$ )

( 19,37 SAY "Vertical stability class (1-7)"

c 19,70 GET vertclass PICTURE "g" valid ( $1<$ =vertclass . and. vertclass $<=7$ )

set color to \&std+\&pup

return

procedure read_systemdata

*procedure to graphically input system data

set color to b/w

0 0,0 SAY "Tiine step start: "

0 0,18 SAY tstepbeg PICTURE "OTI 9999.99"

(2) 0,25 SAY " end:

(d) 0,31 SAY tstepend PICTURE "OTI 9999.99"

a 0,38 SAY

set color to $\mathrm{w} / \mathrm{b}$

o 2,3 SAY "Outside Air"

set color to $w+/ b$

( 2,20 SAY "CONTROL ROOM HABITABILITY SYSTEM FLOWS"

set color to $\mathrm{w} / \mathrm{b}$

a 2,64 SAY "Outside Air"

(2) 3,5 SAY "Intake"

set color to $w+/ b$

(a) 3,11 TO 20,64

set color to $\mathrm{w} / \mathrm{b}$

? 3,66 SAY "Intake" 


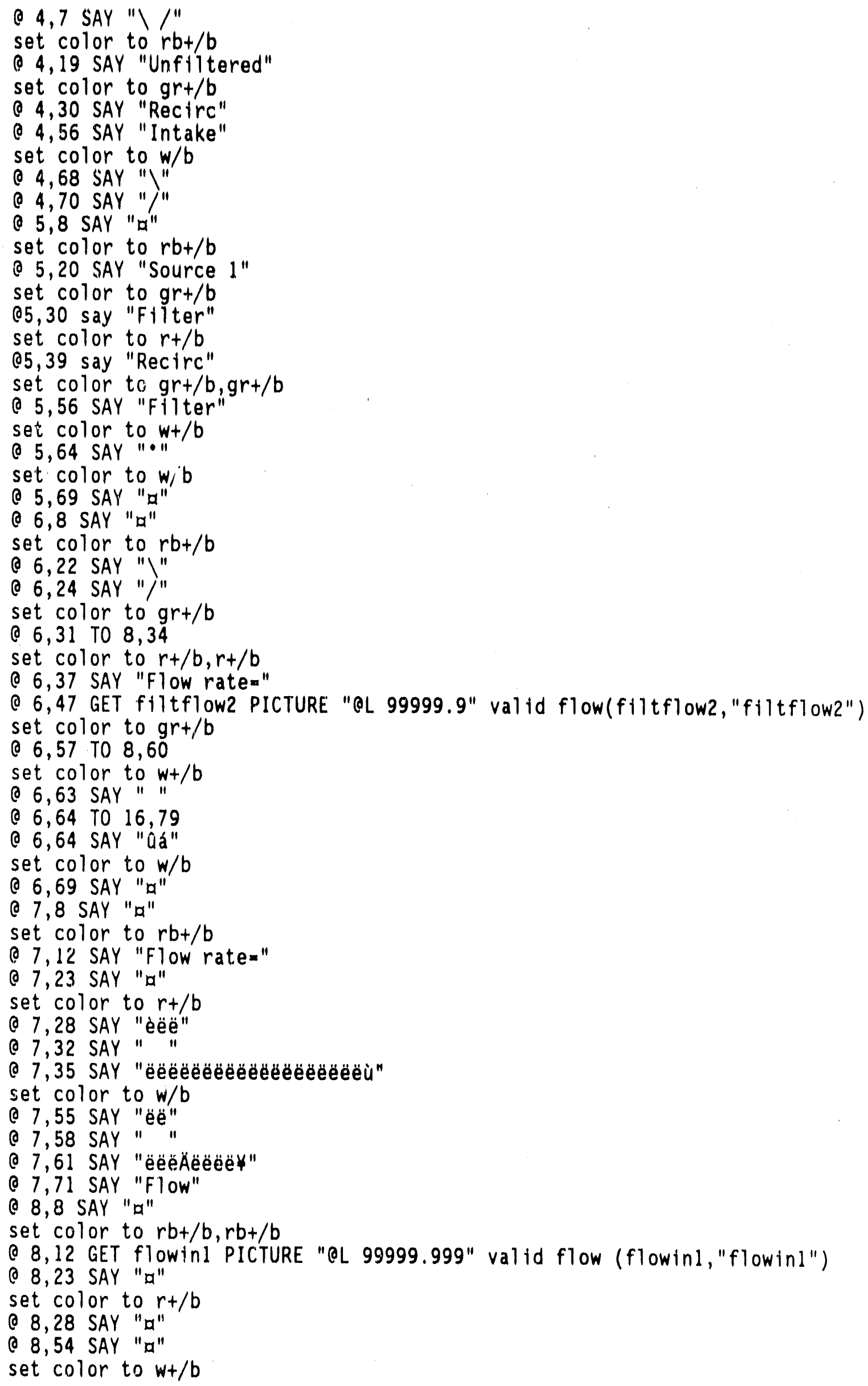




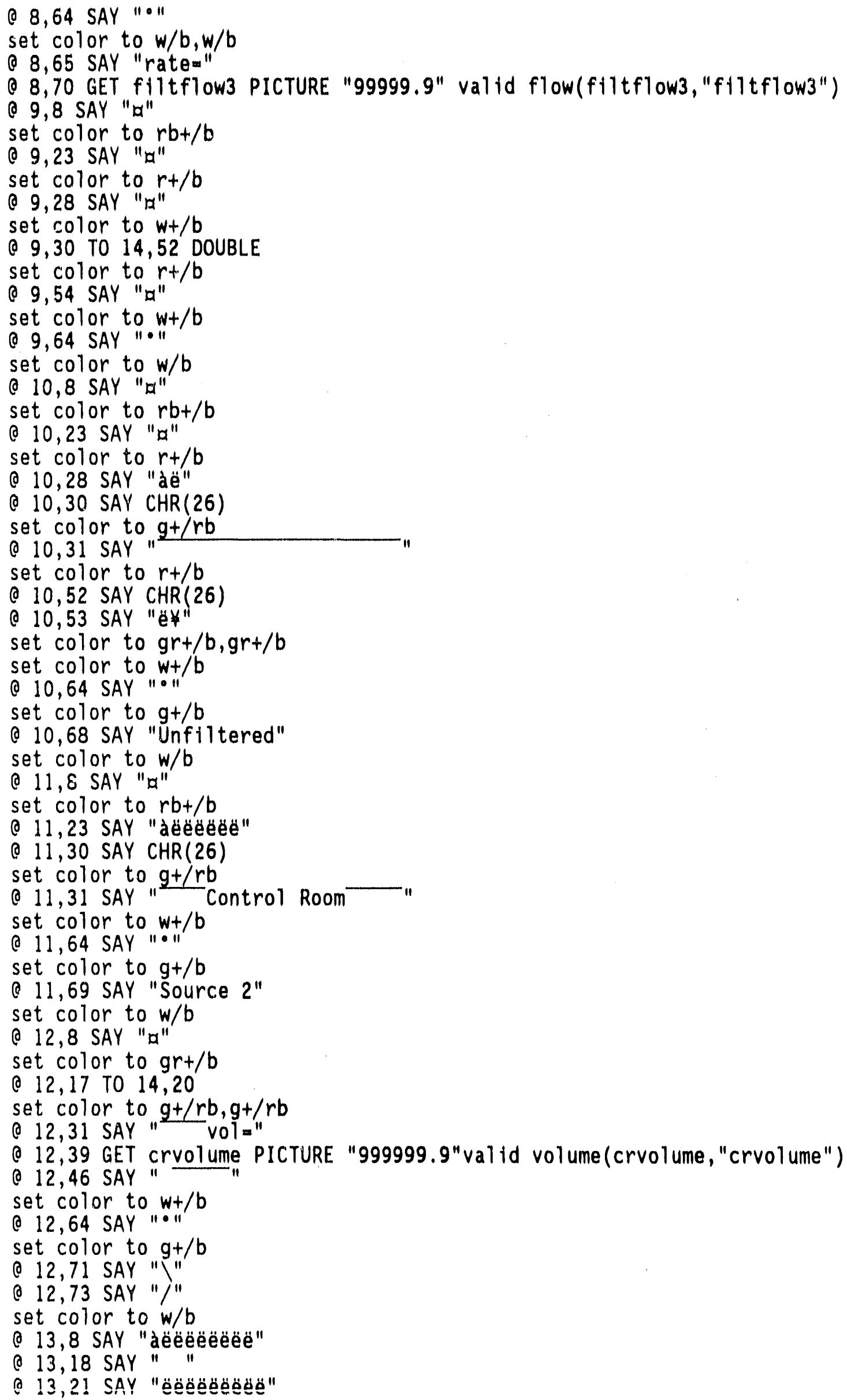




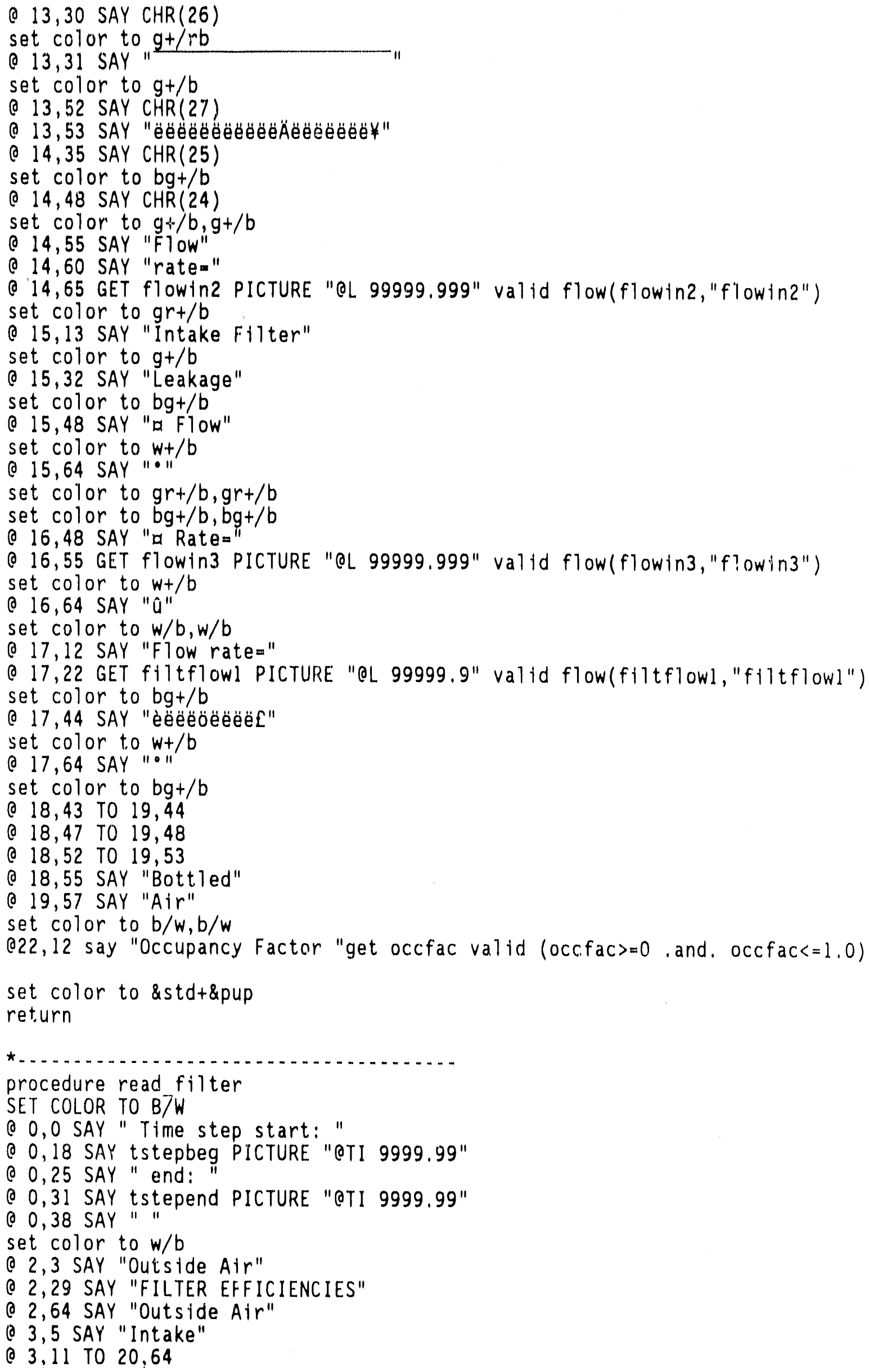




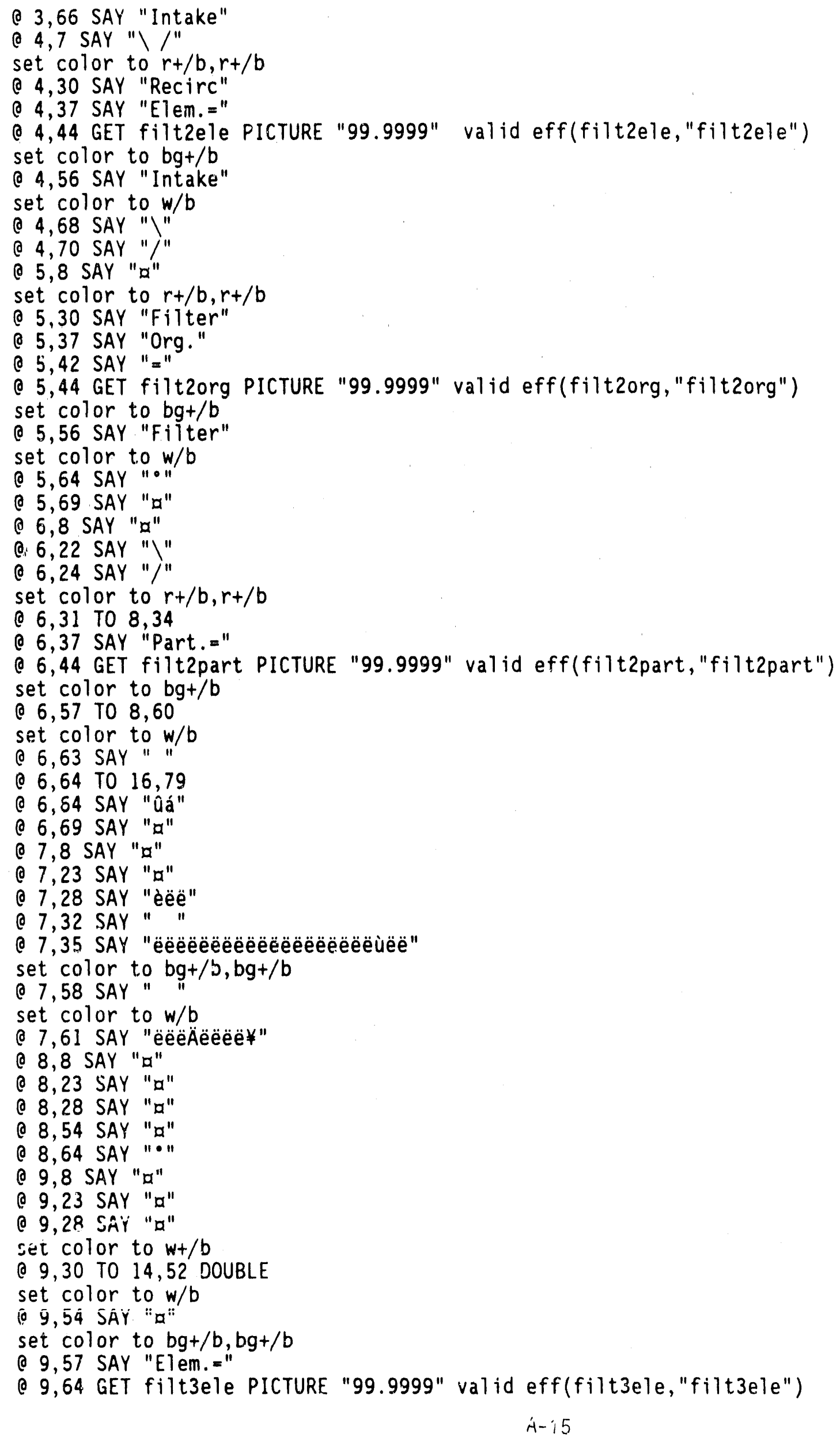




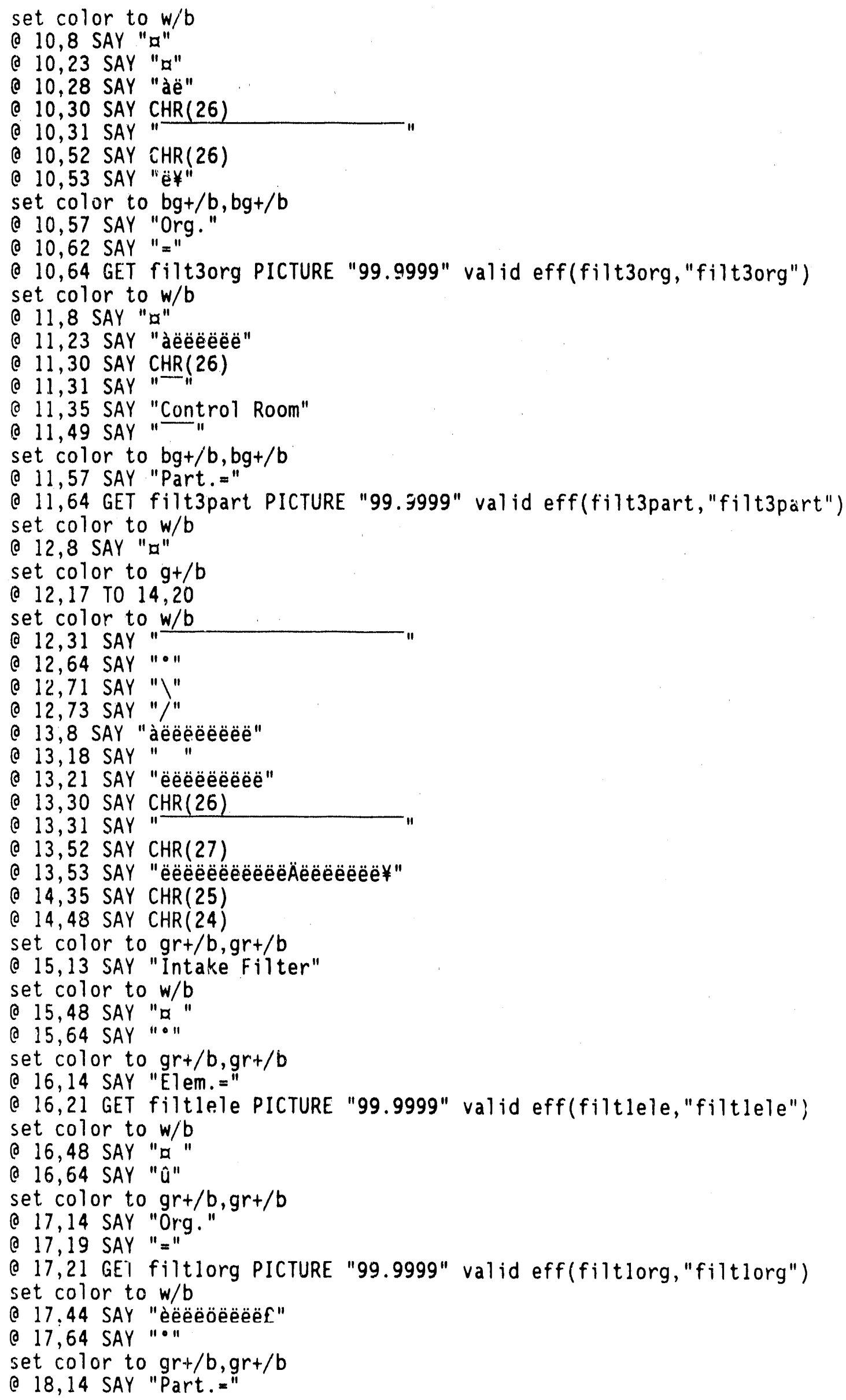


(C) 18,21 GET filtlpart PICTURE "99.9999" valid eff(filtlpart, "filtlpart") set color to $w / b$

(c) 18,43 TO 19,44

(c) 18,47 TO 19,48

c 18,52 TO 19,53

set color to $\mathrm{g}+/ \mathrm{b}, \mathrm{g}+/ \mathrm{b}$

return

procedure set defaults

* carries information for current record forward to next record...

numleft=num fields

append blan $\bar{k}$

do while numleft $>0$

skip -1

fild=field(numleft)

store_prev[numleft] $=\& f l d$

skip

replace \&fld with store prev[numleft]

numleft $=$ numleft -1

enddo

replace tstepbeg with tstepend

return

procedure select_file

* this procedure selects a database file to create or edit

* places file in use in se?ect area 1

set color to \&std

$r w=16$

num=adir ("*. $\left.d b f^{\prime \prime}\right)$

declare dbf file[num]

adir("*.dbf",dbf_file)

asort (dbf file)

old_color $\equiv$ setcolor ()

save screen

declare bar[num+3], sel [num+3]

bar [1] = 'Select a file:'

bar [2] $=1$

bar [3] $=$ ' $\langle$ create $\rangle$

$c n t=0$

$\therefore e][1]=. F$.

sel $[2]=. F$.

if whattodo $={ }^{\prime} C^{\prime}$

sel $[3]=. T$.

else

sel $[3]=. F$.

endif

do while cnt<num

bar $[c n t+4]={ }^{\prime}+d b f$ file $[c n t+1]$

sel $[c n t+4]=. T$.

$c n t=c n t+1$

enddo

set color to \& shadow

if nume 10

$r w=n u i n+6$

end if

04,31 to $r w, 31$ 


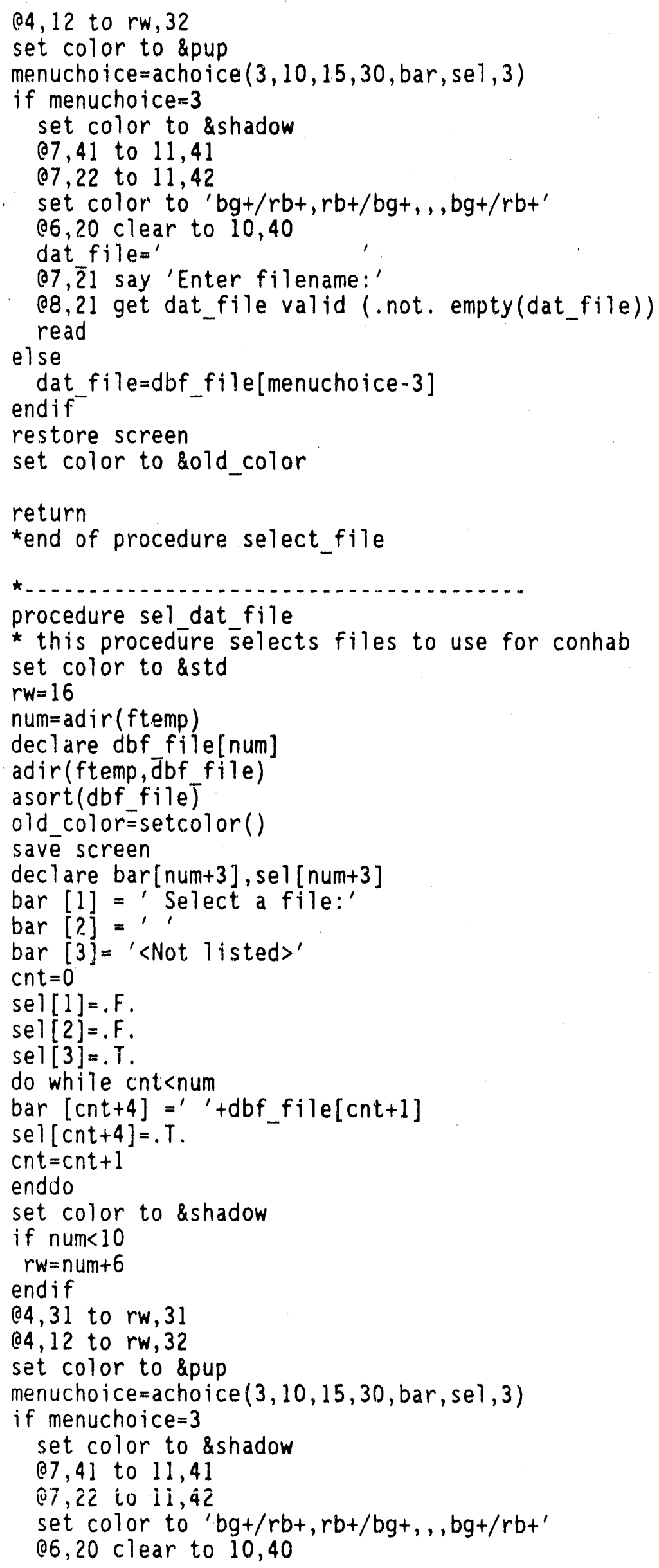




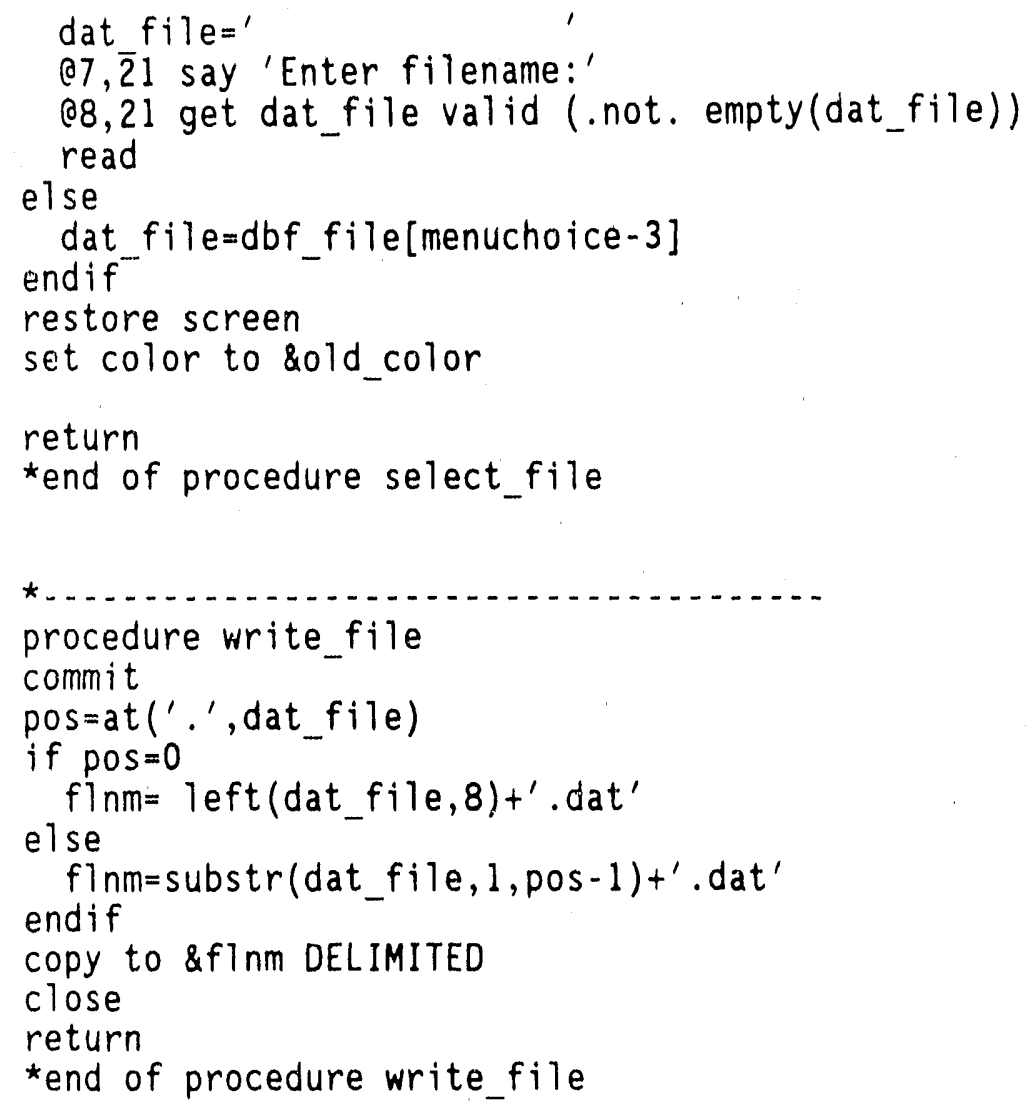




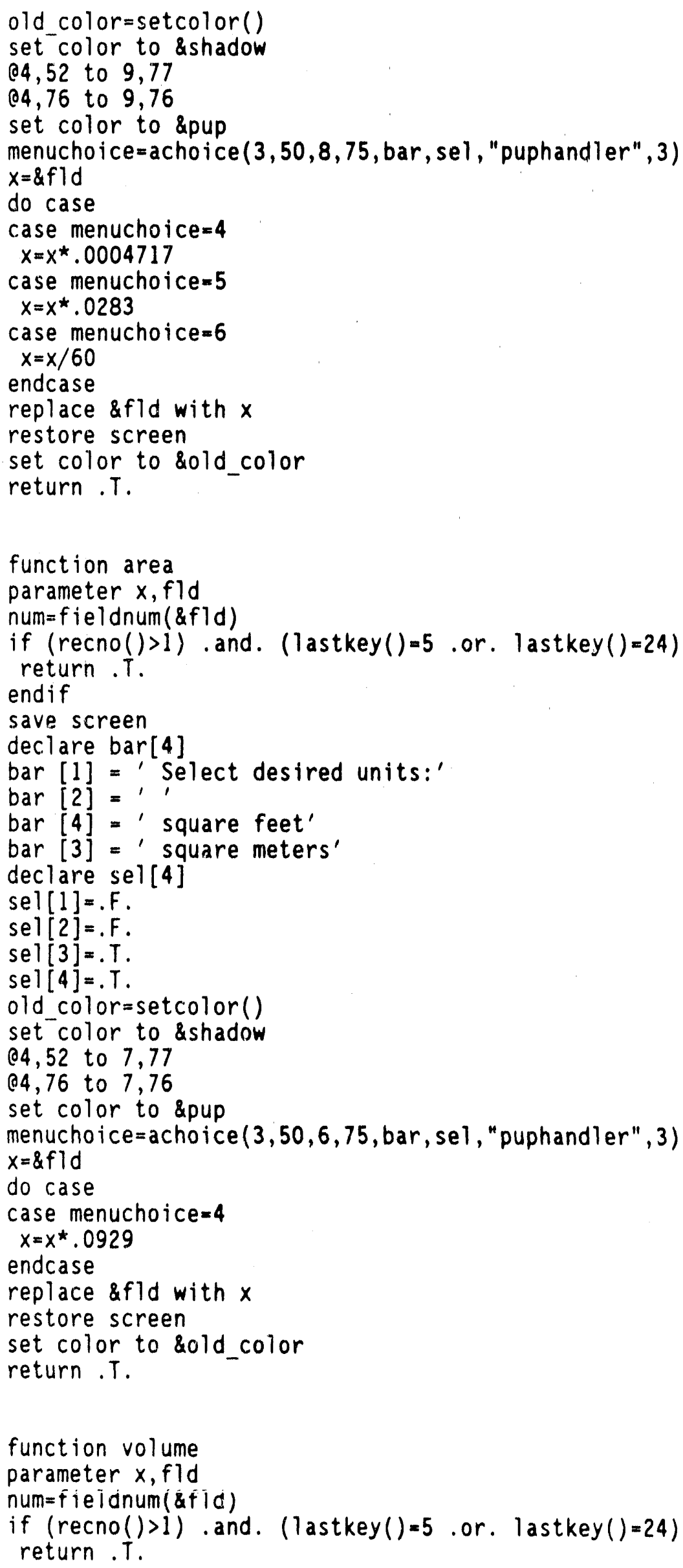


endif

save screen

declare bar [4]

bar [1] = 'Select desired units:'

bar $[2]=11$

bar [4] = 'cubic feet'

bar $[3]=$ ' cubic meters'

declare sel[4]

$\operatorname{sel}[1]=. F$.

$\operatorname{sel}[2]=. F$.

$\operatorname{sel}[3]=. T$.

$\operatorname{sel}[4]=. T$.

old_color $=$ setcolor ()

set $^{-}$color to \&shadow

04,52 to 7,77

04,76 to 7,76

set color to \&pup

menuchoice $=$ achoice $(3,50,6,75$, bar, se 1 , "puphand ler" , 3)

$x=\& f 1 d$

do case

Case menuchoice $=4$

$x=x^{\star} .0283$

endcase

replace \&fld with $x$

restore screen

set color to \&old_color

return.T.

function velo:ity

parameter $x, f i d$

num=fieldnum ( \&fld)

if $($ recno ()$>1)$. and. (1astikey ()$=5$.or. lastkey ()$=24)$

return .T.

endif

save screen

declare bar[6]

bar [1] = 'Select desired units:'

bar [2] $=1$ '

$\operatorname{bar}[4]=1 \mathrm{ft} / \mathrm{min}^{\prime}$

$\operatorname{bar}[5]=\prime \mathrm{ft} / \mathrm{sec}^{\prime}$

bar [6] $='$ miles/hour'

bar [3] = 'meters $/ \mathrm{sec}^{\prime}$

declare sel[6]

$\operatorname{sel}[1]=. F$.

$\operatorname{sel}[2]=. F$.

sel $[3]=. T$.

sel $[4]=. T$.

sel $[5]=. T$.

sel $[6]=. T$.

old_color $=$ setcolor ()

set color to \&shadow

04,52 to 9,77

Q4,76 to 9,76

set color to \&pup

menuchoice $=$ achoice $(3,50,8,75$, bar, se 1 , "puphand ler", 3$)$

$x=\&$ fld

do case

case menuchoice $=\dot{4}$

$x=x^{\star} .00508$

case menuchoice $=5$ 


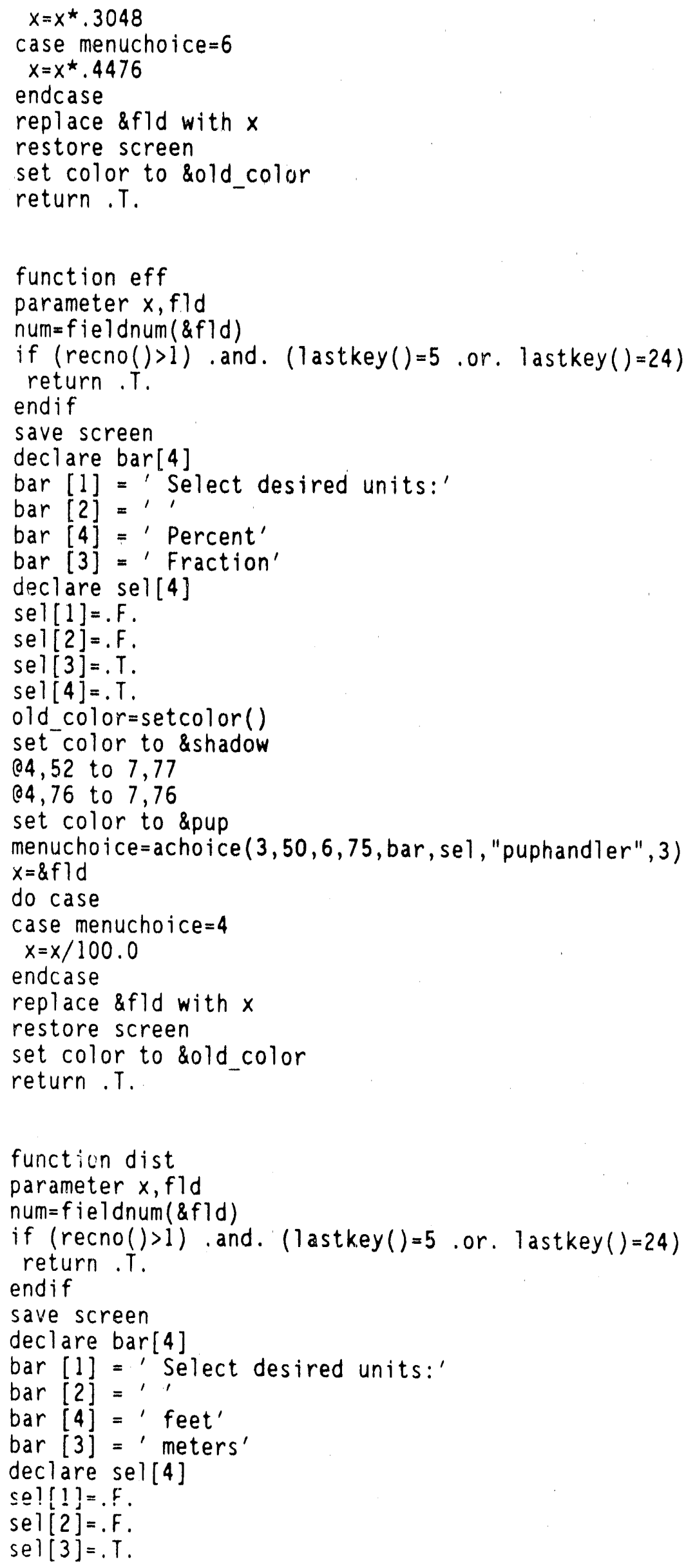




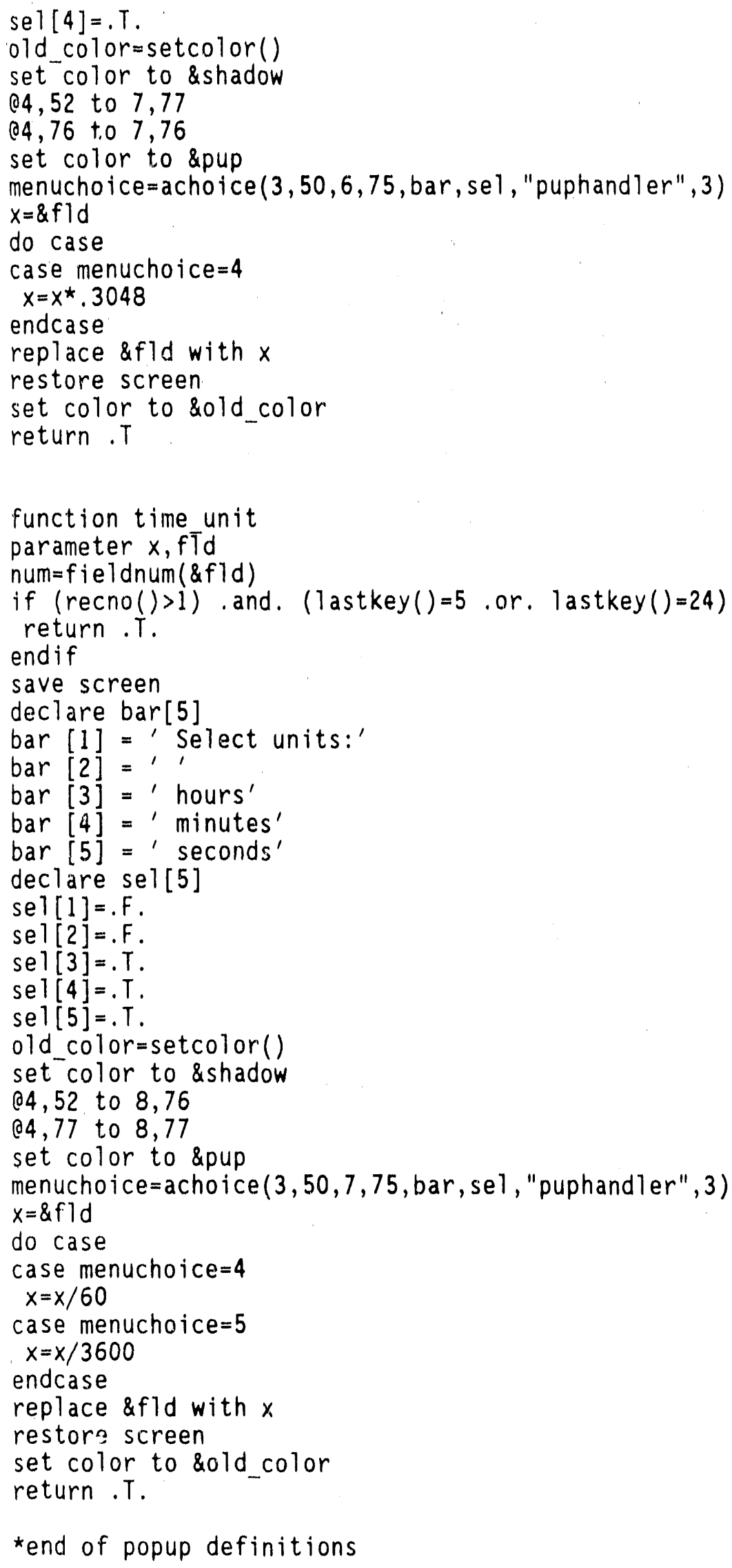

function puphandler 
* handles screen editing for pop up valids and gets

parameters mode, curelem, relpos

if mode $=3$

do case

case lastkey ()$=13$

ret $=1$

case lastkey ()$=27$

ret $=0$

otherwise

ret $=2$

endcase

else

ret $=2$

endif

return ret

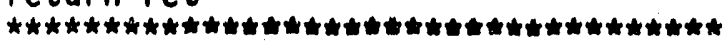


APPENDIX B

CONHAB CODE LISTING 


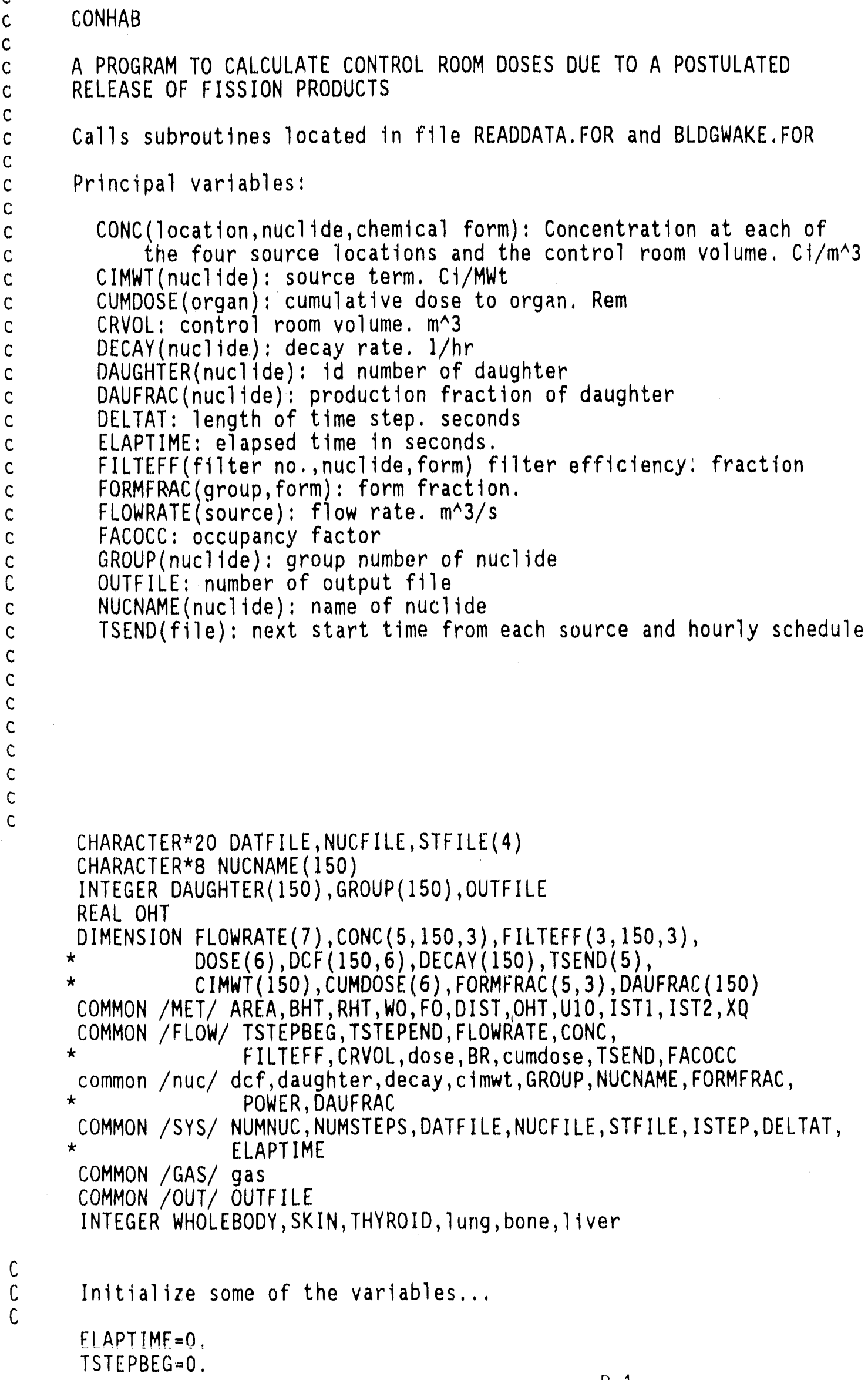




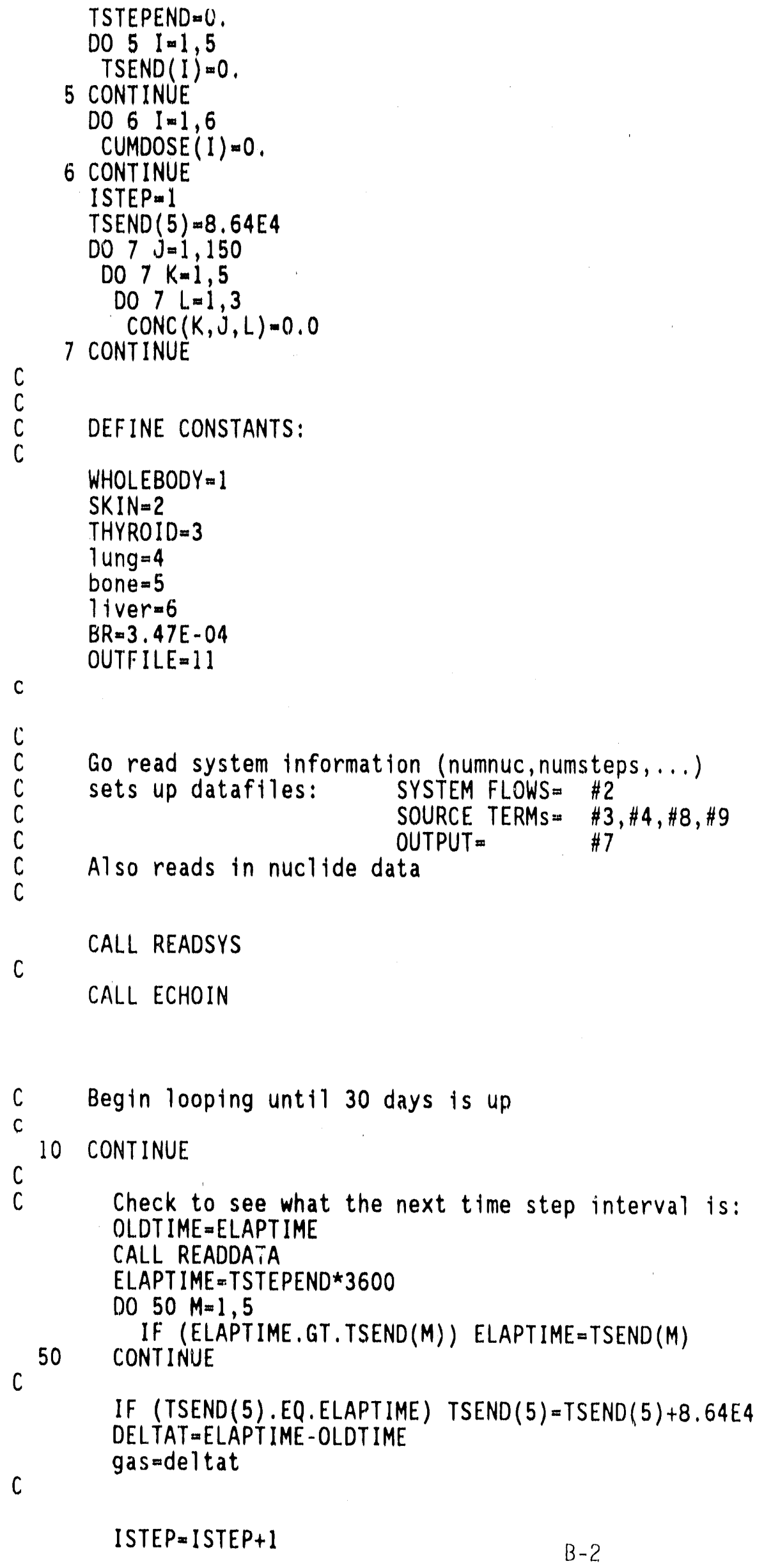

CALL ECHOIN

C Begin looping until 30 days is up

C

10 CONTINUE

c

C Check to see what the next time step interval is:

OLDT IME =ELAPTIME

CALL READDATA

ELAPTIME $=$ TSTEPEND $* 3600$

DO $50 \mathrm{M}=1,5$

50 CONTINUE

If (ELAPTIME,GT.TSEND(M)) ELAPTIME =TSEND(M)

C

IF (TSEND(5) . EQ.ELAPTIME) TSEND(5) $=\operatorname{TSEND}(5)+8.64 E 4$ DELTAT $=E L A P T I M E-O L D T I M E$

C gas $=$ de 1 tat

ISTEP $=$ ISTEP +1 
Begin looping thru all nuclides...

DO 100 NUCLIDE $=1$, NUMNUC

Calculate flows in and out

FLOWOUT =FLOWRATE (1)+FLOWRATE(2) +FLOWRATE(3)+FLOWRATE (4)+ FLOWRATE (6)

Loop over chemtcal forms

$N F=1$

IF (GROUP (NUCLIDE). EQ.1) NF=3

DO $20 \quad I=1, N F$

$a=($ FLOWOUT+FLOWRATE (5)*FILI'TEFF $(1$, NUCLIDE, I ) )/CRVOL

c

If $a=0$, no removal (except decay)

IF $\left((a, N E \cdot 0,0) \cdot\right.$ AND. $\left.\left(A^{*} D E L T A T<80\right)\right)$ THEN

$\operatorname{CONC}(5, N U C L I U E, I)=\operatorname{CONC}(5, N U C L I D E, I) \star E X P\left(-A^{\star} D E L T A T\right)$

$A C T I N=(\operatorname{CONC}(1, N U C L I D E, I) * F L O W R A T E(1)+\operatorname{CONC}(2, N U C L I D E, I) *$ FLOWRATE (2)+CONC (3, NUCLIDE, I ) *FLOWRATE (3)* $(1$ -

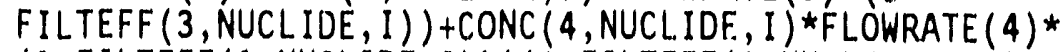
$(1-F I L T E F F(1, N U C L I D E, I)) *(1-F I L T E F F(2, N U C L I D E, I)))$ CONC ( $5, N U C L I D E, I) \star C R V O L)$

$\operatorname{CONC}(5, N U C L I D E, I)=\operatorname{CONC}(5, N U C L I D E, I)+(\operatorname{ACTIN} / a-(A C T I N / a) *$

ENDIF

$\left.\left(\operatorname{EXP}\left(-a^{\star} D E L T A T\right)\right)\right) / C R V O L$

C

$\mathrm{C}$

$\mathrm{C}$

Watch for $\mathrm{NaN}^{\prime} \mathrm{s}$ as conc gets small...

IF (CONC (5, NUCLIDE, I).LT.1.OE-30) THEN $\operatorname{CONC}(5, N U C L I D E, I)=0.0$

ENDIF

C

Calculate doses based on activities...

C

DOSE (WHOLEBODY) $=$ CONC ( 5, NUCL IDE, I $) * D C F$ (NUCLIDE, WHOLE BOCY $) \star D E L T A T /(1173 /(C R V O L \star \star .338))$

DOSE $($ SKIN $)=\operatorname{CONC}(5$, NUCLIDE, I $) * D C F(N U C L I D E$, SKIN $)$ *

DELTAT

DOSE (THYROID) $=\operatorname{CONC}(5$, NUCLIDE , I) $* D C F(N U C L I D E$, THYROID)

${ }^{*} B R * D E L T A T$

C

DOSE (LUNG) $=$ CONC (5, NUCLIDE, I ) *DCF (NUCLIDE, LUNG) *BR*DELTAT

DOSE (BONE) $=\operatorname{CONC}(5, N U C L$ IDE, I $) \star D C F(N U C L$ IDE, BONE) $* B R \star D E L T A T$

DOSE (LIVER) $=\operatorname{CONC}(5, N U C L I D E, I) * D C F(N U C L I D E$, LIVER $) \star B R \star D E L T A T$

C

Sum doses into cumulative dose variables...

DO 15 NORG $=1,6$

15 CONTINUE
20 CONTINUE

100 CONTINUE

C

Go write out time step information to disk and screen... 


\section{CALL STEPOUT}

C

C

IF (ELAPTIME/3600..LT.720.) THEN GOTO 10

ENDIF (-..--End loop over time (post 30 days at this line)

Go writ it summary information to screen...

C

CALL SUMMARY

CLOSE (OUTF ILE)

STOP

END

end of MAIN

SUBROUTINE READSYS

CHARACTER 20 DATFILE, NUCFIL E, STFILE(4), DEVICE

CHARACTER $* 8$ NUCNAME $(150)$

SUBROUTINE TO READ IN SYSTEM DATA

Reads in number of nuclides and time steps, and data file names Also reads in nuclide data

INTEGER DAUAHTER (150), GROUP(150), OUTF ILE DIMENS!ON UCF $(150,6), \operatorname{DECAY}(150), \operatorname{FORMFRAC}(5,3)$, * CIMWT(150), DAUFRAC(150)

COMMON /SYS/ NUMNUC, NUMSTEPS, DATFILE, NUCFILE, STF ILE, ISTEP, DELTAT, * ELAPTIME

common /nuc/ dcf, daughter, decay, cimwt, GROUP, NUCNAME, FORMFRAC,

*

C

COMMON /OUT/ OUTFILE

WRITE $\left(6,{ }^{*}\right)$ 'CHOOSE AN OUTPUT DEVICE:'

$\operatorname{WRITE}(6, *)$

WRITE $(6, *)$ 'LPTI $\quad->$ Output to printer'

WRITE $(6, *)$ 'CON $\quad->$ Oistput to screen'

WRITE $(6, *)$ 'filename $\rightarrow>$ Outpui to file'

WRITE $(6, \div)$

WRITE $(6, *)$ 'Output device:

$\operatorname{READ}\left(5,{ }^{\prime}(1 \mathrm{~A} 20)^{\prime}\right)$ DEVICE

OPEN (OUTF ILE, FILE=DEVICE)

OPEN $\left(2\right.$, FILE $=$ 'CRHSYS. DAT ${ }^{\prime}$, STATUS $={ }^{\prime} O L D^{\prime}$, ACCESS $={ }^{\prime}$ SEGUENT IAL', 


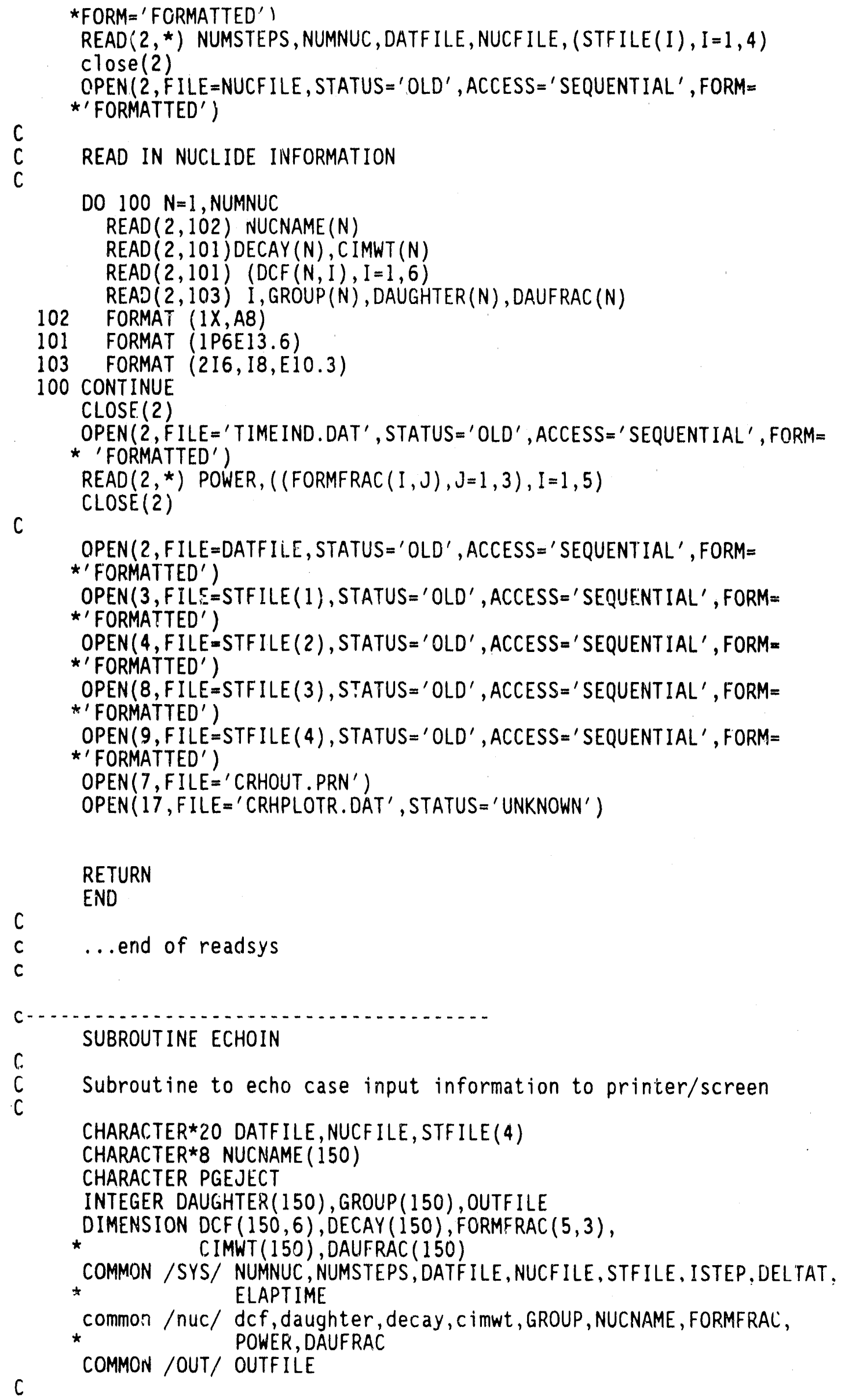




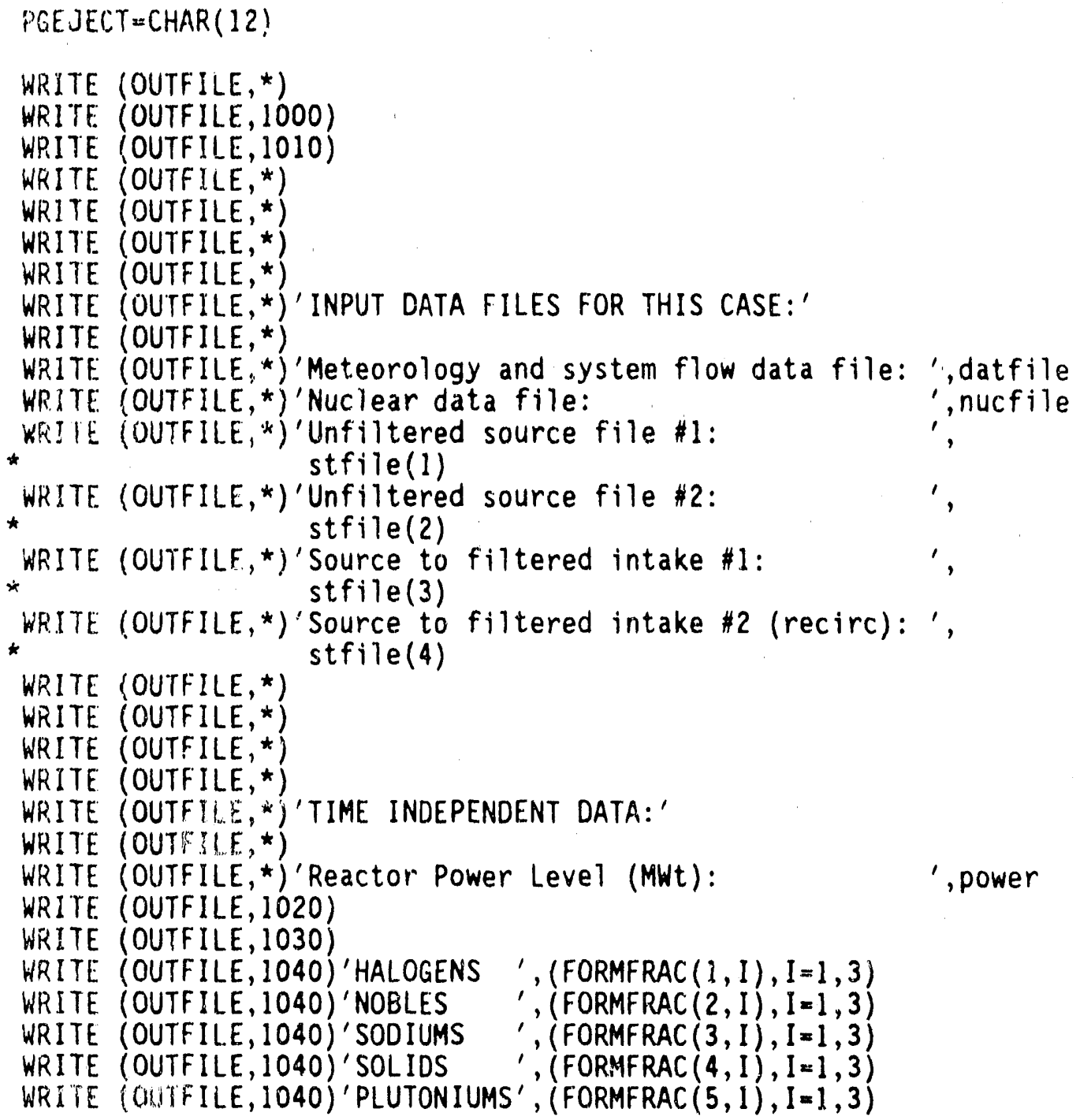




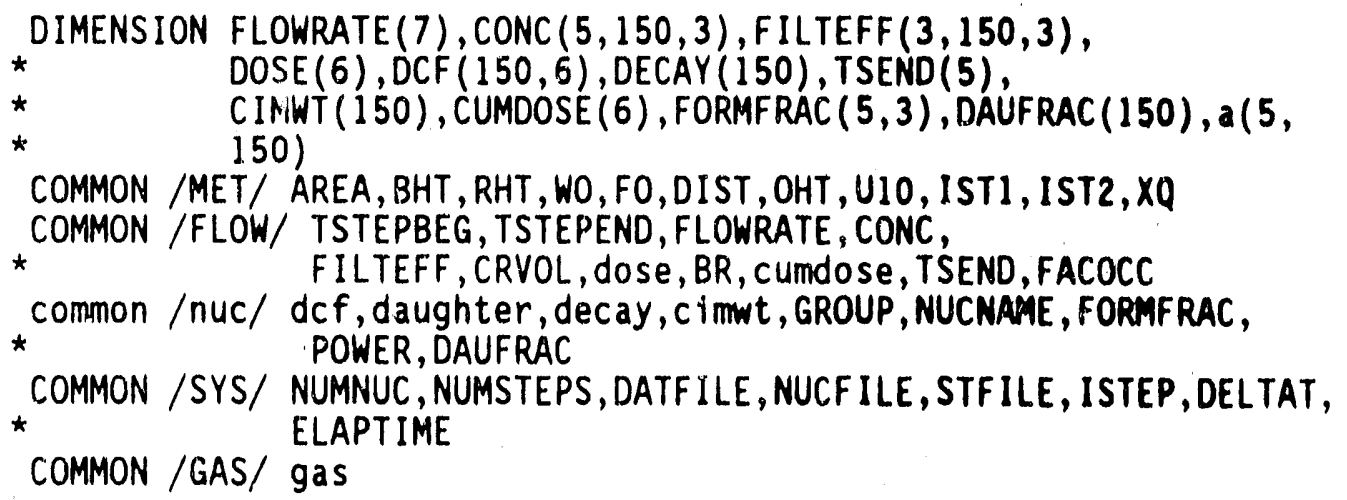

$\mathrm{C}$

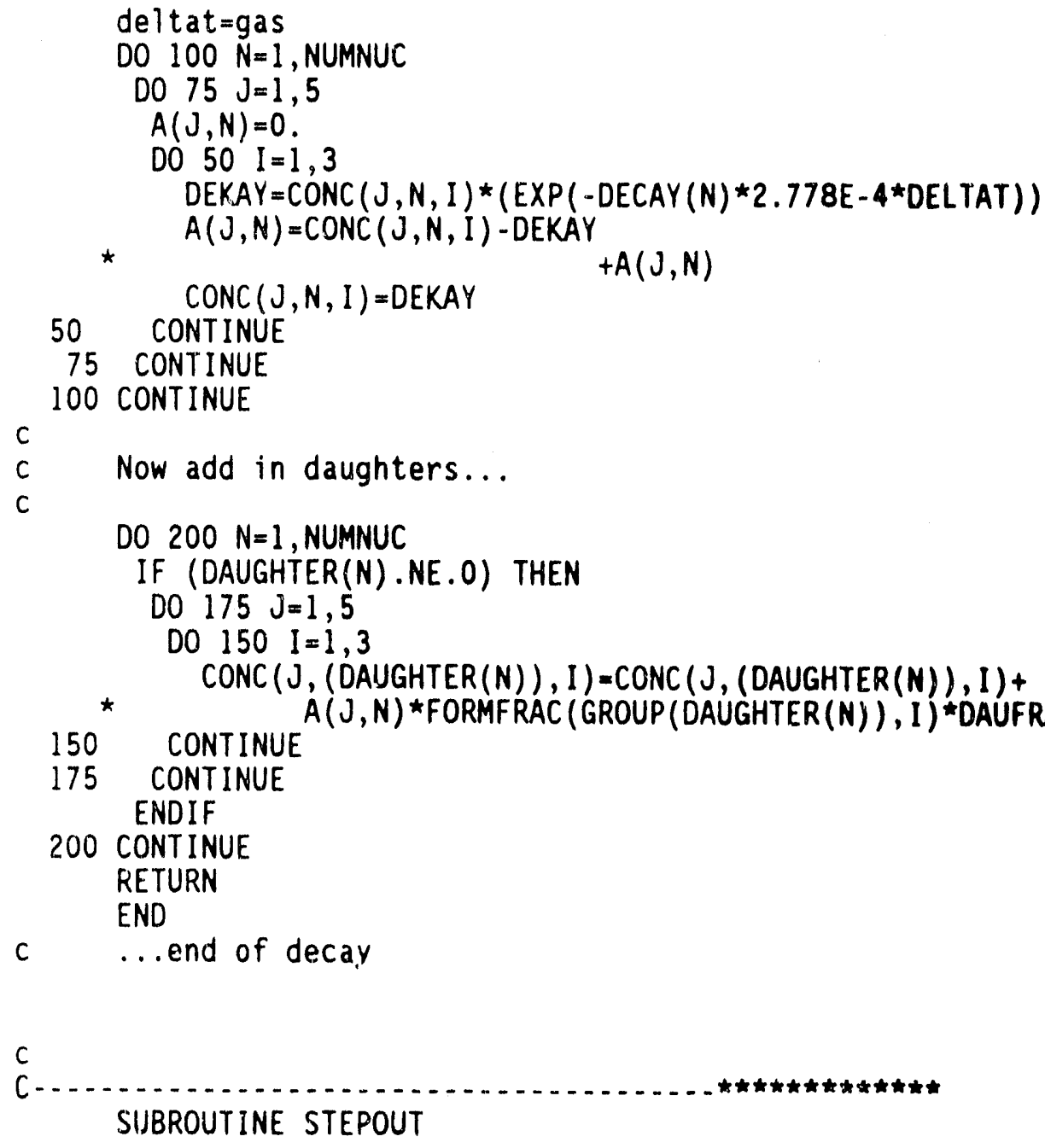




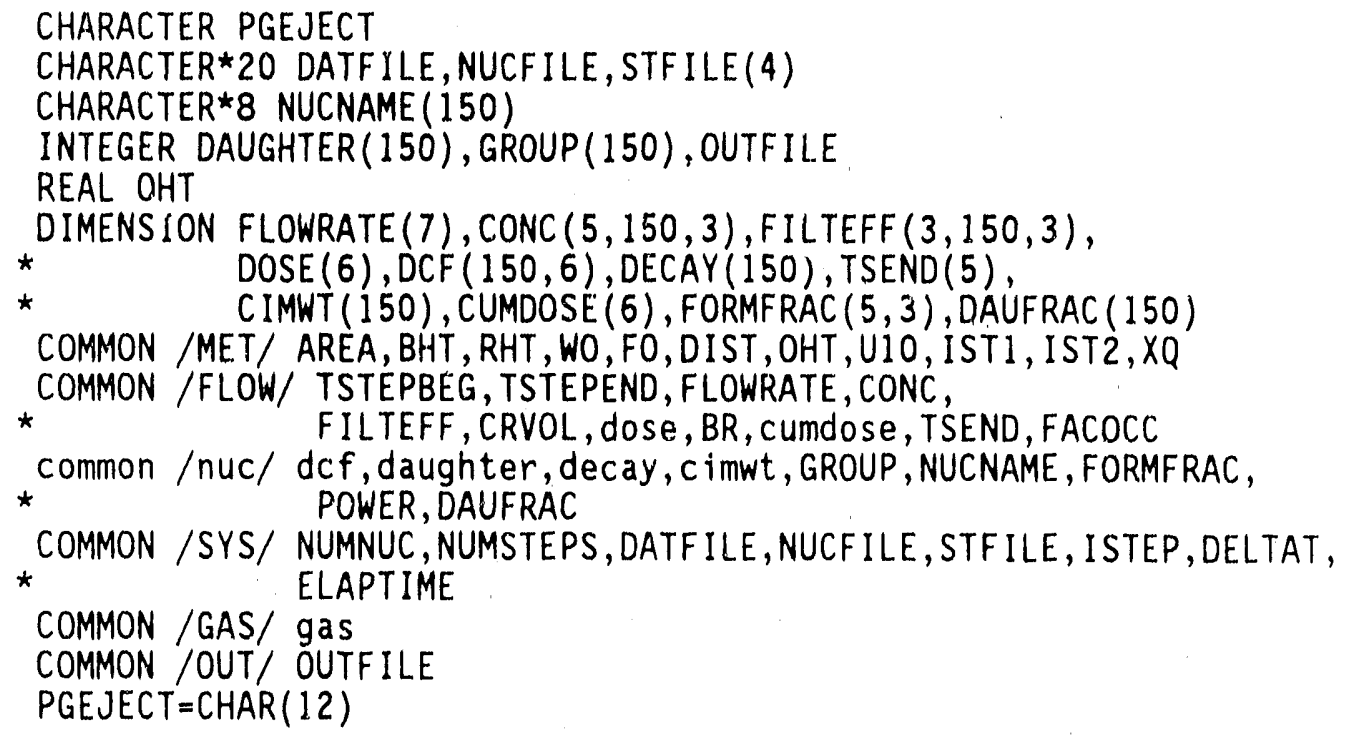



WRITE (OUTFILE, $\left.{ }^{\star}\right)^{\prime C}$ Control room volume $\left(m^{\wedge} 3\right)$ :
crvol

WRITE (OUTFILE, *)

WRITE (OUTFILE, *)

WRITE (OUTFILE, 1000)' CUMULATIVE DOSE'

WRITE (OUTFI'E, 1005)

WRITE (OUTFILE, 1010)

WRITE (OUTFILE, *)

WRITE (OUTFILE, 1045) ELAPTIME/3600, , (CUMDOSE(I), I=1,6)

WRITE $(17,1050)$ ELAPTIME/3600., (CUMDOSE $(I), I=1,6)$

1000 FORMAT $(32 X, A 15)$

1005 FORMAT (IX,'END TIME', 1X,' WH BODY ', 1X,' SKIN ', IX,

* 'THYROID ', IX,

* ' LUNG ', $1 X$, ' BONE ', $1 X$, ' LIVER ')

1010 FORMAT ( $1 X, '$ HOURS ',6(' REM '))

1020 FORMAT (IX,A42,3(F6.4,5X))

1045 FORMAT (1X,1PE9.3,6(1X,1PE9.3))

1050 FORMAT (7(1X,OPF16.8))

RETURN

END

C

c

c

$\mathrm{c}$

end of stepout

SUBROUTINE SUMMARY

CHARACTER 20 DATFILE, NUCFILE, STFILE(4)

CHARACTER 88 NUCNAME $(150)$

INTEGER DAUGHTER(150), GROUP(150), NUMSTEPS, OUTFILE

REAL OHT

DIMENSION FLOWRATE $(7), \operatorname{CONC}(5,150,3), \operatorname{FILTEFF}(3,150,3)$,

* $\operatorname{DOSE}(6), \operatorname{DCF}(150,6), \operatorname{DECAY}(150), \operatorname{TSEND}(5)$,

* CIMWT(150), CUMDOSE (6), FORMFRAC (5, 3), DAUFRAC (150)

COMMON /MET/ AREA, BHT, RHT, WO, FO, DIST, OHT, U1O, IST1, IST2, XQ

COMMON /FLOW/ TSTEPBEG, TSTEPEND, FLOWRATE, CONC,

* FILTEFF, CRVOL, dose, BR, cumdose, TSEND, FACOCC

common /nuc/ dcf, daughter, decay, cimwt, GROUP, NUCNAME, FORMFRAC,

* POWER,DAUFRAC

COMMON /SYS/ NUMNUC, NUMSTEPS, DATFILE, NUCFILE, STFILE, ISTEP, DELTAT,

* ELAPTIME

COMMON/GAS/ gaS

COMMON /OUT/ OUTFILE

ITEMP $=$ OUTF ILE

C WRITE SUMMARY TO OUTPUT DEVICE AND TO SCREEN

DO $10 \quad I=1,2$

WRITE (OUTFILE, *)

WRITE (OUTFILE, *)

WRITE (OUTFILE, *)

WRITE (OUTFILE, *)

WRITE (OUTFILE, *) 'WHOLE BODY

WRITE (OUTFILE, ${ }^{\star}$ ) 'SKIN DOSE

WRITE (OUTFILE, *) THYROID DOSE: ',CUMDOSE (3)

WRITE (OUTFILE, ${ }^{\star}$ ) 'LUNG DOSE: ',CUMDOSE (4)

WRITE (OUTFILE, *) 'BONE OOSE: 'CUUMUÚSE (5)

WRITE (OUTFILE, *) 'LIVER DOSE: ', CUMDOSE $(\varepsilon)$

WRITE (OUTFILE, *) 


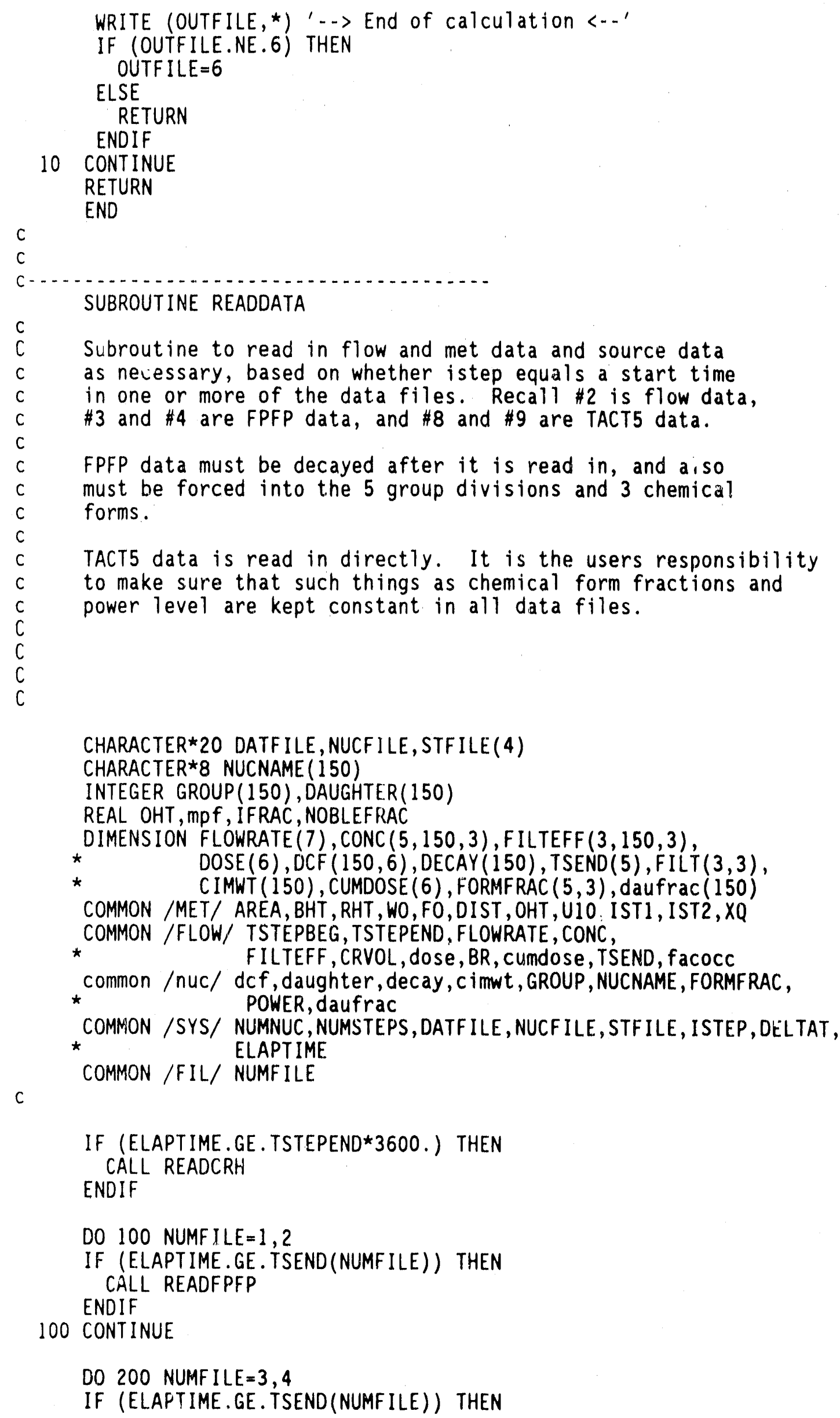

DO 100 NUMF ILE $=1,2$

IF (ELAPTIME.GE.TSEND(NUMFILE)) THEN CALL READFPFP

100 CONTINUE

DO 200 NUMF ILE $=3,4$

IF (ELAPTIME.GE.TSEND(NUMFILE)) THEN 
CALL READTACT

ENDIF

200 CONTINUE

RETURN

END

\author{
SUBROUTINE READCRH
}

C

\title{
CHARACTER 20 DATFILE, NUCF ILE, STFILE(4)
}

CHARACTER $\star 8$ NUCNAME $(150)$

INTEGER GROUP(150), DAUGHTER(150)

REAL OHT, MP F, IFRAC, NOBLEFRAC

DIMENSION FLOWRATE $(7), \operatorname{CONC}(5,150,3), \operatorname{FILTEFF}(3,150,3)$,

* $\quad \operatorname{DOSE}(6), \operatorname{DCF}(150,6), \operatorname{DECAY}(150), \operatorname{TSEND}(5), \operatorname{FilT}(3,3)$,

* CIMWT(150), CUMDOSE $(6)$, FORMFRAC $(5,3)$, daufrac $(150)$

COMMON /MET/ AREA, BHT, RHT, WO, FO, DIST, OHT, UIO, IST1, IST2, XQ

COMMON /FLOW/ TSTEPBEG, TSTEPEND, FLOWRATE, CONC,

* FILTEFF, CRVOL, dose, BR, cumdose, TSEND, facocc

common /nuc/ dcf, daughter, decay, cimwt, GROUP, NUCNAME, FORMFRAC,

* POWER, daufrac

COMMON /SYS/ NUMNUC, NUMSTEPS, DATF ILE, NUCFILE, STFILE, ISTEP, DELTAT,

* ELAPTIME

COMMON /GAS/ gas

C

TSTEP is in hours, istep is in seconds...

C

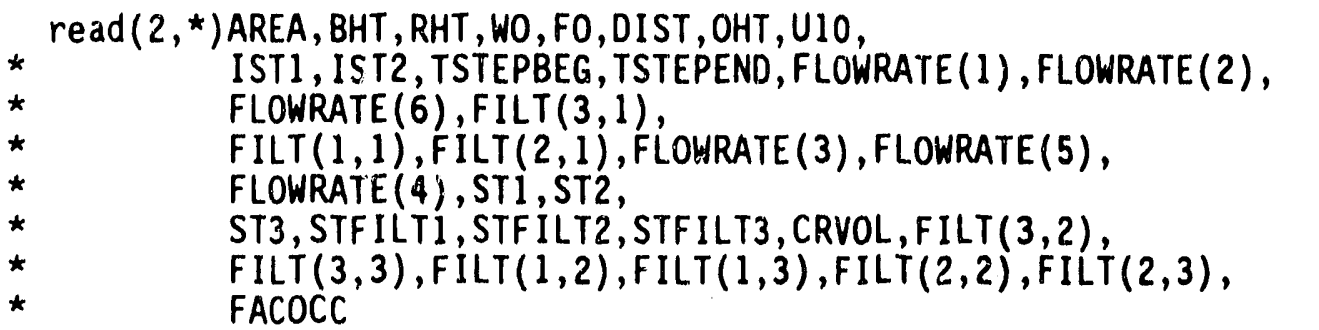

C

Now need to set up the array filteff() for each nuclide... halogens (form) $=$ filt (form) nobles ()$=0$.

$\mathrm{Na}$, solids, $\mathrm{Pu}($ form) $=$ filt (particulate)

DO $10 \mathrm{~N}=1$, NUMNUC

IF (GROUP(N).EQ, 1) THEN 


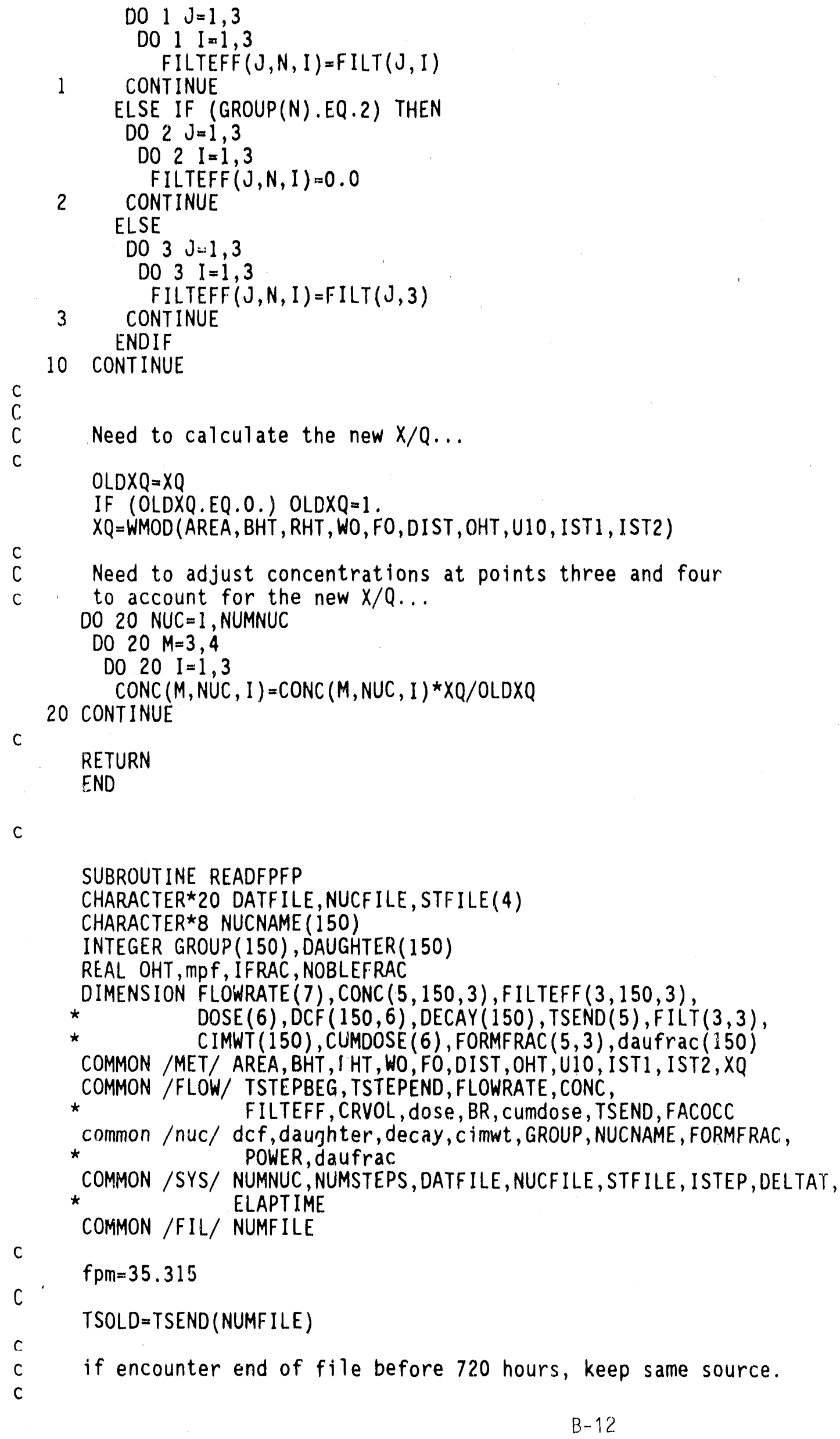


TSEND (NUMFILE) $=$ TSEND (NUMFILE) ${ }^{\star} 60$.

C Now convert these core fractions $/ \mathrm{ft}^{\wedge} 3$ to $\mathrm{ct} / \mathrm{m}^{\wedge} 3$ for each c nuclide based on group number

DO 100 NUC $=1$, NUMNUC

IF (GROUP(NUC). EQ.1) $F R A C=I F R A C$

IF (GROUP(NUC).EQ.2) $F R A C=N O B L E F R A C$

IF (GROUP(NUC).EQ.3) $F R A C=P A R T F R A C$

IF (GROUP(NUC). EQ.4) FRAC=PARTFRAC

IF (GROUP (NUC). EQ.5) FRAC $=$ PARTFRAC

DO $50 \quad I=1,3$

IF ((GROUP(NUC).EQ.1).AND. (I.EQ.3)) FRAC =PARTFRAC

$C I=P O W E R * C I M W T(N U C) * F O R M F R A C(G R O U P(N U C), I) \star F R A C \star f p m$

Now decay since time zero because FPFP doesn't...

(if decay*tsold is greater than 30, don't decay so as to avoid NAN's. Decay will be well below anything significant)

IF (DECAY (NUC)*TSOLD/3600.LT.30) THEN

CONC (NUMFILE, NUC, I) $=C I^{*}(\operatorname{EXP}(-\operatorname{DECAY}(N U C) *(T S O L D) / 3600)$.

ENDIF

100 CONTINUE

RETURN

$1 C 30$ TSEND(NUMFILE) $=2.6 E 6$

RETURN

END

C

c Read in TACT5 data as necessary...

SUBROUTINE READTACT

CHARACTER 20 DATFILE, NUCFILE, STFILE(4)

CHARACTER $\star 8$ NUCNAME (150), NAME

INTEGER GROUP(150), DAUGHTER(150)

REAL OHT, mp $f$, IFRAC, NOBLEFRAC

DIMENSION FLOWRATE $(7), \operatorname{CONC}(5,150,3), \operatorname{FILTEFF}(3,150,3)$,

* $\operatorname{DOSE}(6), \operatorname{DCF}(150,6), \operatorname{DECAY}(150), \operatorname{TSEND}(5), \operatorname{FILT}(3,3)$,

* CIMWT(150), CUMDOSE (6), FORMFRAC $(5,3)$, daufrac (150)

COMMON /MET/ AREA, BHT, RHT, WO, FO, DIST, OHT, U10, IST1, IST2, XQ

COMMON /FLOW/ TSTEPBEG, TSTEPEND, FLOWRATE, CONC,

* FILTEFF, CRVOL, dose, BR, cumdose, TSEND, FACOCC

common / nuc/ dcf, daughter, decay, cimwt, GROUP, NUCNAME, FORMFR A. ,

* POWER, daufrac

COMMON /SYS/ NUMNUC, NUMSTEPS, DATFILE, NUCFILE, STFILE, ISTEP, DELTAT,

* ELAPTIME

C

COMMON /FIL/ NUMFILE

Need to convert curies released to a concentration...

WRITE $\left(6,{ }^{*}\right)$

WRITE $(6, *)$ 'NUCLIDE $'$, 'CONCENTRATION AT INTTAKE'

DO 300 NUC $=1$, NUMNUC 


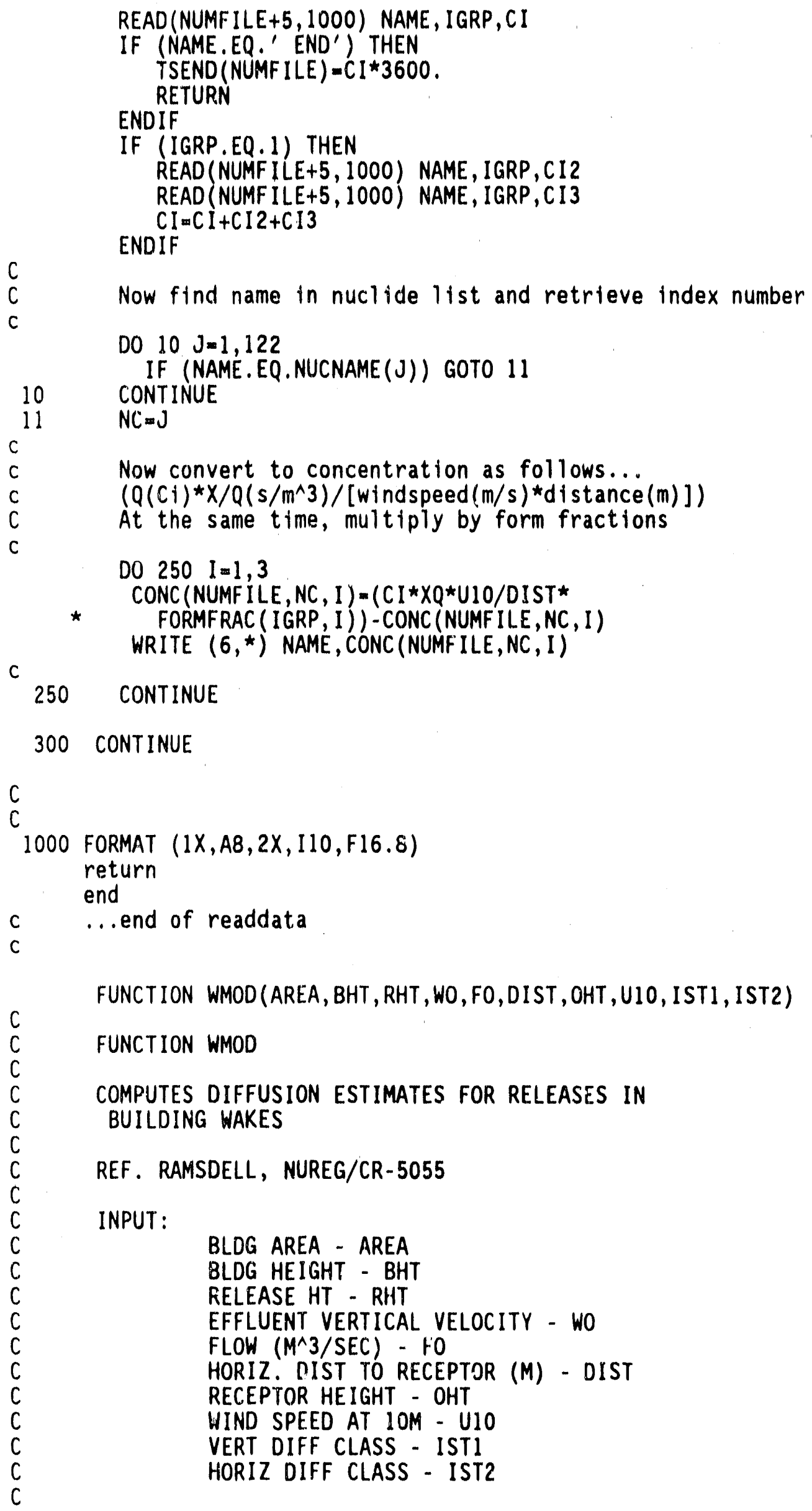


C OUTPUT:

c WMOD $-X / Q$ IN $S / M^{\wedge} 3$

C

$P I=3.1415927$

$\mathrm{CO}=150$

$C X=-1.2$

$C U \approx 0.68$

$C A=C X$

C

CALL SSIGMA (DIST, IST1, IST2, SIGMAZ, SIGMAY)

$P L U M E D=P I * S I G M A Y * S I G M A Z * U 10$

C COMPUTE LIMITING DISTANCE FOR WAKE ENHANCEMENT TO DIFF RATE

$C L=S Q R T$ (AREA)

$X S=D I S T+A B S(R H T-O H T)$

$X S L=A M I N I(X S, 20.0 * C L)$

$B M O D=C O * U 10 * \star C U * S Q R T(F L O A T(I S T 1)){ }^{*} A R E A{ }^{\star \star} C A \star X S L{ }^{* \star} C X$

$W X O q=1.0 /(F O+P L U M E D+1.0 / B M O D)$

IF (WO .GT. O. AND. RHT .GE, BHT) THEN

C SPLIT H MODEL

CALL PROFII.E(U10, ISTI, RHT, RHU)

PLUMED $\approx P$ I*SIGMAY*SIGMAZ*RHU

$\operatorname{VEXP}=\operatorname{EXP}(-0.5 *(R H T / S I G M A Z) \star \star 2)$

EMOD $=V E X P / P L U M E D$

WR $=$ WO $/$ RHU

IF (WR . GT, 1.0) THEN

C COMPUTE FRACTION OF TIME PLUME IS IN WAKE

IF (WR .LE. 1.5) THEN

$W F=2.58-1.58 * W R$

ELSE IF (WR .LT. 5.0) THEN

ELSE

$W F=0.3-0.06 * W R$

$W F=0.0$

ENDIF

$W M O D=(1.0-W F) * E M O D+W F * W X O Q$

ELSE

C PLUME IS IN WAKE ALL OF THE TIME

$W M O D=W X O Q$

ENDIF

ELSE

C PLUME IS ENTRAINED IN WAKE

$W M O D=W X O Q$

ENDIF

C

WRITE $(6, *)$ 'WMOD: ',WMOD

RETURN

END

C

SUBROUTINE SSIGMA(X, STABZ, STABY, SIGMAZ, SIGMAY)

C

$\operatorname{REAL} \operatorname{AY}(7), \operatorname{AZ}(7,3), \operatorname{BZ}(7,3), C Z(7,3)$

INTEGER STADZ, STADY

DATA AY/ $0.3658, .2751, .2089, .1471, .1046, .0722, .0481 /$ 


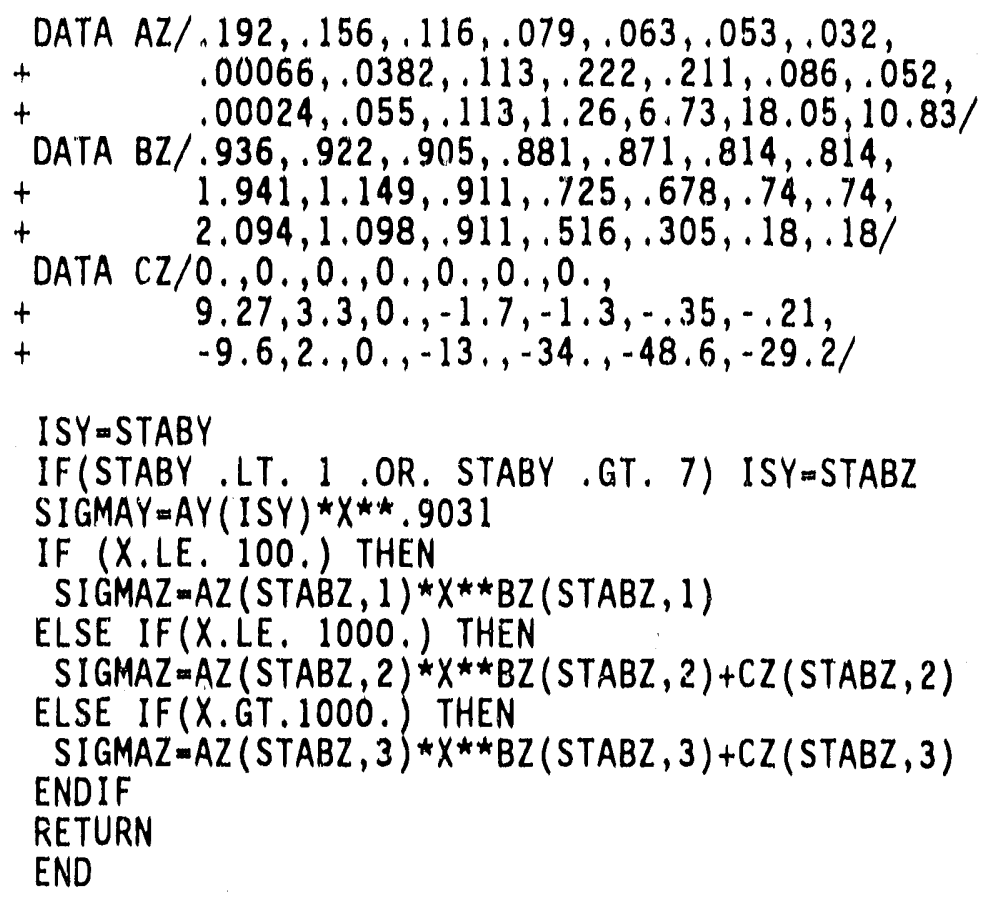

C

SUBROUTINE PROFILE(SPD, IST, SHGHT, RSPD)

DIMENSION MOL.(7)

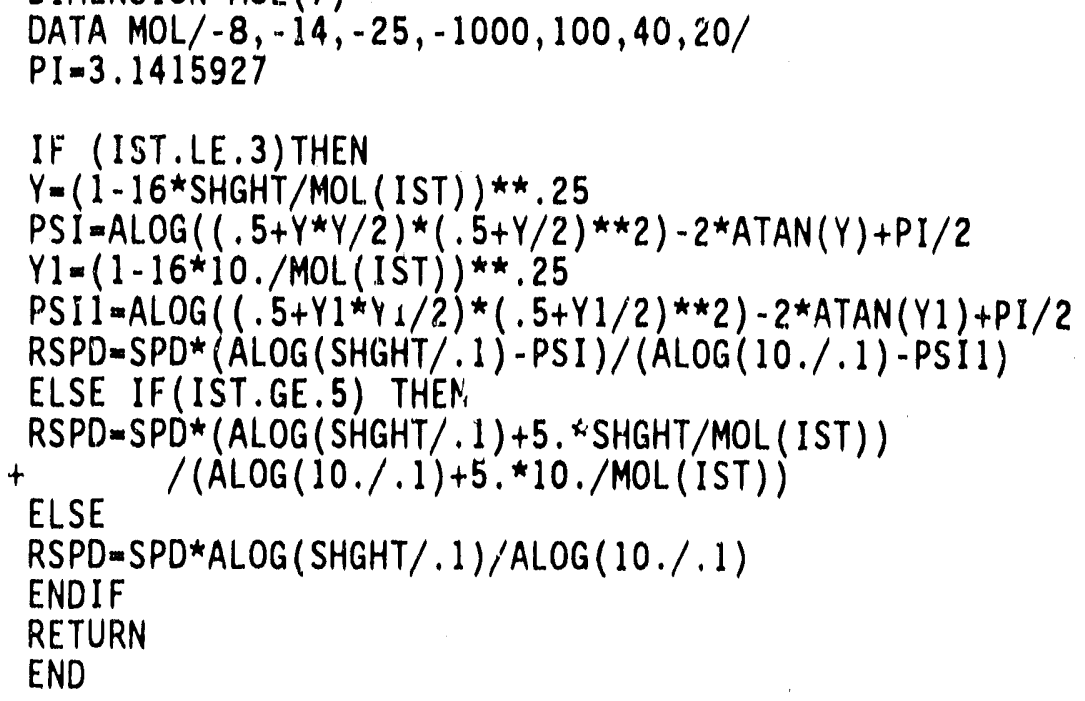


APPENDIX C

CHEM CODE LISTING

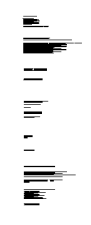




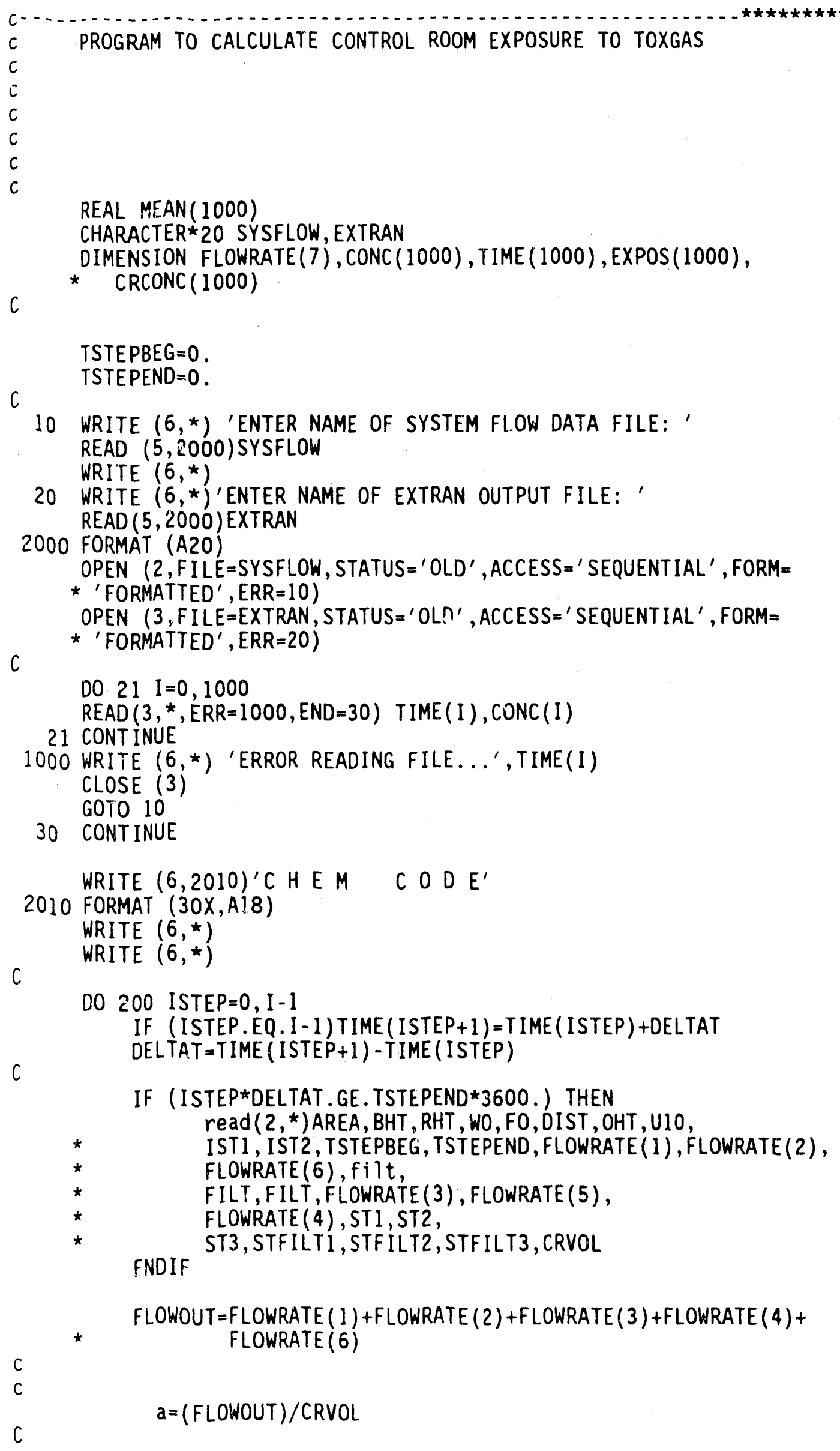


C

If $a=0$, no removal (except decay)

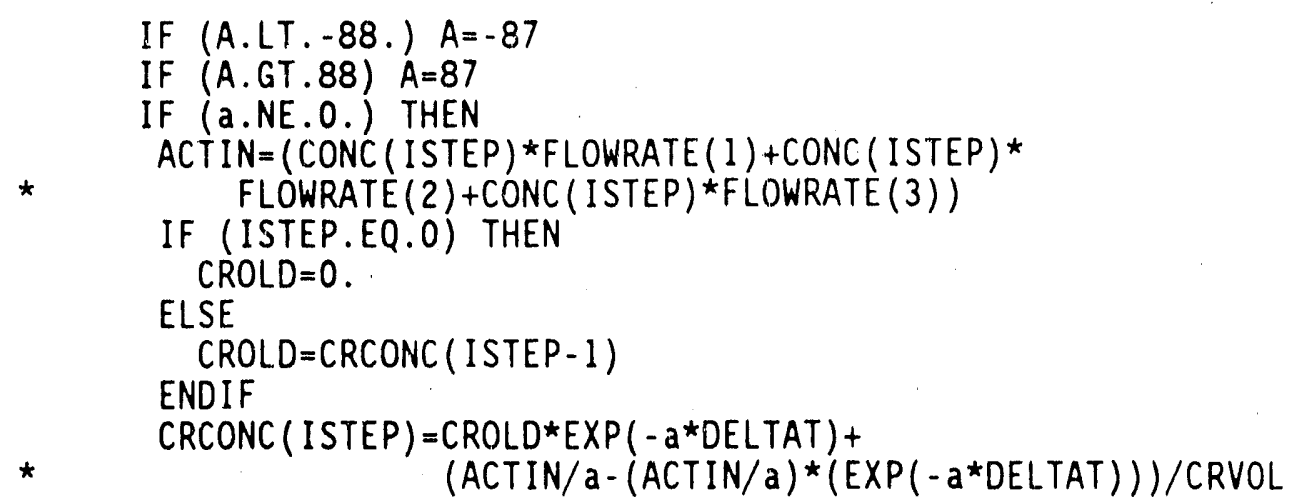

ENDIF

C Calculate EXPOSURE AND MEAN...

IF (ISTEP.EQ.0) EXPOS (ISTEP) $=$ CRCONC (ISTEP) $* D E L T A T$

* IF (ISTEP.GT.0) EXPOS (ISTEP) $=\operatorname{EXPOS(ISTEP-1)+CRCONC~(ISTEP)*~}$

$\operatorname{MEAN}($ ISTEP $)=\operatorname{EXPOS}($ ISTEP $) /(($ ISTEP +1$) \star D E L T A T)$

C

200 CONTINUE

C Go write out summary information to screen...

C

$\operatorname{OPEN}\left(7, \mathrm{FILE}={ }^{\prime}\right.$ CRHPLOTC. DAT' $)$

WRITE $(6,3010)$ 'TIME', 'CONCENTRATION', 'EXPOSURE' , 'MEAN CONC'

WRITE $(6,3020)^{\prime} \mathrm{min}^{\prime},{ }^{\prime} \mathrm{g} / \mathrm{m}^{\wedge} 3^{\prime},{ }^{\prime} \mathrm{g} \mathrm{s}^{\mathrm{s}} / \mathrm{m}^{\wedge} 3^{\prime},{ }^{\prime} \mathrm{g} / \mathrm{m}^{\wedge} 3^{\prime}$

DO 300 ISTEP $=0$, I -1

WRITE $\left(6,{ }^{\star}\right)$ TIME (ISTEP), CRCONC (ISTEP), EXPOS (ISTEP), MEAN (ISTEP)

300 CONTINUE

WRITE $(7,3000)$ TIME (ISTEP), CRCONC (ISTEP), EXPOS(ISTEP), MEAN(ISTEP)

3000 FORMAT (1X,4 (OPF 16.8))

3010 FORMAT (8X, A4,9X,A13,5X,A8,9X,A9)

3020 FORMAT $(8 X, A 3,14 X, A 5,10 X, A 7,10 X, A 5)$

STOP

END 
APPENDIX D

CRHPLOTR CODE LISTING

$\overline{\underline{\underline{\underline{E}}}}$ 
* PROGRAM CRHPLOTR.PRG

* A PlOtTING PROGRAM FOR OUtPUt FROM CONHAB.

$x$

* REQUiRES SOME FORM Gi GRAPHICS ADAPTER

$\star$

* UTILIZES FLIPPER GRAPHICS ROUTINES

clear

prt $={ }^{\prime} N^{\prime}$

05,1 say 'Send graph to printer?' get prt

read

clear

if prts'Yy'

01, l say 'Highlight your printer and hit return...'

declare prnt [75]

afil1 (prnt," ")

for $i=1$ to 75

prnt $[i]=p r t \_l o a d\left(i,{ }^{\prime} p r x . t b l^{\prime}\right)$

next $i$

prtr $=$ achoice $(3,30,20,50$, prnt $)$

clear

endif

FLIP_INIT(6000)

clear

$\operatorname{md} 130={ }^{\prime} N^{\prime}$

C7,1 say 'Do you have an IBM PS-2 Model $30(Y / N)$ ?' get mdl30 read

if $\mathrm{md} 130 \mathrm{~s}^{\prime} \mathrm{Yy}^{\prime}$

set_disply(3)

graphnode (9)

endif

*

min_fh=font_open ("rmn8_17.0")

$\max f h=$ FONT OPEN ("RMN8-21.e")

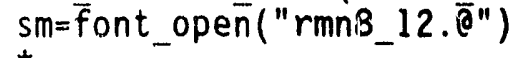

*

INITDATA (4)

SET TYPE $(1,2)$

set_type $(2,2)$

set type $(3,2)$

*set_type $(4,2)$

* set_type $(5,2)$

USE CRHOUT.DBF

ZAP

APPEND FROM CRHPLOTR.DAT DELI WITH BLANK

GO TOP

$W=0$

$T=0$

$T M=0$

DO WHILE .NOT. EOF()

if $(w b<>0)$. and. $(s k<>0)$. and. $($ in $<>0)$

SIORE DATA (X, WB, SK, TH)

end if

SKIP 


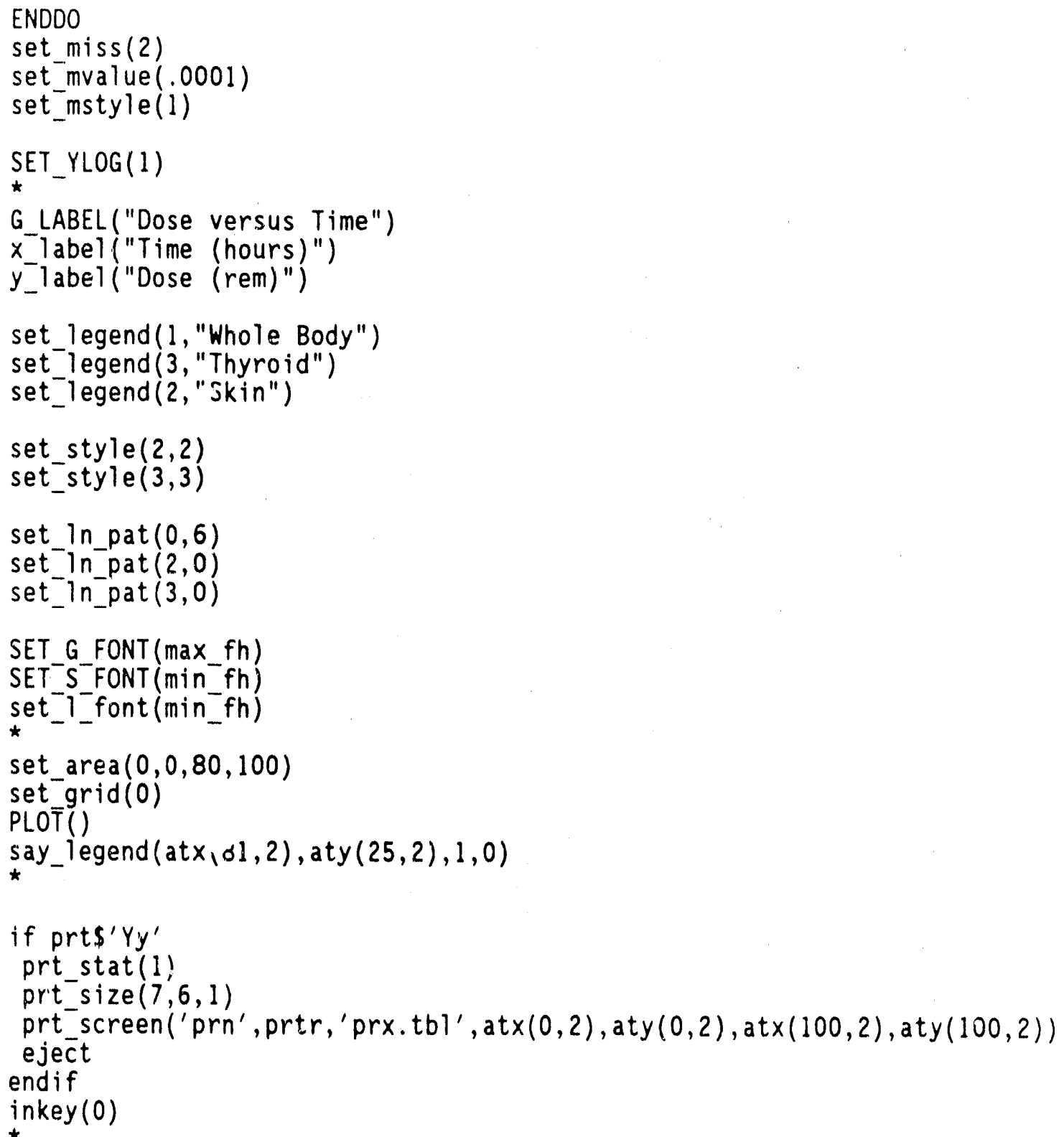




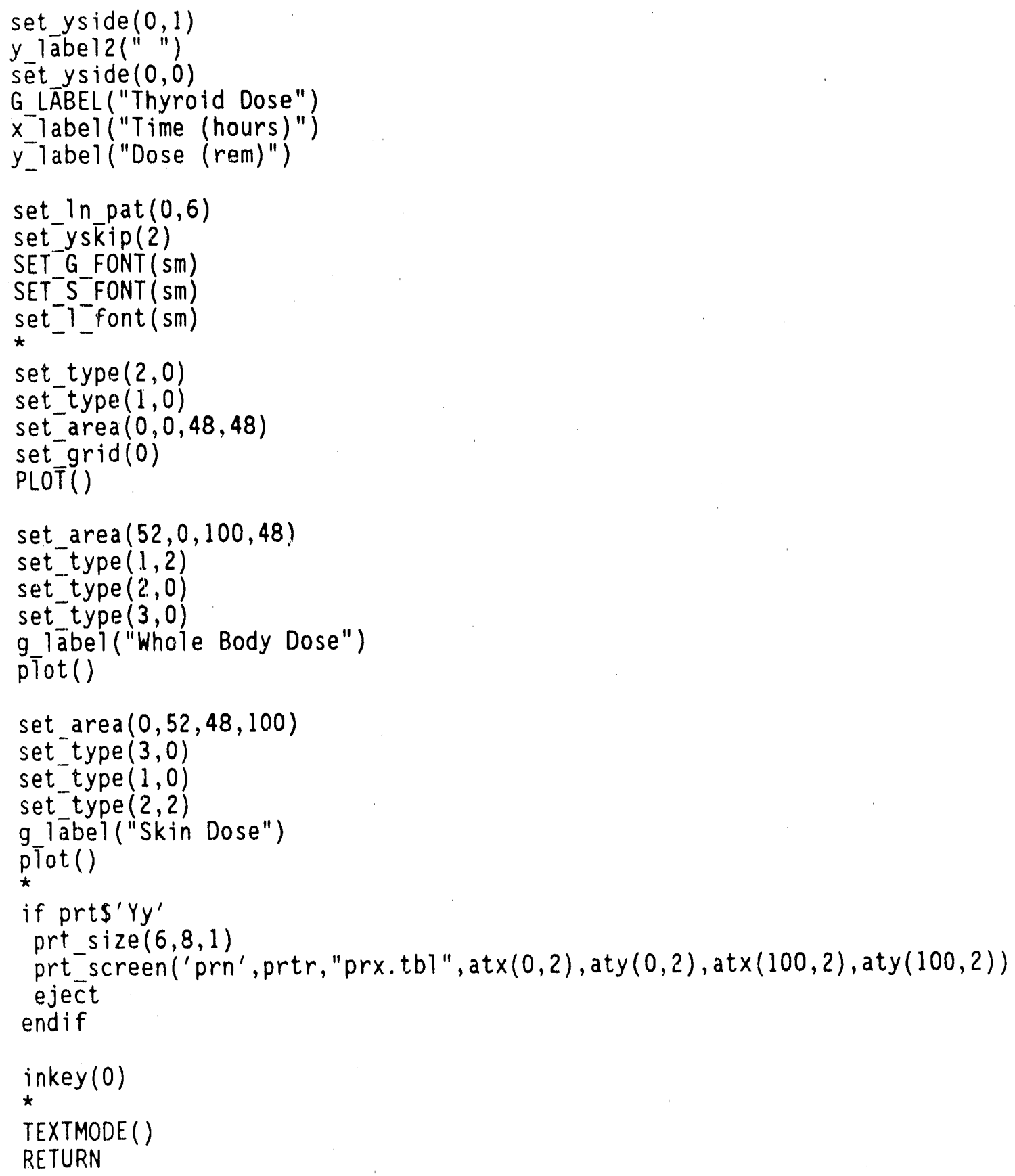


APPENDIX E:

CRHPLOTC CODE LISTING 


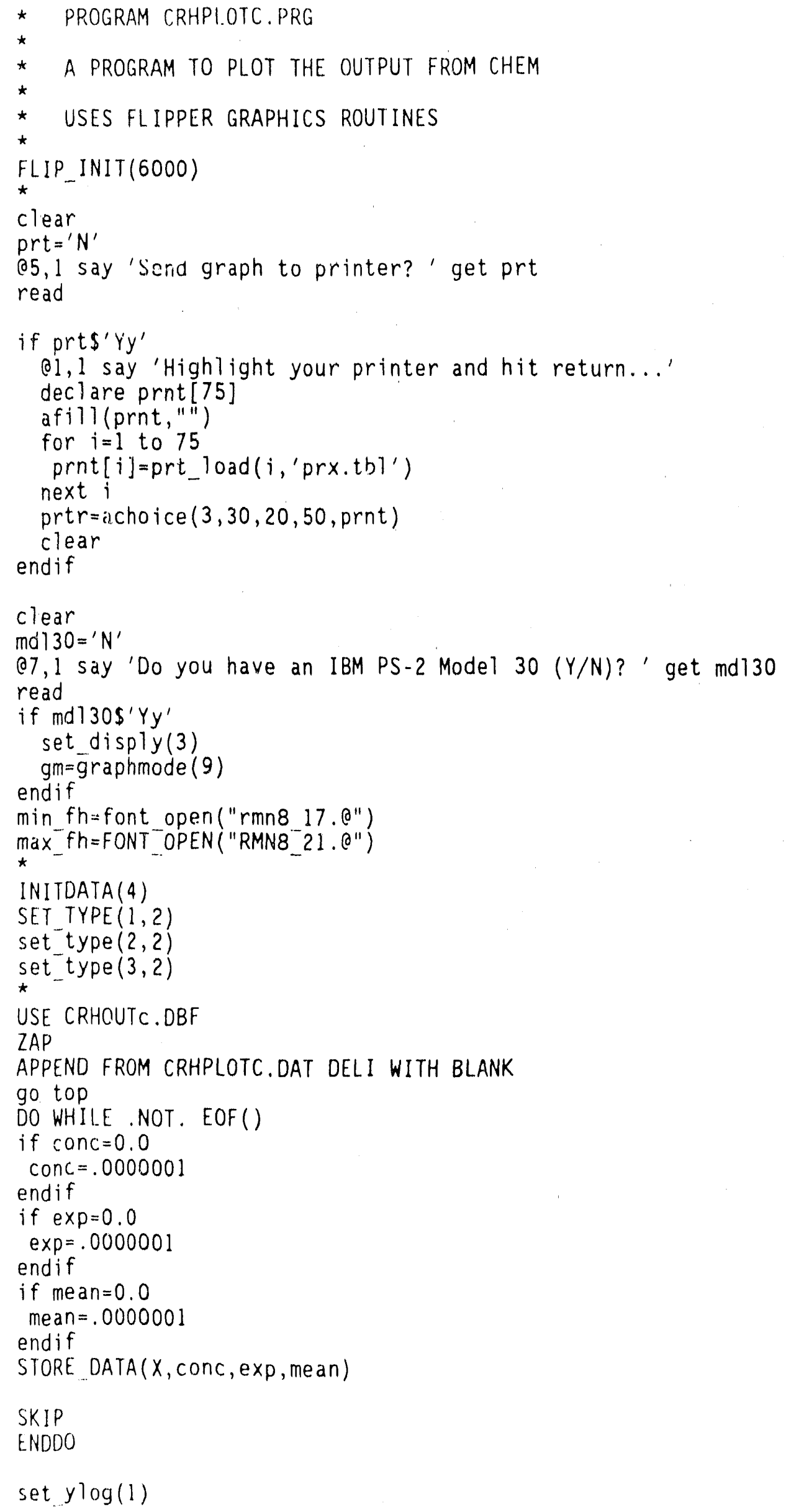




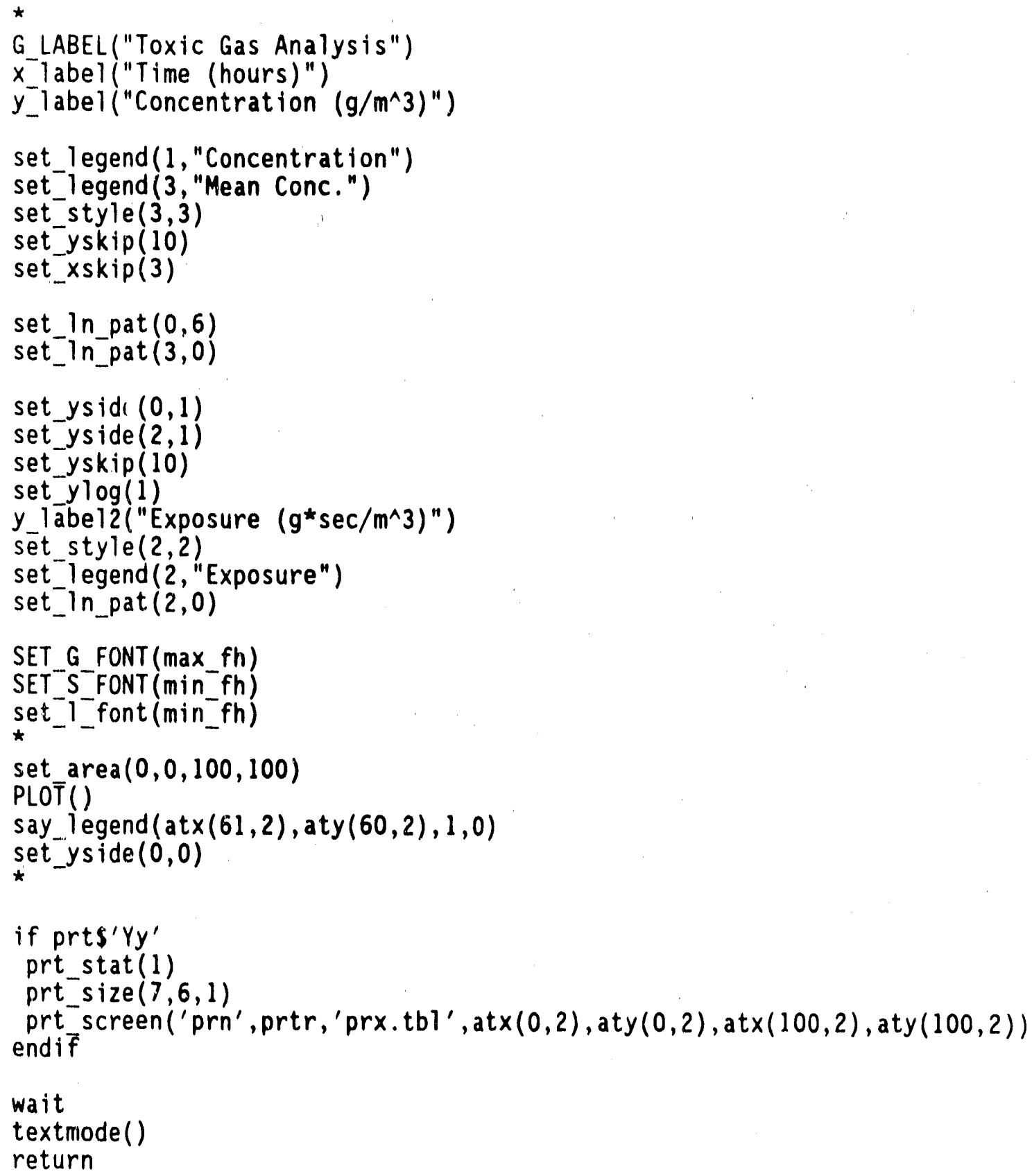


APPENDIX F

NUCLIDE FILE ICRP.02 
NA 22

8.448000E-09 2.384000E-06

$\begin{array}{llrl}0.0 & 0.0 & 0\end{array}$

$\begin{array}{ccccccccc}1.300000 E & 04 & 1.300000 E & 04 & 1.300000 E & 04 & 1.300000 E & 04 \\ 0 & 0 & 0 & 0\end{array}$ NA 24

1.273000E-05 1.429000E+00

0.0

0.0

$1.278000 \mathrm{E}$

$03 \quad 1.278000 \mathrm{E} 03 \quad 1.278000 \mathrm{E} \quad 03 \quad 1.280000 \mathrm{E} 03$ GE 277

$1.703000 E-05 \quad 3.761000 E+01$

$0.0 \quad 0.0 \quad 0.0$

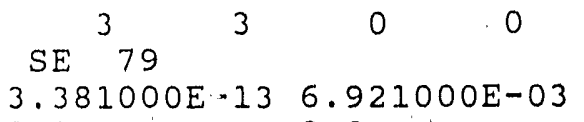

0.0

$\begin{array}{rrr}0.0 & 0.0 \\ 0 & 0 & 0\end{array}$

$\begin{array}{ccc}0 & 0.0 \\ 0 & 0 & 0\end{array}$

0.0

0.0000000000

BR 82

5.456000E-06 6.905000E+01

0.0

0.0

0.0

$4.470000 \mathrm{E} \quad 04 \quad 0.0$
0

$3.830000 \mathrm{E} 02$

KR $83 \mathrm{M}$

1.035000E-04 4..252000E+03

$5.020000 E-06 \quad 1.148000 E-020.0$

0 BR 83

8.021000E-05 2.930000E+03

0.0

0.0

0.0

0.0

0.0

BR 84

3. $646000 \mathrm{E}-04 \quad 4.339000 \mathrm{E}+03$

0.0

0.0

0

.

$5.201000 E-010.0$

0.0

$\mathrm{KR} \quad 85 \mathrm{M}$

4. $385000 \mathrm{E}-05 \quad 1.297000 \mathrm{E}+04$

$3.720000 \mathrm{E}-021.189000 \mathrm{E}-010.0$

$\begin{array}{cccc}9 & 2 & 10 & 0.211\end{array}$ KR 85

2. $042000 E-094.102000 E+02$

5. $250000 E-04 \quad 6.880999 E-02 \quad 0.0$

$\begin{array}{ccccc}10 & 2 & 0 & 0 & 0\end{array}$

BR 85

$3.850000 E-034.923000 E+03$

0.0

0.0

0.0

0.0

0.0

0.0

0.0

$\mathrm{RB}^{11} 86$

4. $289000 E-07 \quad 1.324000 E+02$

0.0

0.0

0.0

0

0.0

0.0

0.0

$\mathrm{KR}^{12} 87$

1. $519000 E-042.335000 E+04$

$1.870000 \mathrm{E}-015.961000 \mathrm{E}-01$

$\mathrm{KR}^{1.3} 88$

KR 88
$6.875000 E-05 \quad 3.200000 E+04$

4. $640000 \mathrm{E}-016.627000 \mathrm{E}-01$

$$
\begin{array}{llll}
14 & 2 & 15 & 1.0
\end{array}
$$

0.0

RB 88

$6.468000 E-04 \quad 1.200000 E+04$

$\begin{array}{lllll}0.0 & & 0.0 & & 0.0 \\ 15 & 3 & 0 & 0 & 0\end{array}$

$\mathrm{KR} 89$

3

$\mathrm{KR} \quad 89$
$3.630000 \mathrm{E}-03 \quad 3.979000 \mathrm{E}+04$

0.0

$\begin{array}{cccc}2.919000 E & 00 & 0.0 & 0.0 \\ 0\end{array}$

$\begin{array}{ccc}2.416000 \mathrm{E} & 000.0 & 0.0\end{array}$

$\begin{array}{lll}0.0 & 0.0 & 0.0\end{array}$

0
0.0
0.0
$1.690000 \mathrm{E} 04$

$0 \quad 0$

$\begin{array}{lll}1.537000 \mathrm{E} & 01 & 0.0 \\ 0 & \end{array}$

0.0

00

$3.136000 \mathrm{E}$
0 010.0

0.0

00

0.0

0.0

$4.840000 \mathrm{E} 01$ 


$$
\begin{aligned}
& 5.250000 \mathrm{E}-01 \quad 9.222200 \mathrm{E}-01 \quad 0.0 \\
& \begin{array}{lllll}
16 & 2 & 17 & 1.0 & 0
\end{array} \\
& \begin{array}{cc}
0.0 \\
0 & 0
\end{array} \\
& 0.0 \\
& 0.0 \\
& 0
\end{aligned}
$$

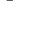

$\begin{array}{lllll} & 17 & 3 & 18 & 1.0\end{array}$
$\mathrm{SR}^{21} 91$

$2.005001 \mathrm{E}-05$

$0.0 \quad 0.0 \quad 0.0$

$2.118000 E+04$ $\mathrm{Y}^{22} 91 \mathrm{M}^{3}$

$23 \quad 0.57424$

$2.292000 \mathrm{E}-04 \quad 1.230000 \mathrm{E}+04$

0.0

$0.0 \quad 0.0$ 2393

$\begin{array}{lll}24 & 1.0 & 0\end{array}$

$1.383000 E-07 \quad 2.121000 E+04$

0.0

$0.0 \quad 0.0$

$\mathrm{SR}^{24} 92 \quad 3$

$7.292000 \mathrm{E}-05 \quad 2.508000 \mathrm{E}+04$

$0.0 \quad 0.0$

0.0

$Y^{25} 923$

$5.346999 E-05$

$2.535000 E+04$

0.0

0.0

0.0

SR 93

$1.444000 E-03 \quad 3.017000 E+04$

0.0

0.0

0.0

0.4260

$4.557000 \mathrm{E} \quad 03 \quad 7.741000 \mathrm{E} \quad 00 \quad 0.0$

Y 93

3

$1.909000 \mathrm{E}-05$

0.0

$3.163000 E+04$

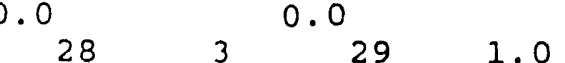

0.0

$2.402000 \mathrm{E} 02 \quad 3.264000 \mathrm{E}-02 \quad 0.0$ $0 \quad 0$

$2.130000 \mathrm{E} \quad 05 \quad 5.781000 \mathrm{E} 04 \quad 0.0$ ZR 93

$2.006000 \mathrm{E}-14 \quad 2.459000 \mathrm{E}-02$

0.0

0.0

0.0

$\mathrm{ZR} 95$

$1.267000 \mathrm{E}-07 \quad 3.858000 \mathrm{E}+04$

0.0

$0.0 \quad 0.0$

NB 95

$2.292000 E-07 \quad 3.842000 E+04$

0.0

31

0.0

0.0

$2.061000 \mathrm{E} 038.431000 \mathrm{E}-010.0$

$1.962000 \mathrm{E}$
0 $03 \quad 1.292000 \mathrm{E} 00 \quad 0.0$ 0.0

$0 \quad 0.0$

0.0

0.0

E.0620U0E $03 \quad 1.18200 C E 010.0$

$2.129000 \mathrm{E}$
0

$2.214000 \mathrm{E}$ O5 $1.339000 \mathrm{E} 04 \quad 4.300000 \mathrm{E} 03$ $6.311000 E_{04} 1.758000 E \quad 03 \quad 9.770000 E \quad 02$ $\mathrm{F}-2$ 
ZR 97

$1.129000 E-05 \quad 4.197000 E+04$

$0.0 \quad 0.0 \quad 0.0$

$\begin{array}{llll}32 & 3 & 33 & 0.947\end{array}$
0.0530

$9.839000 \mathrm{E} \mathrm{O3} 1.214000 \mathrm{E} 012.450000 \mathrm{E} 00$ NB $97 \mathrm{M}$

$1.155000 E-02 \quad 3.987000 E+04$

$0.0 \quad 0.0 \quad 0.0$ $\begin{array}{llll}33 & 3 & 34 & 1.0\end{array}$

NB 97

$1.573000 E-04 \quad 4.235000 E+04$

0.0

$\begin{array}{ll}4.235000 E+04 & \\ 0.0 & 0.0\end{array}$ $\mathrm{MO}^{34} 99$

$2.874000 E-06 \quad 4.885000 E+04$

$\begin{array}{lll}0.0 & 0.0 & 0.0\end{array}$ $\begin{array}{llll}35 & 3 & 30 & 0.886\end{array}$

TC $99 \mathrm{M}$

$3.183000 E-05 \quad 4.278000 E+04$

0.0

$0.0 \quad 0.0$

0.0

0.0

0.0000000000

TC. 99

1.042000 E-13 2.534000E-01

0.0

$0.0 \quad 0.0$

37

3

00

0

TC 101

8.250000E-04 5.188000E+04

$\begin{array}{llrrr}0.0 & & 0.0 & & 0.0 \\ 38 & 3 & 0 & 0 & 0\end{array}$

$38 \quad 3$

RU 103

$\begin{array}{lll}2.025000 E-07 & 5.381000 E+04 & \\ 0.0 & 0.0 & 0.0\end{array}$

0.0

$\begin{array}{rrr}0.0 & 0.0 \\ 0 & 0 & 0\end{array}$

RU 105

4.221000E-05 4.051000E+04

0.0

40

0.0

0.0

RU 106

2.197000E-08 2.270000E+04

0.0

$\begin{array}{ll}2.270000 E+04 \\ 0.0 & 0.0\end{array}$

$2.995000 \mathrm{E} \quad 02 \quad 2.777000 \mathrm{E}-02 \quad 7.030000 \mathrm{E}-03$
0

$\begin{array}{rrrr}41 & 3 & 42 & 1.0\end{array}$

RH 106

2.310000E-02 2.272000E+04

0.0 42

0.0

0.0

0.0
0

$1.140000 \mathrm{E} \quad 04$

0.0

$1.510000 \mathrm{E} 03$

PD 107

$3.139000 E-15 \quad 3.975000 E-03$

0.0

$3.975000 E-03$
0.0

43

0

0.0

RH 109

0.0
0

$1.925000 E-041.223000 E+04$

$0.0 \quad 0.0$

0.0

$$
\begin{aligned}
& 44 \\
& 109
\end{aligned}
$$

$1.407000 E-051.27 .000 E+04$

0.0

$1.27 .000 E+04$

$45 \quad 3$

AG 111

$1.069000 E-06 \quad 3.159000 E+03$

0.0

0.0

$0 \quad 0$

0.0

0.0 46

IN $115 \mathrm{M}$

4.220000E-059.015000E+02

$\underset{0}{1.011000 \mathrm{E}}$ ก5 $3.132001 \mathrm{E} 014.640000 \mathrm{E} \mathrm{OI}$ $4.985001 \mathrm{E} O 1 \quad 5.215000 \mathrm{E}-06 \quad 7.520000 \mathrm{E}-06$
0 $\begin{array}{lllll}6.312000 \mathrm{E} & 04 & 1.906000 \mathrm{E} & 02 & 0.0\end{array}$ $1.375000 \mathrm{E}$
0 $1.174000 \mathrm{E} \quad 06 \quad 8.643000 \mathrm{E} \quad 03 \quad 0.0$ $\begin{array}{lll}0.0 & 0.0 & 0.0000000000 \\ 0 & 0.000\end{array}$ $9.472000 \mathrm{E} \quad 03 \quad 0.0$ $8.270000 E 01$ $\begin{array}{lll}0.0 & 0.0 & 0.0000000000\end{array}$ $1.852000 \mathrm{E}$
0 $4.630000 E-01$ $2.333000 \mathrm{E} \quad 04 \quad 4.253000 \mathrm{E} \quad 01 \quad 1.780000 \mathrm{E} 01$ 0 


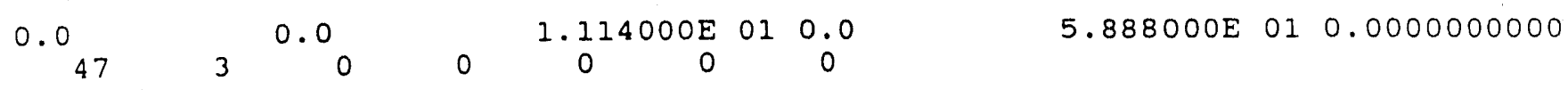
SN 123

$2.750000 E-04 \quad 1.832000 E+02$

0.0

0.0

$\begin{array}{lllllll}5.665000 E & 02 & 2.878000 E & 05 & 3.015000 E \quad 04 \quad 6.670000 E & 02\end{array}$ 48

SN 125

$8.443000 E-07 \quad 5.698000 E+02$

0.0

0.0

49

SB 125

9.158001E-09 6.103000E+02

$\begin{array}{lllllllllll}9.158001 E-09 & 6.103000 E & 0.747000 E & 00 & 2.175000 \mathrm{E} & 05 & 6.665000 \mathrm{E} & 03 & 7.440000 \mathrm{E} & 01 \\ 50 & 3 & 0.0 & 51 & 0.231 & 0 & 0 & 0 & & \end{array}$ TE $125 \mathrm{M}$

1. $383000 E-07 \quad 1.253000 E+02$

0.0

0.0

000

$.878000 \mathrm{E} \quad 05 \quad 3.015000 \mathrm{E} \quad 04 \quad 6.670000 \mathrm{E} \quad 02$

$2.588000 \mathrm{E} \quad 01 \quad 7.367000 \mathrm{E} \quad 04,1.162000 \mathrm{E} \quad 33 \quad 3.120000 \mathrm{E} \quad 01$ 000 51

SB 126

$6.416000 E-079.707000 E+01$

0.0

0.0

52

0

0

$\begin{array}{llllllll}1.313000 E & 02 & 3.919000 E & 04 & 4.268000 E & 02 & 1.980000 E & 02\end{array}$ $\begin{array}{lll}0 & 0 & 0\end{array}$

SB 127

$2.069000 \mathrm{E}-06 \quad 4.527000 \mathrm{E}+03$

0.0

$4.527000 E+03$
0.0

$\begin{array}{cccccccc}2.746000 E & 00 & 9.569000 E & 04 & 4.497000 E & 02 & 9.130000 E & 00 \\ 0 & 0 & 0 & 0 & & \end{array}$

5

53

$7.637999 E-08 \quad 6.114000 E+02$

0.0

0.0

54

0.16955

$3.968000 \mathrm{E}-01 \quad 2.048000 \mathrm{E} 04 \quad 3.293001 \mathrm{E} 01 \quad 7.220000 \mathrm{E}-01$ 54

$2.055999 E-054.501000 E+03$

$\begin{array}{lllllllll}0.0 & 0.0 & 0 & 1.325000 E-01 & 8.137000 E & 02 & 1.754000 E-018.030000 E-02\end{array}$ I 129

$1.294000 \mathrm{E}-150.0000000000$

$3.020000 E-032.435000 E-02 \quad 5.542000 E 06 \quad 0.0$

4.110000E $02 \quad 1.200000 \mathrm{E} \quad 05 \quad 1.575000 \mathrm{E} \quad 03 \quad 7.210000 \mathrm{E} \quad 02$

$\begin{array}{lllllll}56 & 1 & 0 & 0 & 0 & 0 & 0\end{array}$

$2.476000 \mathrm{E} \quad 03 \quad 2.110000 \mathrm{E} \quad 03$

TE 129M

$2.359000 E-07 \quad 1.668000 E+03$

0.0

0.0

$4.297000 E \quad 0$

57

$3 \quad 58$

0.6290

0

$21.448000 \mathrm{E} \quad 05$

$1.219000 \mathrm{E} \quad 03 \quad 5.840000 \mathrm{E} \quad 02$ TE 129

$1.573000 E-04 \quad 1.111000 E+04$

0.0

$1.111000 E+04$
0.0

$4.872002 \mathrm{E}-03 \quad 2.418000 \mathrm{E} \quad 02 \quad 6.219000 \mathrm{E}-03 \quad 2.990000 \mathrm{E}-03$ 58

I 131

$9.963996 \mathrm{E}-072.508000 \mathrm{E}+04$

$\begin{array}{ccccccccc}8.719999 E-02 & 1.655000 E-01 & 1.435000 E & 06 & 0.0 & 3.149000 E & 034.470000 E & 03\end{array}$ XE $131 \mathrm{M}$

$6.680000 E-072.595000 E+02$

$2.920000 E-03 \quad 3.995000 E-020.0$ 60

TE 131

$4.620000 E-042.741000 E+04$

0.0

0.0

613

$3 \quad 59$

1.0

$1.170000 E-03 \quad 1.740000 E+02 \quad 1.390000 E-03 \quad 7.440000 E-04$

TE I31M

$6.416000 E-06 \quad 4.800000 E+03$

0 .

62

0.0

61

0.22259

$6.879000 E \quad 00 \quad 1.823000 E \quad 04 \quad 8.743000 E \quad 00 \quad 5.450000 E \quad 00$

$1.400000 E+00 \quad 0.0 \quad 0.0$

$0 \quad 0$ 
I 132

8. $269001 E-05 \quad 3.806000 E+04$

$5.137000 E=017.927000 E-015.353000 E \quad 040.0$

$1.447000 \mathrm{E} 02 \quad 4.070000 \mathrm{E} 02$ 63

TE 132

$2.506000 E-06 \quad 4.115000 E+04$

0.0

0.0

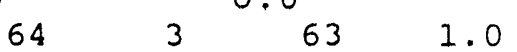

$2.366000 E$ OI $3.598000 E \quad 04 \quad 3.253000 E$ OL $2.690000 \mathrm{E} \quad 01$ I 133

$9.219000 \mathrm{E}-06 \quad 5.622000 \mathrm{E}+04$

$1.551000 E-013.120000 E-013.970000 E 050.0$

$\begin{array}{llcccc}65 & 1 & 66 & 0.029 & 67 & 0.971\end{array}$

$1.077000 \mathrm{E} 03 \quad 1.850000 \mathrm{E} 03$

$X E \quad 133 \mathrm{M}$

3. $490000 E-06 \quad 1.384000 E+03$

8. $000000 E-035.391000 E-02$

$$
66
$$

$\begin{array}{lll}67 & 1.0 & 0\end{array}$

0.0

XE 133

$1.522000 E-06 \quad 5.622000 E+04$

$9.330000 E-035.454000 E-020$. 67

$0 \quad 0$

0.0

$1.573000 \mathrm{E} 00 \quad 0.0$

0.0

TE $133 \mathrm{M}$

$2.310000 E-041.789000 E+04$

0.0

0.0

$6.269000 E-03$

$5.506001 E 027.243998 E-03 \quad 5.400000 E-03$ 68

I $1: 4$

2.2?RC:OE-04 6.575000E+04

5.3L. $100 E-018.593000 E-01$

69

$\begin{array}{ccc}01 & 8.593000 E-01 \\ 1 & 0 & 0\end{array}$

$\begin{array}{crc}2.537000 E & 04 & 0.0 \\ 0 & 0 & 0\end{array}$

$8.047000 E$ O1 2.160000E 02

TE 134

2.750000E-04 3.999000E+04

0.0

0.0

$3.437000 E-03 \quad 4.377000 E$ O2 3.843000E-03 3.220000E-03 70

69

1.0

$\begin{array}{ccc}0 & 0 & 0\end{array}$

CS 134

$9.551002 \mathrm{E}-091.019000 \mathrm{E}+03$

0.0

$0.0 \quad 0.0$

$\begin{array}{ccccccccc}0.0 & & 1.216000 \mathrm{E} & 04 & 4.662000 \mathrm{E} & 04 & 1.060000 \mathrm{E} & 05 \\ 0 & 0 & 0 & & & 0\end{array}$ 71

I 135

$2.864000 E-05 \quad 5.103000 E+04$

4.217000E-01 5.803000E-01 1.235000E 05 0.0 72 73

0.16574

0.8350

$3.353999 E_{02} \quad 8.730000 E \quad 02$

XE $135 \mathrm{M}$

$7.400000 E-041.557000 E+04$

$9.920000 \mathrm{E}-02 \quad 1.484000 \mathrm{E}-010.0$ $\begin{array}{llll}73 & 2 & 74\end{array}$

XE 135

$2.091999 E-05 \quad 5.363000 E+04$

5.720000E-02 I. $620000 E-01$ $\begin{array}{ccccc}74 & 2 & 0 & 0 & 0\end{array}$

CS 135

$7.293001 E-15 \quad 2.909000 E-02$

0.0

0.0

75

30

0.0

0.0
0

I 136

$8.349001 E-030.0000000000$

$6.786000 E-011.300000 E+00$

$\begin{array}{ccccc}76 & 1 & 1.300000 E+00 & 0.0\end{array}$

CS 136

$6.160000 \mathrm{E}-071.667000 \mathrm{E}+03$

0.0

0.0

0.0
0

.0

$\begin{array}{cc}0.0 \\ 0 & 0\end{array}$

$2.231000 E \quad 00 \quad 0.0$

0.0

77

3

$X E 137$

2. $961000 E-035.103000 E+04$

$1.500000 \mathrm{E} \quad 03$

4.061000E $00 \quad 0.0$

0.0

$1.566000 \mathrm{E} \quad 03 \quad 1.459000 \mathrm{E} \quad 04 \quad 1.290000 \mathrm{E} \quad 04$ 0
0.0
0.0000000000

$F-5$ 
$4.520000 \mathrm{E}-02 \quad 5.676000 \mathrm{E}-01 \quad 0.0$

$$
\begin{array}{cccc}
75 & 2 & 79 & 1.0
\end{array}
$$$$
\text { CS } 2.37
$$

$7.292000 E-10 \quad 1.907000 E+03$

0.0

$0.0 \quad 0.0$

$\begin{array}{llll}79 & 3 & 80 & 0.9460\end{array}$

BA $137 M$

$\begin{array}{ll}4.528999 E-03 & 1.811000 E+03 \\ 3.0 & 0.0\end{array}$

$3 . \mathrm{c}$

0.0

SO 138

.796091E-04 4.775000E+04

2. B.OCGODE-O1 4.249000E-01. 0.0

$$
\text { 3. }
$$

$82 \quad 1.0$

C. 133

$3.587001 \mathrm{E}-04$

$\therefore .5$

$$
823
$$

$4.878000 E+04$

0.0

0.0

C. 139

$\begin{array}{ll}1.216000 E-03 & 4.478000 E+04 \\ 0.0 & 0.0\end{array}$

0.0

83

ISA 239

1. $393000 \mathrm{E}-04 \quad 4.604000 \mathrm{E}+04$

0.0

0.0

0.0

84

BP, $I \leqslant 0$

$5.266000 E-07 \quad 4.274000 E+04$

0.0

$0.0 \quad 0.0$

85

[.A. 3.40

$\begin{array}{ll}4.774000 E-06 & 4.342000 E+04 \\ 0.0 & 0.0\end{array}$

0

0.0

BA 141

6.4 J.6000E-04 4.345000E+04

0.0

$\begin{array}{lll}0 & 0.0 \\ 37 & 0.0\end{array}$

0.0

LA 141

4.935399E-05 4.371000E+04

0.0
88
0.0
89

$1.0 \quad 0$

CE 141

$2.506000 E-07 \quad 4.387000 E+04$

$$
0.0
$$

0.0

89

BA 142

1. $050000 E-03 \quad 3.762000 E+04$

$\begin{array}{cccc}0.0 & 0.0 & & \\ 90 & 3 & 91 & 1.0\end{array}$

0.0

LA 142

$1.255000 E-04 \quad 3.883000 E+04$

0.0

0.0

91 3

$C E \quad 143$

6. $030000 E-06 \quad 3.552000 E+04$

0.0

$$
92
$$

0.0

93

1.0

0.0 0

PR 143

5. $854000 E-07 \quad 3.467000 E+04$

0.0

93

0.0

0
$1.748000 \mathrm{E} 010.0$
0.0

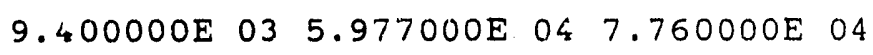
$0 \quad 0$
0.0
0.0
0.0000000000

$0 \quad 0$

$2.445000 \mathrm{E} \quad 010.0$

0.0

$\underset{0}{6.066000 E} 00 \quad 4.137000 E \quad 01 \quad 7.760000 E 01$ $2.837000 \mathrm{E} 00 \quad 2.557001 \mathrm{E} 01 \quad 3.630000 \mathrm{E} 01$ $\underset{0}{4.697000 E 02} 1.167000 E-01 \quad 8.320000 E-05$ $1.587000 E \quad 05 \quad 4.884000 E \quad 03 \quad 6.130000 E \quad 00$ 0

$1.701000 \mathrm{E} 04 \quad 4.300999 \mathrm{E} 01 \quad 2.170000 \mathrm{E} 01$ 0

$2.419000 \mathrm{E} 02 \quad 1.247000 \mathrm{E}-02 \quad 9.410000 \mathrm{E}-06$ 0

$1.345000 \mathrm{E} 03 \quad 5.342000 \mathrm{E}-01 \quad 1.660000 \mathrm{E}-01$ 0

$4.517000 \mathrm{E}$ O4 $2.494000 \mathrm{E} 03 \quad 1.690000 \mathrm{E} 03$ 0

$1.487000 \mathrm{E} 02 \quad 3.294000 \mathrm{E}-03 \quad 3.330000 \mathrm{E}-06$ $7.907000 \mathrm{E} \quad 02$
0 $9.972000 \mathrm{E} \quad 03 \quad 2.334000 \mathrm{E}$ O1 $1.720000 \mathrm{E} 01$ $3.506000 \mathrm{E} \quad 04 \quad 1.168000 \mathrm{E} \quad 03 \quad 4.690000 \mathrm{E} \quad 2$ 0 F-6 
CE 144

$2.766000 E-08 \quad 2.294000 E+04$

$0.0 \quad 0.0 \quad 0.0$

$9.716000 \mathrm{E} \quad 05 \quad 4.286000 \mathrm{E} \quad 05 \quad 1.790000 \mathrm{E} \quad 05$ PR 144

$6.676000 E-04 \quad 2.302000 E+04$

0.0

$\begin{array}{ll}2.302000 E+04 & \\ 0.0 & 0.0\end{array}$

0

$1.272000 \mathrm{E} 02 \quad 3.763000 \mathrm{E}-03 \quad 1.560000 \mathrm{E}-03$ $\begin{array}{llll}95 & 3 & 0 & 0\end{array}$

ND 147

$7.098000 E-07 \quad 1.733000 E+04$

$0.0 \quad 0.0$

0.0 $\begin{array}{lllll}96 & 3 & 97 & 1.0 & 0\end{array}$

PM 147

$8.718001 E-094.881000 E+03$

0.0

$4.881000 \mathrm{E}+03$
0.0

0.0

97

30

$9.664999 E-05 \quad 1.121000 E+04$

$0.0 \quad 0.0$

0.0
0

$98 \quad 3$

PM 149

$3.625000 E-06 \quad 1.122000 E+04$

0.0

0.0

99

PM 151

$6.875000 E-06 \quad 6.828000 E+03$

0.0

0.0

0

100

SM 151

$\begin{array}{ll}2.168000 E-10 & 7.226000 E+01 \\ 0.0 & 0.0\end{array}$

101

3

0

0

$0 \cdot 0$

EU 155

1.292000E-08 2.973000E+02

0.0

$0.0 \quad 0.0$

102

EU 156

$5.347000 E-07 \quad 1.575000 E+03$

0.0

$0.0 \quad 0.0$

103
GD 159

1. $069000 E-053.083000 E+02$

0.0

104

0.0

0.0

0

U 235

$3.095999 E-17$

0.0 105
$\mathrm{U}$

1. $188000 \mathrm{E}-063.456000 \mathrm{E}+03$

0.0

$0.0 \quad 0.0$

9. $169000 \mathrm{E}-05$

$0.0 \quad 0.0$

0
0

106

3

$107 \quad 1.0$

0

NP 237

$1.027000 E-14 \quad 2.150000 E-03$

0.0

0.0

0.0

107

PU 238

$3 \quad 0.000$

$2.431000 E-102.775000 E+01$

0.0

0.0

108

5

NP 238

3. $819000 E-067.741000 E+02$

0.0

0.0
0

$3.676001 E 02 \quad 0.0000000000$

$2.759000 \mathrm{E}$
0

$6.602000 E \quad 04 \quad 8.368000 E \quad 04 \quad 7.870000 E \quad 03$

$7.206000 \mathrm{E} \quad 03 \quad 3.439000 \mathrm{E} 01 \quad 4.870000 \mathrm{E} 00$ 0

0

$3.939000 E 03 \quad 8.496000 E 00 \quad 1.420000 E 00$

$\begin{array}{llllll}4.454000 E & 04 \quad 8.589000 E \quad O 4 \quad 1.480000 E \quad 04\end{array}$ 0

0

$9.463000 E \quad 04 \quad 1.005000 E \quad 05 \quad 1.430000 E \quad 04$

$8.556000 E 04 \quad 1.927000 E 03 \quad 1.480000 E 03$ 0

$0.0 \quad 6.478000 E 02 \quad 0.0000000000$

$0 \quad 0$

$4.896000 \mathrm{E} \quad 07 \quad 1.001000 \mathrm{E} 07 \quad 0.0$

0

$1.020000 E \quad 04 \quad 3.673000 E 010.0$

$5.215000 E \quad 07 \quad 1.693000 E \quad 09 \quad 1.470000 E \quad 08$ 0

$1.825000 E \quad 08 \quad 2.737000 E \quad 09 \quad 3.870000 E \quad 08$ 0 


\begin{tabular}{|c|c|c|c|c|c|c|c|c|c|c|c|}
\hline 0.0 & & 0.0 & & 0.0 & & $1.016000 \mathrm{E}$ & 04 & $2.962000 \mathrm{E}$ & 02 & $8.000000 \mathrm{E}$ & 00 \\
\hline $\begin{array}{l}109 \\
\text { PU } 239\end{array}$ & 3 & 108 & 1.0 & 0 & 0 & 0 & & & & & \\
\hline $\begin{array}{c}\text { PU } 239 \\
9.012000 E\end{array}$ & -13 & 1.227000 & $E+02$ & & & & & & & & \\
\hline 0.0 & & 0.0 & & 0.0 & & $1.716000 \mathrm{E}$ & 08 & $3.188000 \mathrm{E}$ & 09 & $4.310000 \mathrm{E}$ & 08 \\
\hline 110 & 5 & 105 & 1.0 & 0 & 0 & 0 & & & & & \\
\hline U 239 & & & & & & & & & & & \\
\hline $4.916000 \mathrm{E}$ & -04 & 8.928000 & $E+05$ & & & & & & & & \\
\hline 0.0 & & 0.0 & & 0.0 & & 0.0 & & 0.0 & & 0.0 & \\
\hline $\begin{array}{l}111 \\
\text { NP } 239\end{array}$ & 3 & 112 & 1.0 & 0 & 0 & 0 & & & & & \\
\hline $\begin{array}{l}3.442000 \mathrm{E}- \\
0.0\end{array}$ & & $\begin{array}{l}8.293000 \\
0.0\end{array}$ & $E+05$ & 0.0 & & & & & & & \\
\hline 112 & 3 & 0.0 & 1.0 & 0 & 0 & ${ }_{0}^{4.702000 \mathrm{E}}$ & 03 & $2.866000 \mathrm{E}$ & 01 & $2.820000 \mathrm{E}$ & 00 \\
\hline PU 240 & & & & & & & & & & & \\
\hline $3.342000 \mathrm{E}$ & -12 & 7.235000 & $E+01$ & & & & & & & & \\
\hline 0.0 & & 0.0 & & 0.0 & & $1.716000 \mathrm{E}$ & 08 & $3.183000 \mathrm{E}$ & 09 & $4.300000 \mathrm{E}$ & 08 \\
\hline $\begin{array}{c}113 \\
\text { PU } 241\end{array}$ & 5 & 0 & 0 & 0 & 0 & 0 & & & & & \\
\hline $1.671000 E$ & -09 & 3.779000 & $E+03$ & & & & & & & & \\
\hline 0.0 & & 0.0 & & 0.0 & & $1.517000 \mathrm{E}$ & 05 & $6.407000 \mathrm{E}$ & 07 & $3.280000 E$ & 06 \\
\hline $\begin{array}{c}114 \\
\text { AM } 241\end{array}$ & 5 & 115 & 1.0 & 0 & 0 & & & & & & \\
\hline $\begin{array}{l}4.803000 E \\
0.0\end{array}$ & -11 & $\begin{array}{l}1.571000 \\
0.0\end{array}$ & $E+01$ & 0.0 & & $6.062000 \mathrm{E}$ & 07 & $1.013000 E$ & 09 & $3.590000 \mathrm{E}$ & \\
\hline $\begin{array}{l}1.15 \\
\text { PU } 242\end{array}$ & 3 & 107 & 1.0 & 0 & 0 & 0 & & & 10 & & (10 \\
\hline $5.812001 \mathrm{E}$ & -14 & 2.110000 & $E-02$ & & & & & & & & \\
\hline 0.0 & & 0.0 & & 0.0 & & $1.651000 \mathrm{E}$ & 08 & $2.954000 \mathrm{E}$ & 09 & $4.150000 \mathrm{E}$ & 08 \\
\hline $\begin{array}{c}116 \\
\mathrm{CM} 242\end{array}$ & 5 & 0 & 0 & 0 & 0 & 0 & & & & & \\
\hline $4.936000 \mathrm{E}$ & -08 & 9.018000 & $E+02$ & & & & & & & & \\
\hline 0.0 & & 0.0 & & 0.0 & & $3.923000 E$ & 07 & $1.483000 \mathrm{E}$ & 07 & $1.510000 \mathrm{E}$ & 07 \\
\hline $\begin{array}{c}117 \\
\text { AM } 242 M\end{array}$ & 3 & 108 & 1.0 & 0 & 0 & 0 & & & & & \\
\hline $1.432000 \mathrm{E}$ & -10 & 1.457000 & $E+00$ & & & & & & & & \\
\hline 0.0 & & 0.0 & & 0.0 & & $2.443000 \mathrm{E}$ & 07 & $1.019000 \mathrm{E}$ & 09 & $3.460000 \mathrm{E}$ & 08 \\
\hline $\begin{array}{c}118 \\
\text { CM } 243\end{array}$ & 3 & 0 & 0 & 0 & 0 & 0 & & & & & \\
\hline $6.855001 E$ & -10 & 3.528000 & $E-01$ & & & & & & & & \\
\hline 0.0 & & 0.0 & & 0.0 & & $6.312000 \mathrm{E}$ & 07 & $7.856000 \mathrm{E}$ & 08 & $2.970000 \mathrm{E}$ & 08 \\
\hline $\begin{array}{c}119 \\
\text { AM } 243\end{array}$ & 3 & 110 & 0.99 & 980 & 0 & 0 & & & & & \\
\hline $2.766000 \mathrm{E}$ & -12 & 5.306000 & $E-02$ & & & & & & & & \\
\hline 0.0 & & 0.0 & & 0.0 & & $5.747000 \mathrm{E}$ & 07 & $1.013000 \mathrm{E}$ & 09 & $3.470000 \mathrm{E}$ & 08 \\
\hline $\begin{array}{c}120 \\
\text { CM } 244\end{array}$ & 3 & 112 & 1.0 & 0 & 0 & 0 & & & & & \\
\hline $1.248000 E$ & -09 & 2.497000 & $E+00$ & & & & & & & & \\
\hline $\begin{array}{l}0.0 \\
121\end{array}$ & 3 & 0.0 & & 0.0 & 0 & $6.062000 \mathrm{E}$ & 07 & $5.904000 \mathrm{E}$ & 08 & $2.540000 \mathrm{E}$ & 08 \\
\hline AM 244 & & 113 & 1.0 & 0 & U & & & & & & \\
\hline $4.431000 \mathrm{E}$ & -04 & 3.186000 & $E+00$ & & & & & & & & \\
\hline 0.0 & 7 & 0.0 & & 0.0 & & 0.0 & & $2.985000 E$ & 03 & 0.00000000 & 000 \\
\hline 122 & 3 & 121 & 1.0 & 0 & 0 & 0 & & & & & \\
\hline
\end{tabular}


APPENDIX G

NUCLIDE FILE ICRP.30 
NA 22

8.448000 E $-092.384000 E-06$

$\begin{array}{llllllllll}0.0 & 0.0 & 1.300000 E & 04 & 1.300000 E & 04 & 1.300000 E & 04 & 1.300000 E & 04\end{array}$ NA 24

$1.273000 E-05 \quad 1.429000 E+00$

0.0

0.0

1.278000 E O3 1.278000E O3 1.278000E $03 \quad 1.280000$ E 03 GE 77

$1.703000 \mathrm{E}-05 \quad 3.761000 \mathrm{E}+01$
0.0
0.0

0.0

$\begin{array}{ll}0 & 0.0 \\ 0 & 0\end{array}$

$0.0 \quad 0.0$

0.0000000000

SE 79

3.381000 E-13 6.921000E-03
0.0
0.0
0.0
$4.470000 E \quad 040.0$
3.830000 E 02

BR 82

$5.456000 E-06 \quad 6.905000 E+01$

$\begin{array}{lll}0.0 & 0.0\end{array}$

$0.0 \quad 0$.

$\begin{array}{ll}0.0 & 0.0\end{array}$

0.0

KR $83 \mathrm{M}$

1.035000E-04 4.152000E+03

1.270000E-05 0.000000E+00

$0.000000 E+00 \quad 5.201000 E-01 \quad 0.000000 E+B 00.0$

BR 83

$8.021000 E-05 \quad 2.930000 E+03$

$0.0 \quad 0.0$

$\begin{array}{ccccc}0.0 & 0.0 & 0.0 & 0.0 \\ 0 & 0 & 0 & \end{array}$

BR 84

$3.646000 E-04$ 4.339000E+03
0.0
0.0
0.0
0.0
0.0
0.0

KR $85 \mathrm{M}$

4.385000E-05 1.297000E+04

$\begin{array}{cccccccccc}2.310000 E-02 & 4.970000 E-02 & 0.000000 E+00 & 2.919000 E & 00 & 0.000000 E+00 & 0.0\end{array}$ KR 85

$2.042000 E-09$ 4.102000E+02

$\begin{array}{cccccccc}3.310000 E-04 & 4.840000 E-02 & 0.000000 E+00 & 2.416000 E & 00 & 0.000000 E+00 & 0.0\end{array}$

BR 85

$3.850000 E-03 \quad 4.923000 E+03$

$\begin{array}{ccccccccc}0.0 & 0.0 & 0.0 & & 0.0 & 0.0 & 0.0 \\ 11 & 1 & 0 & 0 & 0 & 0 & 0 & \end{array}$

RB 86

4.289000E- 07 1.324000E +02
0.0
0.0
0.0
0.0
0.0
$1.690000 \mathrm{E} 04$

KR 87

$1.519000 E-042.335000 E+04$

$\begin{array}{lllllll}1.330000 E-01 & 3.360000 E-01 & 0.000000 E+00 & 1.537000 E & 01 & 0.000000 E+00 & 0.0\end{array}$ KR 88

$6.875000 E-053.200000 E+04$

$\begin{array}{lllllll}3.380000 E-01 & 7.760000 E-02 & 0.000000 E+00 & 3.136000 E & 01 & 0.000000 E+00 & 0.0\end{array}$ $\begin{array}{ccccccc}14 & 2 & 15 & 1.0 & 0 & 0 & 0\end{array}$

$6.468000 E-041.200000 E+04$
0.0
0.0
0.0
0.0
0.0
4.840000 E 01
$\begin{array}{llllrlr}15 & 3 & 0 & 0 & 0 & 0 & 0\end{array}$ 
KR 89

$3.630000 E-03 \quad 3.979000 E+04$

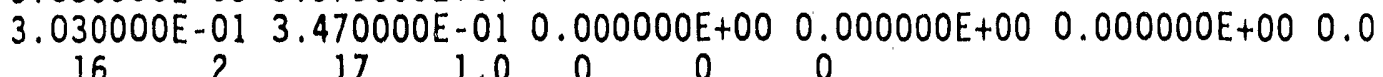
RB 89

$3.629000 E-03 \quad 1.538000 E+04$

$0.0 \quad 0.0$ $\begin{array}{rrrr}17 & 3 & 18 & 1.0\end{array}$

$\begin{array}{llll}0.0 & 0.0 & 0.0 & 3.200000 E\end{array}$

SR 89

$1.588000 E-07 \quad 1.552000 E+04$

$\begin{array}{lll}0.0 & 0.0 & 0.0\end{array}$

$0.0 \quad 1.749000$ E 053.801000 E O4 0.0

RB 90

3. $982000 E-03 \quad 1.335000 E+04$

0.0

19

SR 90

$8.020999 E-107.401000 E+02$

0.0

$0.0 \quad 0.0$

0.0

0

0

(200000 01 $\begin{array}{rrrr}20 & 3 & 21 & 1.0\end{array}$

2. $993000 E-06 \quad 7.887000 E+02$

0.0

$0.0 \quad 0.0$ 21

$3 \quad 0$

$0 \quad 0$

SR 91

2.005001E-05 2.118000E+04

$\begin{array}{lll}0.0 & 0.0 & 0.0\end{array}$

$\begin{array}{llll}22 & 3 & 23 & 0.574\end{array}$

Y $91 \mathrm{M}$

2.292000E-04 1.230000E+04
0.0
0.0

$1.0 \quad 0.0$

23

3

24

1. $383000 E-072.121000 E+04$

0.0

$0.0 \quad 0.0$

24

SR 92

7.292000E-05 2.508000E+04

0.0

$\begin{array}{ll}.292000 E-05 & 2.508000 E+04 \\ .0 & 0.0\end{array}$

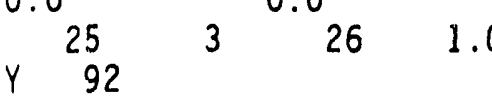

5.346999E-05 2.535000E+04

0.0

26

0.0

0.0

0.0

0.0
0.0000000000

SR 93

$1.444000 E-03 \quad 3.017000 E+04$

0.0 27

Y 93

0.0

0.0

0.0

0.4260

1.196000E O6 1.244000E $07 \quad 0.0$

0

$2.120000 E+042.612000 E \quad 02 \quad 0.0$

0 
NB 95

2.292000E- $07 \quad 3.842000 E+04$

$\begin{array}{cccccccccccc}0.0 & 0.0 & & 0.0 & & 6.311000 \mathrm{E} & 04 & 1.758000 \mathrm{E} & 03 & 9.77 \mathrm{U} O 00 \mathrm{E} & 02\end{array}$ ZR 97

$1.129000 E-05 \quad 4.197000 E+04$

$\begin{array}{lll}0.0 & 0.0 & 0.0\end{array}$

$\begin{array}{lllll}32 & 3 & 33 & 0.94734 & 0.0530\end{array}$

NB $97 \mathrm{M}$

$1.155000 E-02 \quad 3.987000 E+04$
0.0
$0.0 \quad 0.0$
0.0
0.0
0.0000000000
0
0.000000000

NB $\quad 97$

1.573000E-04 4.235000E+04

0.0

$0.0 \quad 0.0$

$9.839000 \mathrm{E} \quad 03 \quad 1.214000 \mathrm{E} \quad 012.450000 \mathrm{E} \quad 00$ MO 34

2.874000E-06 4.886000E+04

$\begin{array}{lll}0.0 & 0.0 & 0.0\end{array}$ $\begin{array}{llll}35 & 3 & 36 & 0.886\end{array}$

TC $99 \mathrm{M}$

3.183000E-05 4.278000E+04

$\begin{array}{lll}0.0 & 0.0 & 0.0\end{array}$

2.995000 E $022.777000 E-02 \quad 7.030000 E-03$

TC 99

$1.042000 E-132.534000 E-01$

0.0

$0.0 \quad 0.0$

$\begin{array}{cccccccc}0.0 & & 1.011000 E & 05 & 3.132001 E & 01 & 4.640000 E & 01\end{array}$

TC 101

8.250000E-04 5.188000E+04

0.0

$\begin{array}{ll}0.0 & 0.0\end{array}$

$1.140000 E 040.0$

$1.510000 E \quad 03$

RU 103

2.025000E-07 5.381000E+04

0.0

$0.0 \quad 0.0$

0

0

$9.546001 E 01 \quad 1.287000 E-04 ? .640000 E-04$ 0

$4.985001 E 01 \quad 5.215000 E-06 \quad 7.520000 E-06$ 0

6.312000 E O4 1.906000 E 020.0

RU 105

4.221000E-05 4.051000E+04

0.0

$0.0 \quad 0.0$

$\begin{aligned} & 1.375000 \mathrm{E} \\ & 0\end{aligned} 03 \quad 9.877002 \mathrm{E}-02 \quad 0.0$

RU 106

2.197000E-08 2.270000E+04

$\begin{array}{lll}0.0 & 0.0 & 0.0\end{array}$

$\begin{array}{lllll}41 & 3 & 42 & 1.0 & 0\end{array}$

RH 106

$2.310000 t-02 \quad 2.272000 E+04$

$\begin{array}{cccc}0.0 & 0.0 & \\ 42 & 3 & 0 & 0\end{array}$

$\begin{array}{llll}0.0 & 0.0 & 0.0 & 0.0000000000\end{array}$

PD 107

$3.139000 E-15 \quad 3.975000 E-03$

$\begin{array}{llll}0.0 & 0.0 & 0.0\end{array}$

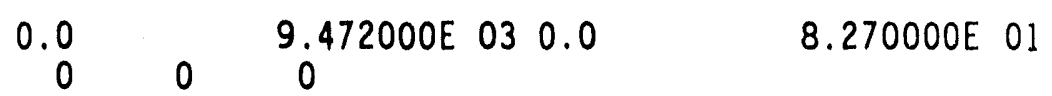

RH 109

$1.925000 E-04 \quad 1.223000 E+04$

0.0

$0.0 \quad 0.0$

1.174000 E 068.643000 E $03 \quad 0.0$

44

$\begin{array}{llll}44 & 3 & 0 & 0\end{array}$

PD 109

$\begin{array}{ccc}0.0 & 0.0 \\ 0 & 0 & 0\end{array}$

$0.0 \quad 0.0$

0.0000000000

$1.407000 E-051.277000 E+04$

0.0

$\begin{array}{lll}45 & 0.0 & 0.0\end{array}$

45

$\begin{array}{rrr}0 & 0 & 0\end{array}$

1.852000 E $03 \quad 0.0$

4.630000E-01 
$A G 111$

$1.069000 E-063.159000 E+03$ $\begin{array}{ll}0.0 & 0.0\end{array}$ 46

IN $115 \mathrm{M}$

4.220000E-05 9.015000E+02

0.0 $\begin{array}{lll}0.0 & 1.114000 \mathrm{E} 010.0\end{array}$

2.333000 E $04 \quad 4.253000 E \quad 011.780000 E \quad 01$ 47

47

SN 123

$2.750000 E-04 \quad 1.832000 E+02$

0.0

0.0

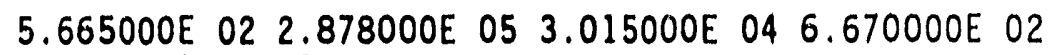
SN 125

$8.443000 E-07 \quad 5.698000 E+02$

0.0

0.0

SB 125

$9.158001 E-096.103000 E+02$

0.0

0.0

TE $125 \mathrm{M}$

$510.2310 \quad 0 \quad 0$

2.588000 E O1 7.367000E O4 1.162000E $03 \quad 3.120000$ E 01

$1.383000 E-07 \quad 1.253000 E+02$

0.0

0.0

1.313000 E $02 \quad 3.919000$ E O4 4.268000E 021.980000 E 02

SB 126

$6.416000 E-079.707000 E+01$

0.0

0.0

2.746000 E OO 9.56900OE O4 4.497000E O2 9.130000E OO

SB 127

2. $069000 E-06 \quad 4.527000 E+03$

$0.0 \quad 0.0$
53
55
0.83154

TE $127 \mathrm{M}$

$7.637999 E-08 \quad 6.114000 E+02$

0.0

54

0.0

$3.968000 \mathrm{E}-012.048000 \mathrm{E} 04 \quad 3.299001 \mathrm{E} 017.220000 \mathrm{E}-01$

$\begin{array}{crrr}2.746000 E & 00 & 9.56 \\ 0 & 0 & 0\end{array}$

5.888000 E 010.0000000000

TE 127

2.055999E-05 4.501000E+03

0.0

0.0

4.110000E 021.200000 E O5 1.575000E $03 \quad 7.210000$ E 02 55

I 129

1.294000E-15 0.0000000000

$3.020000 E-03 \quad 2.435000 E-02 \quad 5.542000 E \quad 060.0$

1.325000E-01 8.137000E $021.754000 E-018.030000$ E-02 56

TE $129 M$

$2.359000 E-07 \quad 1.668000 E+03$

0.0
$\begin{array}{llr}57 \quad 3 & 58\end{array}$
0.0
$58 \quad 0.6290$

4.297000 E O2 1.448000E O5 1.219000E $03 \quad 5.840000$ E 02

TE 129

$1.573000 E-04 \quad 1.111000 E+04$

0.0

0.0

4.872002E-03 2.418000E $02 \quad 6.219000 E-03 \quad 2.990000 E-03$ 58

I 131

$9.963996 E-072.508000 E+04$

5.590000E-02 3.070000E-02 1.100000E $06 \quad 0.000000 E+00 \quad 3.149000 E \quad 03 \quad 4.470000 E \quad 03$ 59

$X E 131 \mathrm{M}$

$60 \quad 0.0110 \quad 0 \quad 0$

$6.680000 E-072.595000 E+02$

$\begin{array}{cccccccc}1.250000 \mathrm{E}-03 & 1.330000 \mathrm{E}-02 & 0.000000 \mathrm{E}+00 & 1.400000 \mathrm{E}+00 & 0.000000 \mathrm{E}+00 & 0.0 \\ 60 & 2 & 0 & 0 & 0 & 0 & 0\end{array}$ 
TE 131

$4.620000 E-042.741000 E+04$

0.0

0.0

613

0.0

1.170000F-03 1.740000E+02 1.390000E-03 7.440000E-04

TE. $131 \mathrm{M}$

$6.416000 E-06 \quad 4.800000 E+03$

0.0

0.0

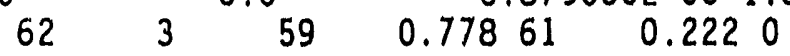

$6.879000 \mathrm{E} \mathrm{O0} 1.823000 \mathrm{E} \mathrm{O4}$

I 132

$8.269001 E-053.806000 E+04$

$3.550000 E-011.100000 E-01$ 63

TE 132

$2.506000 E-06 \quad 4.115000 E+04$

0.0

$\begin{array}{lllllll}64 & 3 & 0.0 & 2.366000 E & 01 & 3.598 \\ 63 & 1.0 & 0 & 0 & 0\end{array}$

I 133

$9.219000 E-06 \quad 5.622000 E+04$

$9.110000 E-02 \quad 8.900000 E-02 \quad 1.800000 E+05 \quad 0.000000 E+00 \quad 1.077000 E+03 \quad 1.850000 E \quad 03$ $\begin{array}{llllll}65 & 1 & 67 & 0.97166 & 0.029 & 0\end{array}$

XE $133 \mathrm{M}$

$3.490000 E-06 \quad 1.384000 E+03$

$\begin{array}{cccccccc}4.290000 E-03 & 2.960000 E-02 & 0.000000 E+00 & 1.890000 E+00 & 0.000000 E+00 & 0.0 \\ 66 & 2 & 67 & 1.0 & 0 & 0 & 0\end{array}$

XE 133

$1.522000 E-06 \quad 5.622000 E+04$

$\begin{array}{cccccccc}4.960000 \mathrm{E}-03 & 9.670000 \mathrm{E}-03 & 0.000000 \mathrm{E}+00 & 1.573000 \mathrm{E}+00 & 0.000000 \mathrm{E}+00 & 0.0 \\ 67 & 2 & 0 & 0 & 0 & 0 & 0 & 0\end{array}$

TE $133 \mathrm{M}$

$2.310000 E-04 \quad 1.789000 E+04$

0.0

0.0

$6.269000 E-03 \quad 5.506001 E 02 \quad 7.243998 E-03 \quad 5.400000 E-03$

68
134

$2.228000 \mathrm{E}-04 \quad 6.575000 \mathrm{E}+04$

$4.110000 E-011.420000 E-01 \quad 1.100000 E \quad 03 \quad 0.000000 E+008.047000 E+012.160000 E \quad 02$ 69

TE 134

$2.750000 E-04 \quad 3.999000 E+04$

0.0

0.0

3.437000E-03 4.377000E O2 3.843000E-03 3.220000E-03
70
69
1.0

$\begin{array}{ccc}3.437000 E-03 & 4.377 \\ 0 & 0 & 0\end{array}$

CS 134

$9.551002 E-091.019000 E+03$

0.0

71

$0.0 \quad 0.0$

$\begin{array}{llllll}0.0 & 1.216000 E & 04 \quad 4.662000 E & 04 & 1.060000 E & 05\end{array}$

I 135

$2.864000 E-05 \quad 5.103000 E+04$

$2.490000 E-01 \quad 7.860000 E-02 \quad 3.100000 E+04 \quad 0.000000 E+00 \quad 3.353999 E+02 \quad 8.730000 E \quad 02$
72
$74 \quad 0.835 \quad 73$
0.1650

XE $135 M$

$7.400000 E-04 \quad 1.557000 E+04$

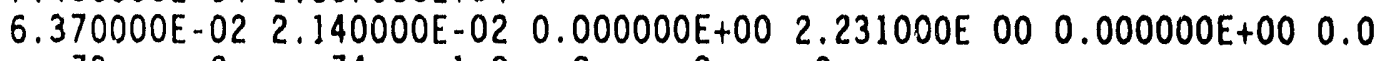

$\begin{array}{lllllll}73 & 2 & 74 & 1.0 & 0 & 0 & 0\end{array}$

$X E 135$

$2.091999 E-05 \quad 5.363000 E+04$

3.59000DE-02 6.320000E-02

$$
\begin{array}{llll}
74 & 2 & 0 & 0
\end{array}
$$

CS 135

$7.293001 E-15 \quad 2.909000$ E-02

0.0

75

0.0

0.0

$0.000000 E+00 \quad 4.061000 E \quad 00 \quad 0.000000 E+00 \quad 0.0$

$0 \quad 0 \quad 0$

$.061000 E \quad 00 \quad 0.000000 E+00 \quad 0.0$

3

0

0

0

1.566000 E $03 \quad 1.459000$ E 041.290000 E O4 
I 136

$8.349001 E-03 \quad 0.0000000000$

$6.786000 E-011.300000 E+000.0$ 76

CS 136

$6.160000 E-07 \quad 1.667000 E+03$

$\begin{array}{cccccccccccc}0.0 & 0.0 & & 0.0 & & 1.500000 \mathrm{E} & 03 & 4.879000 \mathrm{E} & 03 & 1.830000 \mathrm{E} & 04\end{array}$ $X E 137$

2.961000E-03 5.103000E+04

$2.830000 E-02 \quad 4.590000 E-01 \quad 0.000000 E+00 \quad 1.748000 E \quad 01 \quad 0.000000 E+00 \quad 0.0$ $\begin{array}{lllllll}78 & 2 & 79 & 1.0 & 0 & 0 & 0\end{array}$

CS 137

$7.292000 E-101.907000 E+03$

$\begin{array}{lll}0.0 & 0.0 & 0.0\end{array}$

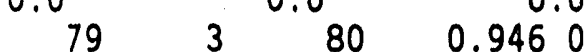

BA $137 \mathrm{M}$

4.528999E-03 1.811000E+03

$\begin{array}{llccccccc}0.0 & 0.0 & 0.0 & & 0.0 & 0.0 & 0.0000000000\end{array}$

XE 138

$6.796001 E-04 \quad 4.775000 E+04$

$\begin{array}{ccccccccc}1.870000 E-01 & 1.470000 E-01 & 0.000000 E+00 & 2.445000 E & 01 & 0.000000 E+00 & 0.0\end{array}$

CS 138

$3.587001 E-04 \quad 4.878000 E+04$

0.0

$\begin{array}{ll}0.0 & 0.0\end{array}$

C $\begin{aligned} & 82 \\ & 139\end{aligned}$

$1.216000 E-03 \quad 4.478000 E+04$

0.0

$0.0 \quad 0.0$

9.400000 E O3 5.977000E O4 7.760000E O4 0

83

3

$0 \quad 0$

0.0

6.066000 E OO 4.137000 E 017.760000 E 01

BA 139

1.393000E-04 4.604000E+04

0.0

$3 \begin{array}{cccr}0.0 & 0.0 \\ 0 & 0 & 0\end{array}$

84

BA 140

$6.266000 E-07 \quad 4.274000 E+04$

0.0

$\begin{array}{ll}0.0 & 0.0\end{array}$

85
LA 140

$4.774000 E-06 \quad 4.342000 E+04$

0.0

$\begin{array}{ll}0.0 & 0.0\end{array}$

BA 141

863

0

$0 \quad 0$

$6.416000 E-04 \quad 4.345000 E+04$

0.0

$0.0 \quad 0.0$

87
141

$88 \quad 1.0 \quad 0$

0

2.837000 E O0 2.557001E 013.630000 E 01 0

4.935999E-05 4.371000E+04
0.0
0.0
0.0

CE 141

2. $506000 \mathrm{E}-07$

0.0

$89 \quad 1.0$

0

4.697000E O2 1.167000E-01 8.320000E-05 0

1.587000 E $05 \quad 4.884000$ E 036.130000 E 00 00

1.701000 E O4 4.300999E 012.170000 E 01 0

2.419000E O2 1.247000E-02 9.410000E-06 0

1.345000 E $03 \quad 5.342000 E-01 \quad 1.660000$ E-01 00

4.517000 E O4 2.494000I: 031.690000 E 03 BA 142

$1.050000 E-03 \quad 3.762000 E+04$

0.0

90

$0.0 \quad 0.0$

$\begin{array}{ll}4.387000 E+04 \\ 0.0 & 0.0\end{array}$

0

0

1.487000 E O2 3.294000E-03 3.380000E-06 
LA 142

1.255000E-04 3.883000E+04

0.0

$0.0 \quad 0.0$

7.907000E $02 \quad 8.535999 E-02 \quad 3.880000$ E-02 $\begin{array}{lllllll}91 & 3 & 0 & 0 & 0 & 0 & 0\end{array}$

CE 143

$6.030000 E-063.552000 E+04$

$\begin{array}{lll}0.0 & 0.0 & 0.0\end{array}$ $\begin{array}{lllll}92 & 3 & 93 & 1.0 & 0\end{array}$

PR 143

$5.854000 E-073.467000 E+04$

$\begin{array}{lll}0.0 & 0.0 & 0.0\end{array}$ $\begin{array}{lllll}93 & 3 & 0 & 0 & 0\end{array}$

CE 144

$2.766000 E-08 \quad 2.294000 E+04$

$\begin{array}{lll}0.0 & 0.0 & 0.0\end{array}$

$0.0 \quad 9.716000 E \quad 05 \quad 4.286000 E \quad 05 \quad 1.790000 E \quad 05$ PR 144

$6.676000 E-042.302000 E+04$

0.0

$0.0 \quad 0.0$

$9.972000 E_{03} 2.334000 E \quad 01 \quad 1.720000 E \quad 01$ 95 3 0

0

7.098000E-07 $1.733000 E+04$

$\begin{array}{lll}0.0 & 0.0 & 0.0\end{array}$ PM $\begin{array}{llll}96 & 3 & 97 & 1.0\end{array}$

$8.718001 E-094.881000 E+03$

0.0

$0.0 \quad 0.0$

0

3.506000 E O4 1.168000E O3 4.690000E 02 0

ND $\begin{array}{ll}97 \\ 149\end{array}$

9.6649 ?: $: 05-051.121000 E+04$

0.0

$\begin{array}{ll}0.0 & 0.0\end{array}$

$\begin{array}{lllll}98 & 3 & 0 & 0 & 0\end{array}$

PM 149

3.625000E-06 1.122000E+04

0.0

$0.0 \quad 0.0$

0.0
0

99

PM 151

$6.875000 E-06 \quad 6.828000 E+03$

0.0

0.0

0.0

1.272000 E $02 \quad 3.763000$ E-03 1.560000E-03 100

SM 151

$2.168000 E-107.226000 E+01$

0.0

$0.0 \quad 0.0$ 101

30.0

0

EU 155

$1.292000 E-082.973000 E+02$

0.0

102

$0.0 \quad 0.0$

2.759000 E O4 6.592000E O2 7.620000E O2 0

6.602000 E O4 8.368000 E 047.870000 E 03 0

0.0

$3.676001 \mathrm{E} \quad 02 \quad 0.0000000000$

EU 156

$5.347000 E-07 \quad 1.575000 E+03$

0.0

0.0

0.0 103 3 0

GD 159

$1.069000 E-053.083000 E+02$

0.0

0.0

0.0 104

U 235

3.095999E-17 9.169000E-05

0.0

105

0.0

0.0

7.206000 E $03 \quad 3.439000$ E $01 \quad 4.870000$ E 00 0

3.939000 E O3 8.496000 E OO 1.420000 E OO 0

4.454000 E O4 8.589000E O4 1.480000 E 04 0

9.463000 E O4 1.005000 E O5 1.430000 E O4 0

8.556000 E O4 1.927000 E $03 \quad 1.480000$ E 03 0

0.0

6.478000 E $02 \quad 0.0000000000$

0

4.896000 E $07 \quad 1.001000$ E 070.0 
U 237

$1.188000 E-06 \quad 3.456000 E+03$

$\begin{array}{llll}0.0 & 0.0 & 0.0\end{array}$

1.020000 E 043.673000 E 010.0

$\begin{array}{lllllll}106 & 3 & 107 & 1.0 & 0 & 0 & 0\end{array}$

NP 237

1.027000E-14 2.150000E-03

0.0

$\begin{array}{lll}0 & 0.0 & 0.0\end{array}$ 107

PU 238

$2.431000 E-102.775000 E+01$

0.0

$0.0 \quad 0.0$

$\begin{array}{lrrrr}108 & 5 & 0 & 0 & 0\end{array}$

NP 238

$3.819000 E-067.741000 E+02$

0.0

$109 \quad 3 \quad 0.0108 \quad 1.00 .0$

$0.0 \quad 1.016000$ E 042.962000 E 028.000000 E 00

PU 239

$9.012000 E-13 \quad 1.227000 E+02$

0.0

$\begin{array}{llllr}0 & 0.0 & 0.0 \\ 110 & 5 & 105 & 1.0 & 0\end{array}$

U 239

4. $916000 E-04$ 8.928000E+05

0.0

$0.0 \quad 0.0$

$\begin{array}{llll}111 & 3 & 112 & 1.0\end{array}$

NP 239

3.442000E-06 8.293000E+05

0.0

$\begin{array}{lll}0.0 & 0.0\end{array}$

$\begin{array}{lllll}112 & 3 & 110 & 1.0 & 0\end{array}$

PU 240

3.342000E-12 7.235000E+01

0.0

0.0

0.0 113

PU 241

$1.671000 E-093.779000 E+03$

0.0

$0.0 \quad 0.0$

$\begin{array}{llll}114 & 5 & 115 & 1.0\end{array}$

AM 241

4.803000E-11 1.571000E+01

0.0

$\begin{array}{lll}4.003000 E-11 & 1.571000 E+01 & 0.0\end{array}$

$\begin{array}{lllll}115 & 3 & 107 & 1.0 & 0\end{array}$

PU 242

5.812001E-14 2.110000E-02

0.0

0.0

$\begin{array}{lr}0 & 0.0 \\ 0 & 0\end{array}$

116

50

CM 242

4.936000E-08 9.018000E+02

0.0

$\begin{array}{ll}0.0 & 0.0\end{array}$

$\begin{array}{llll}117 & 3 & 108 & 1.0\end{array}$

AM $242 M$

$1.432000 E-101.457000 \bar{i}+00$

0.0

0.0

0.0

118

CM 243

300

0

$6.855001 E-103.528000 E-01$

0.0

$0.0 \quad 0.0$ 119

AM 243

2.766000E-12 5.306000E-02

U. U

$\begin{array}{ll}0.00 & 0.0\end{array}$ 120

5.215000E $07 ? .693000$ E 09 1.470000E 08

1.825000E $08 \quad 2.737000$ E 093.870000 E 08 0

1.716000E 08 3.188000E 09 4.310000E 08 00
0.0
0.0
0.0

$0 \quad 0$

4.702000E 032.866000 E O1 2.820000E 00 0

1.716000E 08 3.183000E $09 \quad 4.30$ UOOOE 08

1.517000 E O5 6.407000E 073.280000 E 06 0

0

6.062000 E 07 1.013000E O9 3.590000E 08 0

1.651000E $08 \quad 2.954000$ E O9 4.150000E 08

3.923000 E 071.483000 E 071.510000 E 07

2.443000E 07 1.019000E O9 3.460000E 08 0

6.312000 E 077.856000 E 082.970000 E 08 0

5.747000E O7 1.013000E O9 3.470000E O8 
CM 244

$1.248000 E-091.497000 E+00$

0.0 121

0.0

0.0

AM 244 3 $113 \quad 1.0$

4.431000E-04 3.186000E+00

0.0 122

0.0

0.0

0.0

0

$2.985000 E \quad 03 \quad 0.0000000000$

P.062000E 075.904000 E 082.540000 E 08 0

$\begin{array}{lllll}121 & 1.0 & 0 & 0 & 0\end{array}$


APPENDIX H

DATABASE FILE STRUCTURES 
Structure for database: A:timeind.dbf Number of data records: Date of last update Field Field Name Type $03 / 07 / 90$

1 POWER

2 HELE

3 HORG

4 HPART

5 NELE

6 NORG

7 NPART

8 NAELE

9 NAORG

10 NAPART

11 SELE

12 SORG

13 SPART

14 PELE

15 PORG

16 PPART

** Total

Numeric

Numeric

Numeric

Numeric

Numeric

Numeric

Numeric

Numeric

Numeric

Numeric

Numeric

Numeric

Numeric

Numeric

Numeric

Numeric

Width Dec

$\begin{array}{ll}9 & 2 \\ 7 & 4\end{array}$

$7 \quad 4$

$7 \quad 4$

74

64

$7 \quad 4$

$7 \quad 4$

$7 \quad 4$

$7 \quad 4$

$7 \quad 4$

$7 \quad 4$

$\begin{array}{ll}7 & 4\end{array}$

74

$7 \quad 4$

114 


\begin{tabular}{|c|c|c|c|c|}
\hline $\begin{array}{l}\text { Struc } \\
\text { Numbe } \\
\text { Date }\end{array}$ & $\begin{array}{l}\text { dre for dat } \\
\text { of data re } \\
\text { E last upda }\end{array}$ & $\begin{array}{l}\text { pase: } A: \\
\text { ords: } \\
\text { : }\end{array}$ & $\begin{array}{l}\text { et. } d b f \\
0 \\
190\end{array}$ & \\
\hline Field & Field Name & Type & width & Dec \\
\hline 1 & BLDGAREA & Numeric & 9 & 2 \\
\hline 2 & BLDGHT & Numeric & 7 & 2 \\
\hline 3 & RELHT & Numeric & 7 & 2 \\
\hline 4 & EFFVERTVEL & Numeric & 7 & 2 \\
\hline 5 & EFFFLOW & Numeric & 7 & 2 \\
\hline 6 & HORIZDIST & Numeric & 7 & 2 \\
\hline 7 & RECEPTHT & Numeric & 7 & 2 \\
\hline 8 & WINDSPEED & Numeric & 7 & 2 \\
\hline 9 & VERTCLASS & Numeric & 1 & \\
\hline 10 & HORIZCLASS & Numeric & 1 & \\
\hline 11 & TSTEPBEG & Numeric & 7 & 2 \\
\hline 12 & TSTEPEND & Numeric & 7 & 2 \\
\hline 13 & FLOWIN I & Numeric & 11 & 4 \\
\hline 14 & FLOWIN2 & Numeric & 11 & 4 \\
\hline 15 & FLOWIN 3 & Numeric & 11 & 4 \\
\hline 16 & FILTIELE & Numeric & 7 & 4 \\
\hline 17 & FILT2ELE & Numeric & 7 & 4 \\
\hline 18 & FILT3ELE & Numeric & 7 & 4 \\
\hline 19 & FILTFLOWI & Numeric & 11 & 4 \\
\hline 20 & FILTFLOW2 & Numeric & 11 & 4 \\
\hline 21 & FILTFLOW3 & Numeric & 11 & 4 \\
\hline 22 & ST1 & Numeric & 7 & 4 \\
\hline 23 & ST2 & Numeric & 7 & 4 \\
\hline 24 & $\mathrm{ST} 3$ & Numeric & 7 & 4 \\
\hline 25 & STFILTI & Numeric & 7 & 4 \\
\hline 26 & STFILT2 & Numeric & 7 & 4 \\
\hline 27 & STFILT 3 & Numeric & 7 & 4 \\
\hline 28 & CRVOLUME & Numeric & 9 & 2 \\
\hline 29 & FILT1ORG & Numeric & 7 & 4 \\
\hline 30 & FILTIPART & Numeric & 7 & 4 \\
\hline 31 & FILT2ORG & Numeric & 7 & 4 \\
\hline 32 & FILT2PART & Numeric & 7 & 4 \\
\hline 33 & FILT3ORG & Numeric & 7 & 4 \\
\hline 34 & FILT3 PART & Numeric & 7 & 4 \\
\hline 35 & OCCFAC & Numeric & 7 & 4 \\
\hline Tot & n & & 26 & \\
\hline
\end{tabular}




\section{APPENDIX I}

SAMPLE OUTPUT FROM CONHAB

$=$ 
INPUT DATA FILES FOR THIS CASE:

Meteorology and system flow data file: EXAMPLE.DAT Nuclear data file:

Unfiltered source file \#1:

Unfiltered source file \#2:

ICRP. 02

CRHFPFP1.OUT

CRHFPFP2.OUT

Source to filtered intake \#1:

CRHTACT1.DAT

Source to filtered intake \#2 (recirc): CRHTACT2.DAT

TIME INDEPENDENT DATA:

Reactor Power Level (MWt):

ISOTOPIC GROUP

HALOGENS

NOBLES

SODIUMS

SOLIDS

PLUTONIUMS
ELEMENTAL

0.9200

1.0000

1.0000

1.0000

1.0000
2700.00000000

FORM FRACTIONS ORGANIC

0.0500

0.0000

0.0000

0.0000

0.0000
PARTICULATES

0.0400

0.0000

0.0000

0.0000

0.0000 
TIME STEP START: $\quad 0.00000000 E-01$
TIME STEP END:
0.13333334

Building cross sectional area $\left(m^{\wedge} 2\right)$ :

Building height $(m)$ :

Release height $(\mathrm{m})$ :

Effluent vertical velocity $(\mathrm{m} / \mathrm{s})$ :

Effluent flow rate $\left(\mathrm{m}^{\wedge} 3 / \mathrm{s}\right)$ :

Horizontal distance to receptor $(m)$ :

Air intake height $(\mathrm{m})$ :

Windspeed $(\mathrm{m} / \mathrm{s})$ :

Vertical dispersion class:

Horizontal dispersion class:

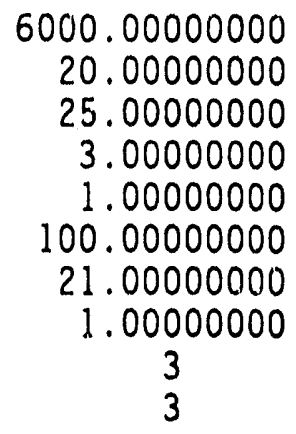

Flow in from unfiltered source $1\left(\mathrm{~m}^{\wedge} 3 / \mathrm{s}\right): 0.00000000 \mathrm{E}-01$

Flow in from unfiltered source $2\left(\mathrm{~m}^{\wedge} 3 / \mathrm{s}\right): 0.00000000 \mathrm{E}-01$

Filtered intake flow source $1\left(\mathrm{~m}^{\wedge} 3 / \mathrm{s}\right): \quad 0.00000000 \mathrm{E}-01$

Filter efficiency \#1 (ele,org,part frac): $0.9900 \quad 0.9000 \quad 0.9900$

Recirculation flow rate $\left(\mathrm{m}^{\wedge} 3 / \mathrm{s}\right)$ :

5.66039991

Recirc filter efficiency (e,0,p frac): $0.9900 \quad 0.9000$

Filtered intake flow 2 (feeds recirc):

Intake 2 filter efficiency (e,0,p frac):

Bottled air flow rate $\left(m^{\wedge} 3 / s\right)$ :

Control room volume $\left(m^{\wedge} 3\right)$ :

0.56599998

$\begin{array}{lll}0.9900 & 0.9000 & 0.9900\end{array}$

$0.00000000 E-01$

8490.00000000

$\begin{array}{ccccccc}\begin{array}{c}\text { END TIME } \\ \text { HOURS }\end{array} & \begin{array}{c}\text { WH BODY } \\ \text { REM }\end{array} & \begin{array}{c}\text { SKIN } \\ \text { REM }\end{array} & \begin{array}{c}\text { CUMULATIVE } \\ \text { THYROID } \\ \text { REM }\end{array} & \begin{array}{l}\text { LOSE } \\ \text { REM }\end{array} & \begin{array}{l}\text { BONE } \\ \text { REM }\end{array} & \begin{array}{c}\text { LIVER } \\ \text { REM }\end{array} \\ 1.333 E-01 & 2.525 E-04 & 2.842 E-02 & 1.887 E-03 & 3.549 E-04 & 4.510 E-06 & 7.670 E-06\end{array}$


$\begin{array}{ll}\text { TIME STEP START: } & 0.13333334 \\ \text { TIME STEP END: } & 2.00000000\end{array}$

Buflding cross sectional area $\left(m^{\wedge} 2\right)$ : $\quad 6000.00000000$

Building height (m):

Release height (m):

Effluent vertical velocity $(\mathrm{m} / \mathrm{s})$ :

20.00000000

25.00000000

3.00000000

Effluent flow rate $\left(m^{\wedge} 3 / s\right)$ :

1.00000000

Horizontal distance to receptor (m):

100.00000000

Air intake height $(\mathrm{m})$ :

21.00000000

Windspeed $(\mathrm{m} / \mathrm{s})$ :

Vertical dispersion class:

1.00000000

Horizontal dispersion class:

3

3

Flow in from unfiltered source $1\left(\mathrm{~m}^{\wedge} 3 / \mathrm{s}\right): 0.00000000 \mathrm{E}-01$

Flow in from unfiltered source $2\left(\mathrm{~m}^{\wedge} 3 / \mathrm{s}\right): 0.00000000 \mathrm{E}-01$

Filtered intake flow source $1\left(\mathrm{~m}^{\wedge} 3 / \mathrm{s}\right): \quad 0.00000000 \mathrm{E}-01$

Filter efficiency \#1 (ele,org,part. frac): $0.9900 \quad 0.9000$

0.9900

Recirculation flow rate $\left(\mathrm{m}^{\wedge} 3 / \mathrm{s}\right)$ :

5.66039991

Recirc filter efficiency (e,o,p frac):

Filtered intake flow 2 (feeds recirc):

Intake 2 filter efficiency (e,0,p frac):

Bottled air flow rate $\left(m^{\wedge} 3 / s\right)$ :

Control room volume $\left(m^{\wedge} 3\right)$ :

$0.9900 \quad 0.9000$

0.9900

$0.9900 \quad 0.9000$
$0.00000000 E-01$

0.9900

$0.00000000 \mathrm{E}-01$

8490.00000000

$\begin{array}{cclcccc}\text { END TIME } & \text { WH BODY } & \text { SKIN } & \text { CUMULATIVE } & \text { DOSE } \\ \text { HOURS } & \text { REM } & \text { REM } & \text { REM } & \text { REM } & \text { BONE } & \text { LIVER } \\ \text { HOMEM } & \text { REM }\end{array}$

$2.000 E+00 \quad 4.303 E-02 \quad 4.843 E+00 \quad 9.655 E-02 \quad 6.049 E-02 \quad 2.321 E-04 \quad 3.941 E-04$ 
TIME STEP START:

TIME STEP END:
2.00000000

8.00000000

Building cross sectional area $\left(m^{\wedge} 2\right)$ :

Building height $(\mathrm{m})$ :

Release height $(\mathrm{m})$ :

Effluent vertical velocity $(\mathrm{m} / \mathrm{s})$ :

Efflueint flow rate $\left(m^{\wedge} 3 / s\right)$ :

Horizontal distance to receptor $(m)$ :

Air intake height (m):

Windspeed $(\mathrm{m} / \mathrm{s})$ :

Vertical dispersion class:

Horizontal dispersion class:

Flow in from unfiltered source $1\left(\mathrm{~m}^{\wedge} 3 / \mathrm{s}\right)$ :

Flow in from unfiltered source $2\left(\mathrm{~m}^{\wedge} 3 / \mathrm{s}\right)$ :

Filtered intake flow source $1\left(m^{\wedge} 3 / s\right)$ :

Filter efficiency \#1 (ele,org, part frac):

Recirculation flow rate $\left(\mathrm{m}^{\wedge} 3 / \mathrm{s}\right)$ :

Recirc filter efficiency $(e, 0, p$ frac):

Filtered intake flow 2 (feeds recirc):

Intake 2 filter efficiency (e, $0, p$ frac):

Bottled air flow rate $\left(m^{\wedge} 3 / s\right)$ :

Control room volume $\left(m^{\wedge} 3\right)$ :

6000.00000000

20.00000000

25.00000000

3.00000000

1.00000000

100.00000000

21.00000000

1.00000000

3

3

$0.00000000 E-01$

$0.00000000 \mathrm{E}-01$

$0.00000000 E-01$
0.9900
5.66039991
0.9900
0.9900
0.28299999
0.9900
$0.9900 \quad 0.9000$
0.9900
8490.00000000

$\begin{array}{ccccccc}\text { END TIME } & \text { WH BODY } & \text { SKIN } & \text { CUMULATIVE DOSE } \\ \text { HOURS } & \text { REM } & \text { REM } & \text { REID } & \text { LUNG } & \text { BONE } & \text { LIVER } \\ \text { REM } & \text { REM } & \text { REM } & \text { REM } & \text { REM }\end{array}$

$\begin{array}{llllllll}8.000 E+00 & 3.118 E-01 & 3.727 E+01 & 5.309 E-01 & 4.497 E-01 & 1.255 E-03 & 2.062 E-03\end{array}$ 
TIME STEP START:

8.00000000

TIME STEP END:

24.00000000

Butlding cross sectional area $\left(m^{\wedge} 2\right)$ :

Building height (m):

6000.00000000

Release height (m):

20.00000000

Efiluent vertical velocity $(\mathrm{m} / \mathrm{s})$ :

Effluent flow rate $\left(m^{\wedge} 3 / s\right)$ :

25.00000000

3.00000000

1.00000000

Horlzontal distance to receptor $(m)$ :

100.00000000

Air intake height (m):

Windspeed $(\mathrm{m} / \mathrm{s})$ :

Vertical dispersion class:

Horizontal dispersion class:

21.00000000

1.00000000

3

Flow in from unfiltered source $1\left(m^{\wedge} 3 / s\right): 0.00000000 E-01$

Flow in from unfiltered source $2\left(\mathrm{~m}^{\wedge} 3 / \mathrm{s}\right): 0.00000000 \mathrm{E}-01$

Filtered intake flow source $1\left(m^{\wedge} 3 / s\right)$ :

$0.00000000 E-01$

Filter efficiency \#1 (ele, org,part frac): 0.9900

Recirculation flow rate $\left(\mathrm{m}^{\wedge} 3 / \mathrm{s}\right)$ :

$0.9000 \quad 0.9900$

Recirc filter efficiency (e, $0, p$ frac):

Filtered intake flow 2 (feeds recirc):

5.66039991

$0.9900 \quad 0.9000$

0.9900

Intake 2 filter efficiency $(e, 0, p$ frac):

Bottled air flow rate $\left(m^{\wedge} 3 / s\right)$ :

Control room volume $\left(m^{\wedge} 3\right)$ :

0.28299999

$0.9900 \quad 0.9000 \quad 0.9900$

$0.00000000 \mathrm{E}-01$

8490.00000000

$\begin{array}{ccccccc}\text { END TIME } & \text { WH BODY } & \text { SKIN } & \text { CUMULATIVE } & \text { DOSE } \\ \text { HOURS } & \text { REM } & \text { REM } & \text { REM } & \text { REM } & \text { BONE } & \text { LIVER } \\ \text { REM } & \text { REM }\end{array}$

$2.400 E+01 \quad 1.841 E+00 \quad 2.500 E+02 \quad 3.528 E+00 \quad 2.850 E+00 \quad 8.176 E-03 \quad 1.296 E-02$ 
TIME STEP START:

TIME STEP END:
24.00000000

48.00000000

Butlding cross sectional area $\left(m^{\wedge} 2\right)$ :

Bullding height (m):

Release height (m):

Effluent vertical veloctty $(\mathrm{m} / \mathrm{s})$ :

Effluent flow rate $\left(\mathrm{m}^{\wedge} 3 / \mathrm{s}\right)$ :

6000.00000000

20.00000000

25.00000000

3.00000000

1.00000000

Horizontal distance to receptor $(\mathrm{m})$ :

100.00000000

Air intake height (m):

Windspeed $(\mathrm{m} / \mathrm{s})$ :

Verticial dispersion class:

Horlzontal dispersion class:

21.00000000

1.00000000

3

3

Flow in from unfiltered source $1\left(\mathrm{~m}^{\wedge} 3 / \mathrm{s}\right): 0.00000000 \mathrm{E}-01$

Flow in from unflitered source $2\left(\mathrm{~m}^{\wedge} 3 / \mathrm{s}\right): 0.00000000 \mathrm{E}-01$

Filtered intake flow source $1\left(\mathrm{~m}^{\wedge} 3 / \mathrm{s}\right): \quad 0.00000000 \mathrm{E}-01$

Filter efficiency \#1 (ele,org, part frac): $0.9900 \quad 0.9000$

Recirculation flow rate $\left(\mathrm{m}^{\wedge} 3 / \mathrm{s}\right)$ :

Recirc fllter efflctency (e,0,p 5.66039991

Filtered intake flow 2 (feeds rectrc):

$0.9900 \quad 0.9000$

0.9900

Fllered intake flow 2 (feeds recirc):

0.28299999

Bottled air flow rate $\left(\mathrm{m}^{\wedge} 3 / \mathrm{s}\right)$ :

Control room volume $\left(\mathrm{m}^{\wedge} 3\right)$ :

0.9900

0.9900
0.23590000
8490.00000000
$0.9900 \quad 0.9000$

\begin{tabular}{|c|c|c|c|c|c|c|}
\hline & & & CUMULATIV & DOSE & & \\
\hline $\begin{array}{c}\text { END TIME } \\
\text { HOURS }\end{array}$ & $\begin{array}{c}\text { WH BODY } \\
\text { REM }\end{array}$ & $\begin{array}{l}\text { SKIN } \\
\text { REM }\end{array}$ & $\begin{array}{c}\text { THYROID } \\
\text { RFM }\end{array}$ & $\begin{array}{l}\text { LUNG } \\
\text { REM }\end{array}$ & BONE & LIVER \\
\hline
\end{tabular}

$\begin{array}{llllll}4.800 E+01 & 3.016 E+00 \quad 4.473 E+02 & 1.085 E+01 & 5.015 E+00 & 2.452 E-02 & 3.754 E-02\end{array}$ 
TIME STEP START: $\quad 696.00000000$

TIME STEP END: $\quad 720.00000000$

Bullding cross sectional area $\left(m^{\wedge} 2\right): \quad 6000.00000000$

Butlding height $(\mathrm{m})$ :

20.00000000

25.00000000

Release height (m):

3.00000000

1.00000000

Effluent flow rate $\left(\mathrm{m}^{\wedge} 3 / \mathrm{s}\right)$ :

Horizontal distance to receptor $(m)$ :

100.00000000

Air intake height (m):

Windspeed $(\mathrm{m} / \mathrm{s})$ :

Vertical dispersion class:

Horizontal dispersion class:

21.00000000

1.00000000

3

Flow in from unfiltered source $1\left(\mathrm{~m}^{\wedge} 3 / \mathrm{s}\right): 0.00000000 \mathrm{E}-01$

Flow in from unfiltered source $2\left(\mathrm{~m}^{\wedge} 3 / \mathrm{s}\right): 0.00000000 \mathrm{E}-01$

Filtered intake flow source $1\left(\mathrm{~m}^{\wedge} 3 / \mathrm{s}\right): \quad 0.00000000 \mathrm{E}-01$

Filter efficiency \#1 (ele,org, part frac): $0.9900 \quad 0.9000 \quad 0.9900$

Recirculation flow rate $\left(m^{\wedge} 3 / s\right)$ :

Recirc filter efficiency (e,0,p frac): $\begin{array}{llll}0.9900 & 0.9000 & 0.9900\end{array}$

Filtered intake flow 2 (feeds recirc):

Intake 2 filter efficiency (e,0,p frac):

Bottled air flow rate $\left(\mathrm{m}^{\wedge} 3 / \mathrm{s}\right)$ :

Control room volume $\left(m^{\wedge} 3\right)$ :

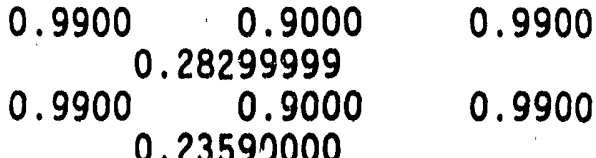

8490.00000000

\begin{tabular}{|c|c|c|c|c|c|c|}
\hline & & & CUMULATII & DOSE & & \\
\hline $\begin{array}{l}\text { ND TIME } \\
\text { HOURS }\end{array}$ & $\begin{array}{c}\text { WH BODY } \\
\text { REM }\end{array}$ & $\begin{array}{l}\text { SKIN } \\
\text { REM }\end{array}$ & $\begin{array}{l}\text { THYROID } \\
\text { REM }\end{array}$ & $\begin{array}{l}\text { LUNG } \\
\text { REM }\end{array}$ & $\begin{array}{l}\text { BONE } \\
\text { REM }\end{array}$ & $\begin{array}{c}\text { LIVER } \\
\text { REM }\end{array}$ \\
\hline
\end{tabular}

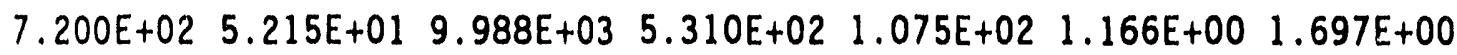

SUMMARY

ORGAN DOSE (REM)

WHOLE BODY DOSE: $\quad 52.14751430$

SKIN DOSE: $\quad 9987.56836000$

THYROID DOSE: $\quad 530.98608400$

LUNG DOSE: $\quad 107.54503600$

BONE DOSE: $\quad 1.16612422$

LIVER DOSE: $\quad 1.69656670$

$\rightarrow$ End of calculation $<-$ - 


\section{Dose versus Time}

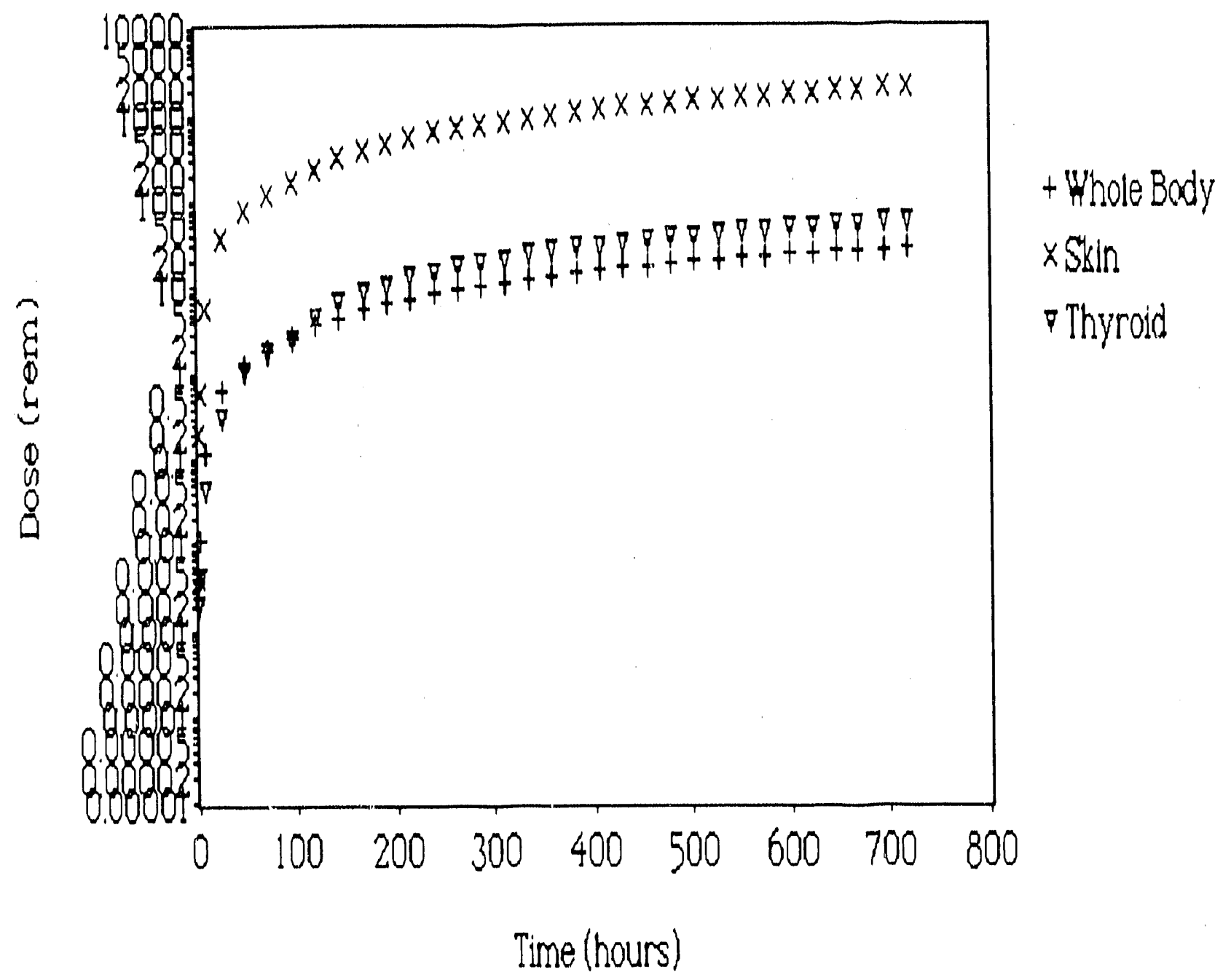


APPENDIX $\mathrm{J}$

SAMPLE OUTPUT FROM CHEM 


\section{CHEM CODE}

\begin{tabular}{|c|c|c|c|}
\hline $\begin{array}{l}\text { TIME } \\
\text { min } \\
00000000 \mathrm{E}-01 \\
5.00000000 \\
10.00000000 \\
15.00000000 \\
20.00000000 \\
25.00000000 \\
30.00000000 \\
35.00000000 \\
40.00000000 \\
45.00000000 \\
50.00000000 \\
55.00000000 \\
60.00000000 \\
65.00000000 \\
70.00000000 \\
75.00000000 \\
80.00000000 \\
85.00006000 \\
90.00000000 \\
95.00000000 \\
100.00000000 \\
105.00000000 \\
110.00000000 \\
115.00000000 \\
120.00000000 \\
125.00000000 \\
130.00000000 \\
135.00000000 \\
140.00000000 \\
145.00000000 \\
150.00000000 \\
155.00000000 \\
160.00000000 \\
165.00000000 \\
170.00000000 \\
175.00000000 \\
180.00000000 \\
185.00000000 \\
190.00000000 \\
195.00000000 \\
200.00000000 \\
205.00000000 \\
210.00000000 \\
215.00000000 \\
220.00000000 \\
225.00000000 \\
230.00000000 \\
235.00000000 \\
240.00000000 \\
245.00000000 \\
250.00000000 \\
255.00000000\end{array}$ & $\begin{array}{r}\text { CONCENTRATION } \\
\text { g/m^3 } \\
1.37873400 E-07 \\
1.63820312 E-06 \\
8.91709806 E-06 \\
2.96821672 E-05 \\
7.16643917 E-05 \\
1.38497475 E-04 \\
2.27981101 E-04 \\
3.33703135 E-04 \\
4.48164239 E-04 \\
5.63941547 E-04 \\
6.74826617 E-04 \\
7.76032743 E-04 \\
8.65296286 E-04 \\
9.41607810 E-04 \\
1.00457808 E-03 \\
9.48029396 E-04 \\
8.94663914 E-04 \\
8.44302413 E-04 \\
7.96775799 E-04 \\
7.51924526 E-04 \\
7.09597953 E-04 \\
6.69653993 E-04 \\
6.31958537 E-04 \\
5.96384984 E-04 \\
5.62813890 E-04 \\
5.31132566 E-04 \\
5.01234608 E-04 \\
4.73019609 E-04 \\
4.46392864 E-04 \\
4.21264966 E-04 \\
3.97551543 E-04 \\
3.75172967 E-04 \\
3.54054122 E-04 \\
3.34124081 E-04 \\
3.15315905 E-04 \\
2.97566468 E-04 \\
2.80816166 E-04 \\
2.65008741 E-04 \\
2.50091136 E-04 \\
2.36013264 E-04 \\
2.22727846 E-04 \\
2.10190279 E-04 \\
1.98358466 E-04 \\
1.87192680 E-04 \\
1.76655420 E-04 \\
1.667111310 E-04 \\
1.57326969 E-04 \\
1.48470877 E-04 \\
1.40113305 E-04 \\
1.32226196 E-04 \\
1.24783051 E-04 \\
1.17758893 E-04\end{array}$ & 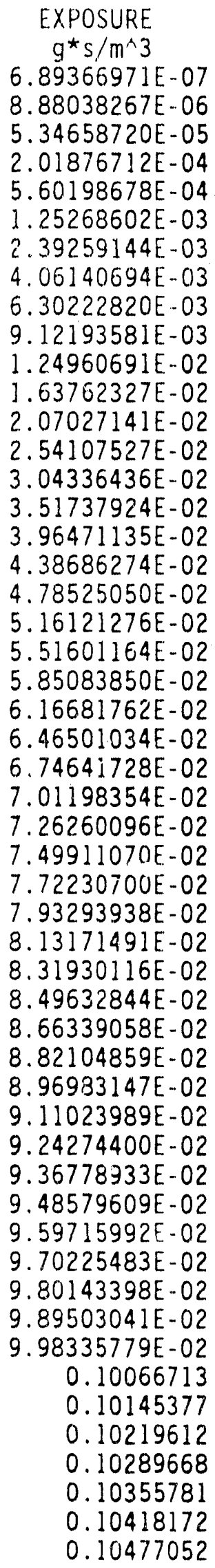 & $\begin{array}{c}\text { MEAN CONC } \\
\text { g/m^3 } \\
1.37873400 E-07 \\
8.88038244 E-07 \\
3.56439136 E-06 \\
1.00938360 E-05 \\
2.24079467 E-05 \\
4.17562005 E-05 \\
6.83597536 E-05 \\
1.01535174 E-04 \\
1.40049509 E-04 \\
1.82438715 E-04 \\
2.27201250 E-04 \\
2.72937206 E-04 \\
3.18503298 E-04 \\
3.63010768 E-04 \\
4.05781902 E-04 \\
4.39672411 E-04 \\
4.66436642 E-04 \\
4.87429206 E-04 \\
5.03710588 E-04 \\
5.16121276 E-04 \\
5.25334443 E-04 \\
5.31894388 E-04 \\
5.36245003 E-04 \\
5.38750843 E-04 \\
5.39713365 E-04 \\
5.39383327 E-04 \\
5.37970453 E-04 \\
5.35650761 E-04 \\
5.32572914 E-04 \\
5.28862642 E-04 \\
5.24626754 E-04 \\
5.19956346 E-04 \\
5.14929008 E-04 \\
5.09611215 E-04 \\
5.04059892 E-04 \\
4.98323992 E-04 \\
4.92445426 E-04 \\
4.86460223 E-04 \\
4.80399467 E-04 \\
4.74289816 E-04 \\
4.681541477 E-04 \\
4.62012133 E-04 \\
4.55880654 E-04 \\
4.49774117 E-04 \\
4.43704805 E-04 \\
4.37683193 E-04 \\
4.31718159 E-04 \\
4.25817154 E-04 \\
4.19986463 E-04 \\
4.14231239 E-04 \\
4.08555759 E-04 \\
4.02963546 E-04\end{array}$ \\
\hline
\end{tabular}


260.00000000

265.00000000

270.00000000

$1.11130132 E-04$

$1.04874511 \mathrm{E}-04$

9.89710243E-05
0.10532617

0.10585054

0.10634539

$3.97457246 \mathrm{E}-04$

3. $92039045 \mathrm{E}-04$

3.86710512E-04

A: $\backslash>$ 
Toxic Gas Analysis

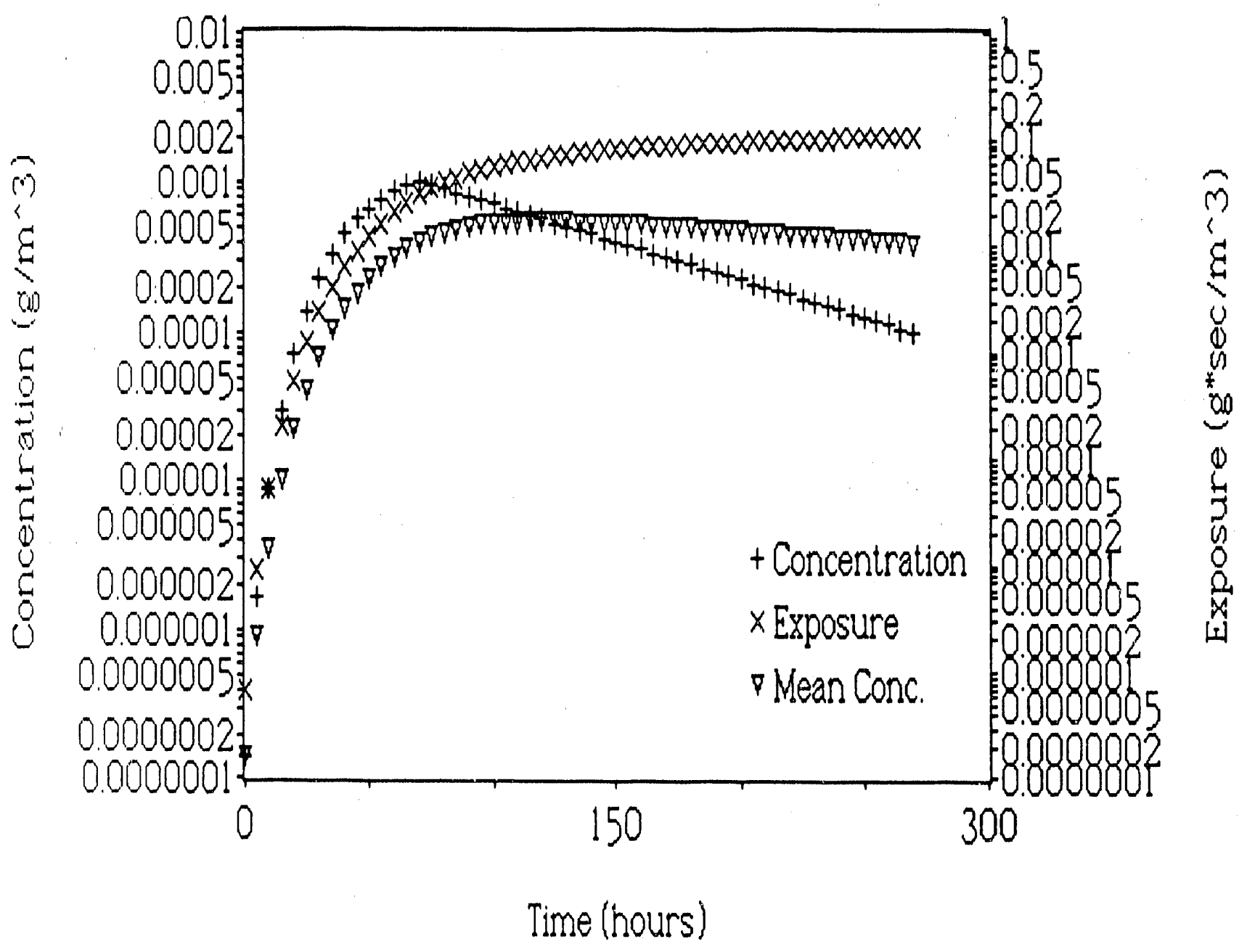




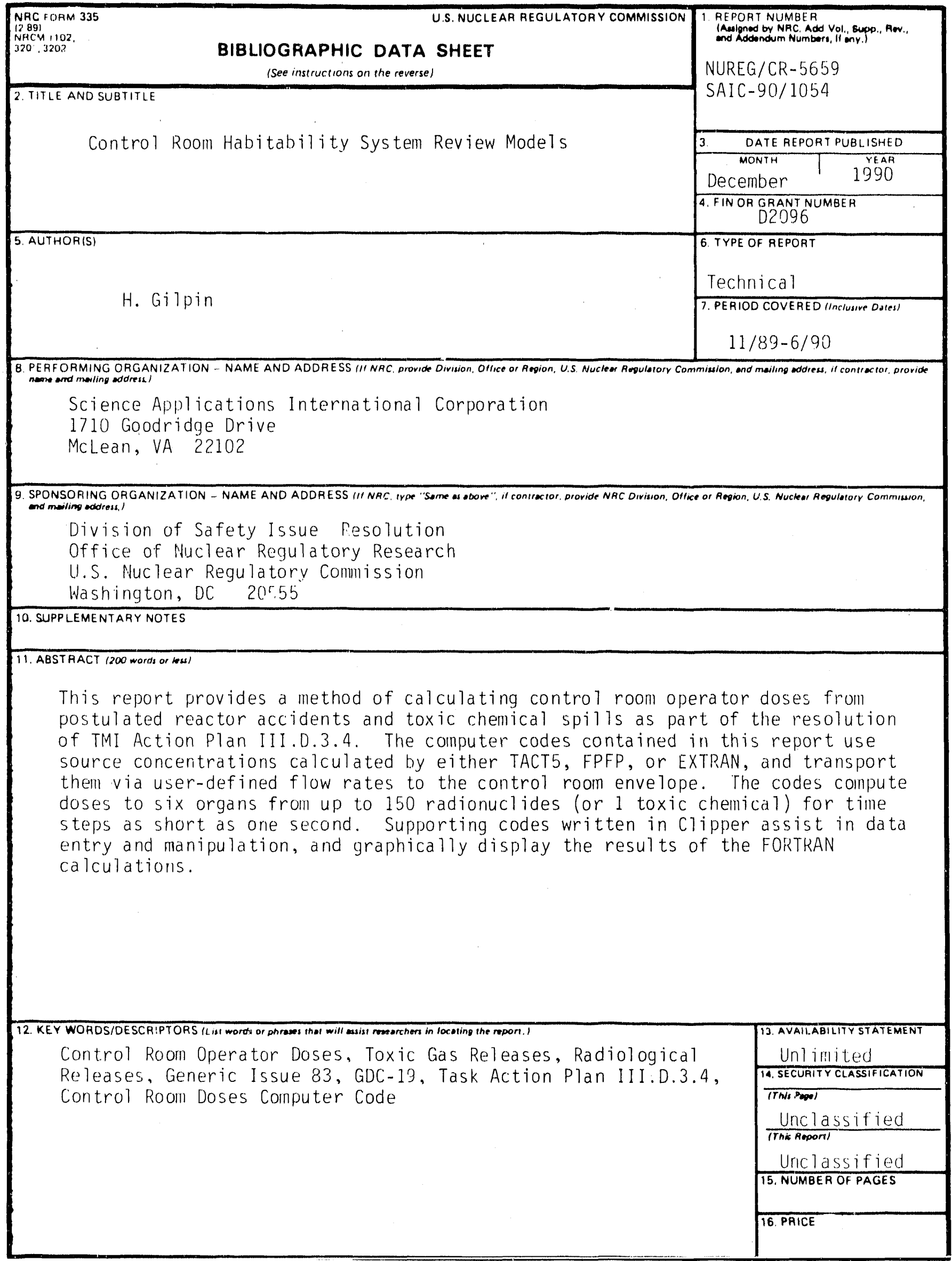



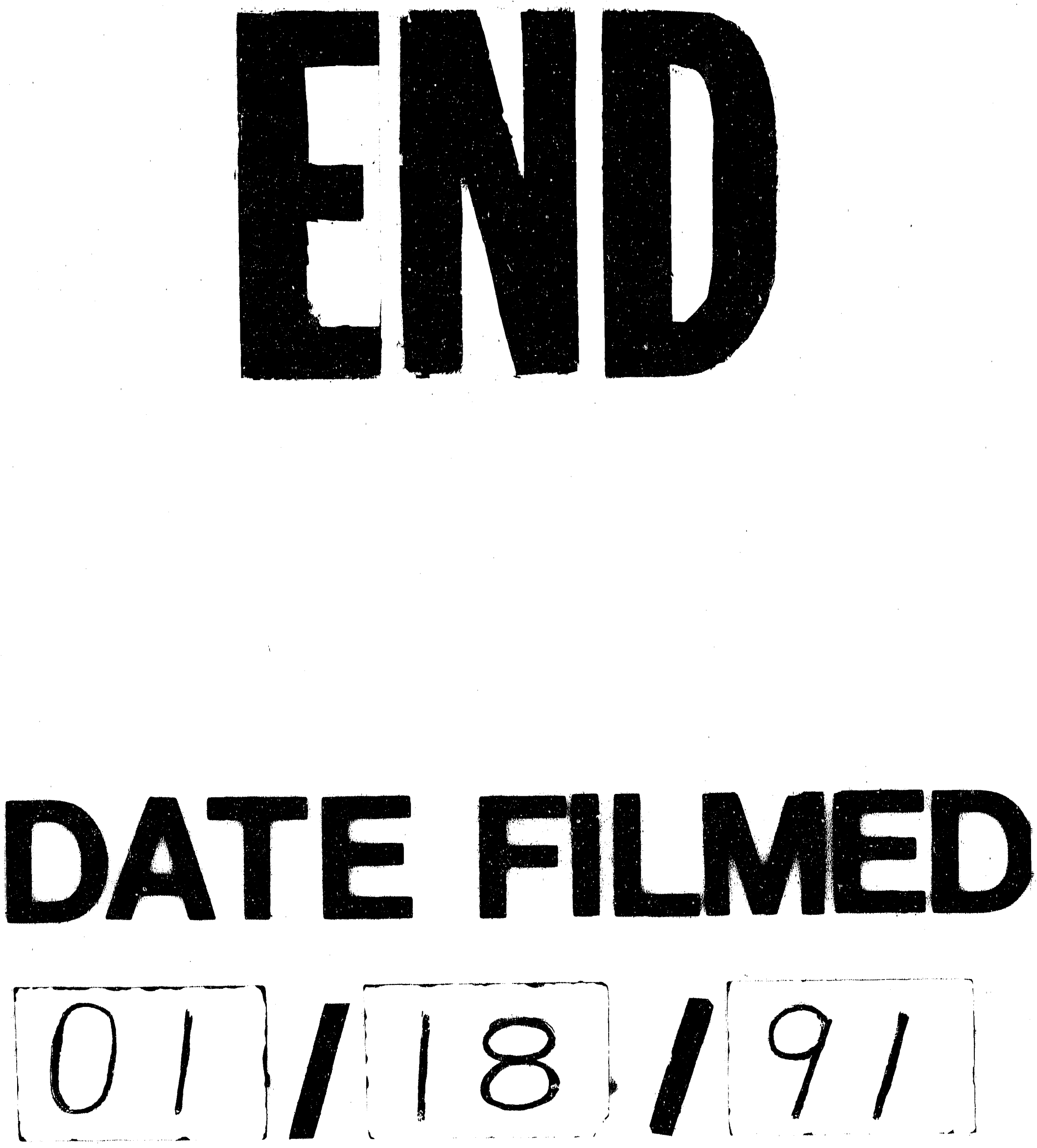
